NELSON MIMURA GONZALEZ

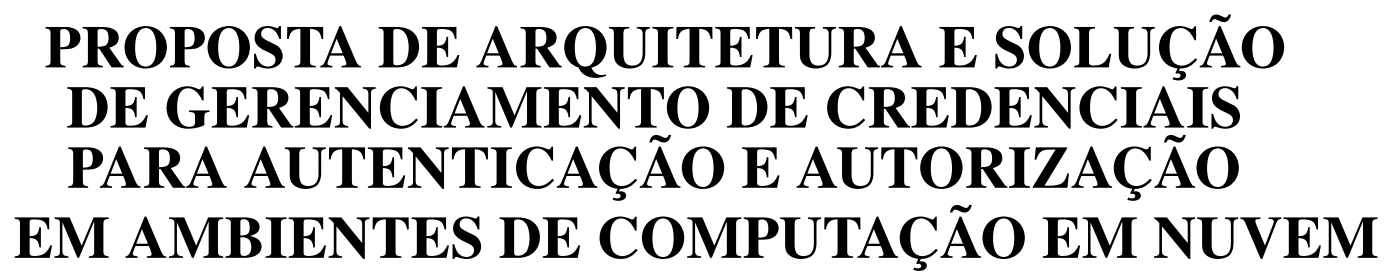


NELSON MIMURA GONZALEZ

\section{PROPOSTA DE ARQUITETURA E SOLUÇÃO DE GERENCIAMENTO DE CREDENCIAIS PARA AUTENTICAÇÃO E AUTORIZAÇÃ̃O EM AMBIENTES DE COMPUTAÇÃO EM NUVEM}

Dissertação apresentada à Escola Politécnica da Universidade de São Paulo para obtenção do Título de Mestre em Ciências. 
NELSON MIMURA GONZALEZ

\section{PROPOSTA DE ARQUITETURA E SOLUÇÃO DE GERENCIAMENTO DE CREDENCIAIS PARA AUTENTICAÇÃO E AUTORIZAÇÃO EM AMBIENTES DE COMPUTAÇÃO EM NUVEM}

Dissertação apresentada à Escola Politécnica da Universidade de São Paulo para obtenção do Título de Mestre em Ciências.

Área de Concentração:

Engenharia de Computação

Orientador:

Tereza Cristina Melo de Brito Carvalho 
Este exemplar foi revisado e alterado em relação à versão original, sob responsabilidade única do autor e com a anuência de seu orientador.

São Paulo, 18 de março de 2014.

Assinatura do autor

Assinatura do orientador

FICHA CATALOGRÁFICA

Gonzalez, Nelson Mimura

Proposta de arquitetura e solução

de gerenciamento de credenciais

para autenticação e autorização

em ambientes de computação em nuvem/ N. M. Gonzalez. ed. rev. - - São Paulo, 2014.

$138 \mathrm{p}$.

Dissertação (Mestrado) - Escola Politécnica da Universidade de São Paulo. Departamento de Engenharia de Computação e Sistemas Digitais (PCS).

1. Computação em nuvem (Segurança). 2. Autenticação e autorização. I. Universidade de São Paulo. Escola Politécnica. Departamento de Engenharia de Computação e Sistemas Digitais. II. t. 
"If I had asked people what they wanted, they would have said faster horses." Henry Ford 


\section{AGRADECIMENTOS}

À minha orientadora, Tereza Cristina Melo de Brito Carvalho, pela orientação e ajuda desde a época da graduação até hoje. Admiro sua paixão pelo trabalho e espero que possamos desenvolver muitos outros trabalhos juntos.

Aos meus pais, Vilma e Nelson, pelo incansável apoio, pelos grandes conselhos, e por reconhecerem o trabalho e o estudo como ferramentas imprescindíveis para o desenvolvimento não só pessoal mas também da humanidade.

Aos meus colegas de pós-graduação e do LARC (Laboratório de Arquitetura e Redes de Computadores), em especial a: Charles, Karen, Akio, Pedro, Torrez, Schwarz, Bruno, Jonas, Wando, Vinícius, Simplício, Fernando, Rony, Rosângela, Alan, Ricardo, Sbampato, Ewerton, e Cléber. A amizade e o trabalho foram essenciais ao longo desta experiência, ajudando a construir o conhecimento e os laços que hoje partilhamos.

À Ericsson Telecomunicações do Brasil, pelo suporte financeiro (por meio da FDTE), e à Ericsson Research (Suécia, Canadá, Finlândia) pelo apoio durante a pesquisa e o desenvolvimento de trabalhos e projetos. Em especial, agradeço à Mats Näslund, Makan Pourzandi, Jan-Erik Mångs, e Maria Valéria Marquezini pela ajuda e apoio, sempre contribuindo com grandes idéias e sugestões para o desenvolvimento do trabalho.

À FDTE (Fundação para o Desenvolvimento Tecnológico da Engenharia) pelo suporte administrativo em todos os projetos que estive envolvido. Agradeço em especial à Edilaine, que sempre buscou ajudar da melhor maneira possível em todos os momentos oportunos.

Por fim, agradeço à Universidade de São Paulo e à Escola Politécnica, não só por oferecerem um espaço que viabilizasse o desenvolvimento da pesquisa, ou por contar com grandes professores que sempre auxiliaram na construção do conhecimento, mas por fazerem parte da minha vida. A Poli é e sempre será o meu segundo lar. 


\section{RESUMO}

O modelo de computação em nuvem (cloud computing) reúne características como elasticidade, compartilhamento de recursos, obtenção de serviços sob demanda, e escalabilidade. Este modelo aumenta a eficiência de utilização de recursos, reduzindo drasticamente o custo de manutenção de infraestruturas de hardware e software. Contudo, diversos problemas relacionados a aspectos de segurança são observados nos ambientes de nuvem, o que reduz a adoção da tecnologia de maneira significativa. Os principais problemas identificados referem-se à confidencialidade dos dados dos usuário e à proteção dos canais de comunicação. Estes problemas podem ser resolvidos por meio do emprego de mecanismos de autenticação e autorização que controlem efetivamente o acesso aos recursos e aos serviços da nuvem por parte dos usuários e quaisquer outras entidades que consigam acessar estes elementos. Isto sugere a utilização de credenciais, que permitem estabelecer permissões e obrigações das entidades de um ecossistema de computação em nuvem. Esta dissertação apresenta uma proposta de Sistema de Gerenciamento de Credenciais (SGC) para computação em nuvem, que visa implementar uma solução de identificação de entidades e controle de acesso à nuvem. Para isto foi realizada uma pesquisa para levantar as principais referências relativas à computação em nuvem, segurança em computação em nuvem, e gerenciamento de credenciais. A partir dos resultados desta pesquisa, foi definido um modelo conceitual que descreve a solução proposta, identificando os seus requisitos e a sua arquitetura. Finalmente foi desenvolvido um protótipo para realização de testes, de modo a validar a solução proposta e verificar o atendimento aos requisitos definidos previamente. Os resultados revelam a possibilidade de desenvolver um Sistema de Gerenciamento de Credenciais (SGC) capaz de prover os mecanismos de segurança adequados para a nuvem sem a necessidade de modificar as aplicações e serviços originais da mesma, culminando em uma solução transparente para usuários, desenvolvedores, e administradores da nuvem. O sistema proposto foi, também, capaz de estabelecer canais de comunicação seguro entre as entidades da nuvem, permitindo proteger de maneira seletiva as informações que trafegam pela rede. Desta forma, é possível afirmar que soluções em nuvem podem ser tornar mais seguras (e confiáveis) por meio do emprego de mecanismos transparentes e abrangentes para autenticação e autorização de entidades e operações. 


\begin{abstract}
Cloud computing is a computing model based on characteristics such as elasticity, resource sharing, on-demand resource acquisition, and scalability. This model increases resource usage efficiency, drastically reducing maintenance costs of hardware and software infrastructures. However, problems related to security aspects represent obstacles for a wider adoption of the technology. The main problems identified are related to data confidentiality and communication channels protection. These problems can be addressed by authentication and authorization mechanisms which are able to effectively control the access to resources and services. This suggests the use of credentials which define the permissions and obligations of entities from a cloud computing ecosystem. This work presents a Credential Management System (CMS) for cloud computing, which implements a solution for identification and access control in the cloud environment. The research included a survey of references related to cloud computing, security in cloud computing, and credential management. Taking the results of this research, it was specified a conceptual model which describes the proposed solution, identifying the main requirements of the solution and its architecture. Finally it was developed a prototype in order to perform tests to validate the solution and verify if the requirements were addressed. The results reveal the possibility of developing a credential management solution able to provide the adequate security mechanisms without the need to modify the original applications and services, leading to a transparent solution for users, developers, and cloud administrators. The solution was also able to establish secure communication channels between cloud entities, allowing to selectively protect information that is exchanged in the network. The conclusion is that it is possible to make cloud applications and services more secure (and reliable) by using transparent and comprehensive mechanisms for authentication and authorization of entities and operations.
\end{abstract}




\section{SUMÁRIO}

\section{Lista de Ilustrações}

\section{Lista de Tabelas}

\section{Lista de Abreviaturas e Siglas}

$\begin{array}{lll}1 & \text { Introdução } & 17\end{array}$

1.1 Motivação . . . . . . . . . . . . . . . . . . . . . 17

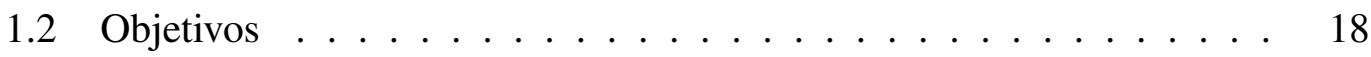

1.3 Método . . . . . . . . . . . . . . . . . . . . . . 19

1.4 Organização do trabalho . . . . . . . . . . . . . . . . . 19

2 Computação em nuvem $\quad 21$

2.1 Histórico .......................... 21

2.2 Características principais . . . . . . . . . . . 25

2.3 Tipos de serviços . . . . . . . . . . . . . . . . 27

2.3.1 Modelo SPI . . . . . . . . . . . . . . . . . . . 27

2.3.2 Modelo Youseff . . . . . . . . . . . . . . . . . 28

2.3.3 Modelo Linthicum . . . . . . . . . . . . . . . . . . . 29

2.3.4 Comparação dos modelos . . . . . . . . . . . 30

2.3.5 Taxonomia proposta ................. 31 
2.4 Modelos de organização . . . . . . . . . . . . . . 32

2.5 Considerações do capítulo . . . . . . . . . . . . . . . . . 34

3 Segurança $\quad 35$

3.1 Classificação proposta . . . . . . . . . . . . . 36

3.1 .1 Segurança de rede ................ 37

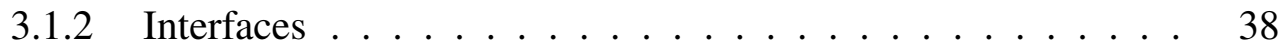

3.1 .3 Segurança de dados . . . . . . . . . . . . . 38

3.1 .4 Virtualização . . . . . . . . . . . . . . . . 39

3.1 .5 Governança ................... 41

3.1.6 Conformidade .................... . . 41

3.1 .7 Questões legais . . . . . . . . . . . . . . . . 42

3.2 Taxonomia proposta . . . . . . . . . . . . 43

3.3 Análise .......................... 44

3.3.1 Problemas ..................... 45

3.3 .2 Soluções . . . . . . . . . . . . . . . . . 46

3.3 .3 Comparação . . . . . . . . . . . . . . . . . . 48

3.4 Considerações do capítulo . . . . . . . . . . . . . . 52

4 Credenciais $\quad 54$

4.1 Definições . . . . . . . . . . . . . . . . 55

4.1.1 Levantamento de definições . . . . . . . . . . . . . 55

4.1.2 Definições consolidadas .............. . 56 
4.2 Classificação . . . . . . . . . . . . . . . . 58

4.3 Ciclo de vida . . . . . . . . . . . . . . . . . . . 61

4.4 Arcabouço proposto . . . . . . . . . . . . . . . . . . 64

4.5 Considerações do capítulo . . . . . . . . . . . . . . . . 67

5 Sistema de gerenciamento de credenciais

5.1 Especificação de requisitos . . . . . . . . . . . . . . . . . . . 69

5.1 Requisitos funcionais . . . . . . . . . . . . . 70

5.1.2 Requisitos não funcionais . . . . . . . . . . . 72

5.2 Descrição da arquitetura proposta . . . . . . . . . . . 72

5.3 Implementação da solução . . . . . . . . . . . . . . . . . . . 75

$5.3 .1 \quad$ Middleware .................. 75

$5.3 .2 \quad$ SGC ......................... 76

5.4 Trabalhos relacionados . . . . . . . . . . . . . . 77

5.4.1 Tecnologias consolidadas . . . . . . . . . . . . . . 77

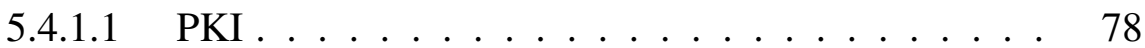

5.4.1.2 Kerberos ................ 79

5.4 .2 Publicações . . . . . . . . . . . . . . . . . . 80

5.5 Considerações do capítulo . . . . . . . . . . . . . . . . 81

6 Implementação $\quad 82$

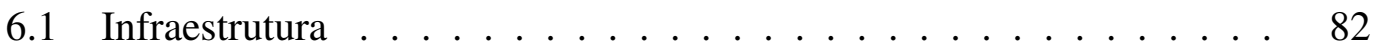

6.1 .1 OpenStack ..................... 87 
6.1 .2 Keystone: Visão geral _ . . . . . . . . . . . . . . . 88

6.1.3 Keystone: Middleware . . . . . . . . . . . . . . . . . 91

6.1.4 Keystone: Requisitos e utilização . . . . . . . . . . . . . 91

6.1.5 Keystone: Limitações . . . . . . . . . . . . . . . 93

6.2 SGC cliente . . . . . . . . . . . . . . . . . . . . . 94

6.3 SGC servidor . . . . . . . . . . . . . . . . . 97

6.4 Limitações da implementação . . . . . . . . . . . . . . . . . 100

6.5 Considerações do capítulo . . . . . . . . . . . . . . . 100

$\begin{array}{llr}7 & \text { Ambiente de experimentação } & 102\end{array}$

7.1 Configuração do ambiente de teste . . . . . . . . . . . . . . . . 102

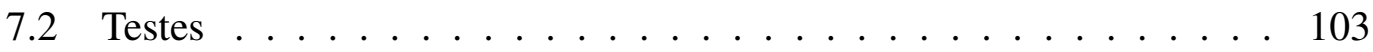

7.2.1 Teste 1: Com SGC, proteção parcial . . . . . . . . . . . . . . 104

7.2.1.1 Sequência ................. 105

7.2.1.2 Teste .................... 108

7.2.2 Teste 2: Com SGC, proteção total . . . . . . . . . . . . 113

7.2.2.1 Sequência . . . . . . . . . . . . 113

7.2.2.2 Teste ..................... 114

7.2.3 Teste 3: Com SGC, não autorizado . . . . . . . . . . . . 115

7.2.3.1 Sequência . . . . . . . . . . . . 116

7.2.3.2 Teste ................... 117

7.2.4 Teste 4: Sem SGC . . . . . . . . . . . . . . . 118 
7.2.4.1 Sequência . . . . . . . . . . 118

7.2.4.2 Teste .................... 119

7.2.5 Teste 5: Sem SGC, reusando token . . . . . . . . . . . 120

7.2.5.1 Sequência . . . . . . . . . . . 120

7.2.5.2 Teste .................... 122

7.3 Análise dos resultados . . . . . . . . . . . . . . . 123

7.4 Considerações do capítulo . . . . . . . . . . . . . . . . . 124

8 Considerações finais $\quad 127$

8.1 Contribuições e inovações . . . . . . . . . . . . . . . . 127

8.2 Publicações . . . . . . . . . . . . . . . . . . . . . . . . 128

8.3 Trabalhos futuros . . . . . . . . . . . . . . 131

$\begin{array}{ll}\text { Referências } & 132\end{array}$ 


\section{LISTA DE ILUSTRAÇÕES}

1 Linha do tempo de evolução do conceito de computação em nuvem e o surgimento de serviços nos anos $2000 \ldots \ldots$. . . . . . . . 23

2 Gráfico gerado a partir da ferramenta Google Trends utilizando o termo-chave cloud computing . . . . . . . . . . . . . . . 24

3 Modelo de ciclo de vida de adoção de tecnologias, baseado em (MEADE; RABELO, 2004) . . . . . . . . . . . . . . . . 25

4 Taxonomia de serviços de nuvem em forma de árvore (GONZALEZ et

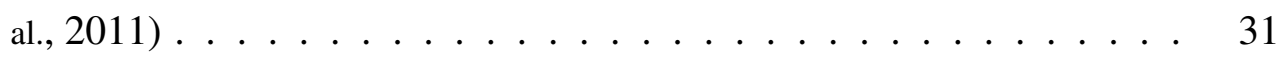

5 Resumo das categorias de segurança em computação em nuvem . . . 36

6 Proposta de classificação de problemas de segurança em computação em nuvem . . . . . . . . . . . . . . . . . . . 44

7 Gráfico relativo aos problemas de segurança em computação em nuvem 46

8 Gráfico relativo aos problemas de segurança com categorias agrupadas 47

9 Gráfico relativo às soluções de segurança em computação em nuvem . 48

10 Gráfico relativo às soluções de segurança com categorias agrupadas . 49

11 Gráfico de comparação entre problemas e soluções . . . . . . . . . 50

12 Gráfico de comparação entre problemas e soluções com categorias

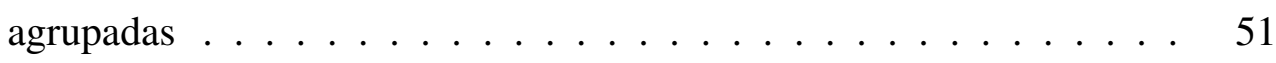

13 Comparação entre problemas e soluções para a categoria de virtualização 52 
14 Proposta de modelo entidade-relacionamento para entidades, identidades, atributos e credenciais . . . . . . . . . . . . . 57

15 Proposta de classificação de credenciais . . . . . . . . . . . . 61

16 Proposta de ciclo de vida para credenciais . . . . . . . . . . . . 63

17 Proposta de ciclo de vida para identidades . . . . . . . . . . . . 63

18 Resumo da proposta de organização de ciclo de vida de credenciais e identidades ............................ 63

19 Proposta de arcabouço de gerenciamento de credenciais . . . . . . . . 66

20 Arquitetura do Sistema de Gerenciamento de Credenciais . . . . . . . 74

21 Lista dos projetos mais ativos segundo o site Ohloh.net. Dados obtidos em 19/08/2013. . . . . . . . . . . . . . . . . . 84

22 Comparação do número de contribuidores (desenvolvedores) dos projetos OpenStack, OpenNebula, e Eucalyptus. Dados obtidos em

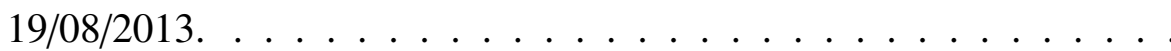

23 Comparação do número de contribuições (commits) dos projetos OpenStack, OpenNebula, e Eucalyptus. Dados obtidos em 19/08/2013. 85

24 Comparação do número de contribuidores (desenvolvedores) dos projetos OpenStack, Linux Kernel, e KVM. Dados obtidos em 19/08/2013. 86

25 Comparação do número de contribuições (commits) dos projetos OpenStack, Linux Kernel, e KVM. Dados obtidos em 19/08/2013. . . 86

26 Comando enviado pelo cliente em modo debug, com destaque para as informações confidenciais sendo enviadas por meio de um canal

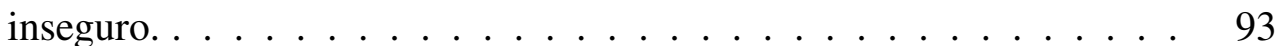


27 Dados capturados pela ferramenta Wireshark, com destaque para as informações confidenciais capturadas no canal de comunicação. . . . 94

28 Especificações das máquinas, rede, e topologia . . . . . . . . . . . 102

29 Diagrama de sequência para Teste 1 (a) . . . . . . . . . . . . . 106

30 Diagrama de sequência para Teste 1 (b) (continuação) . . . . . . . . . 107

31 Requisição e resposta no cliente - Teste 1 . . . . . . . . . . . . . . . 109

32 Requisições 1 e 2 recebidas no servidor - Teste 1 . . . . . . . . . 110

33 Requisição 3 recebida no servidor - Teste $1 \ldots \ldots 111$

34 Tráfego enviado e recebido pelo cliente relativo à etapa da autorização - Teste $1 \ldots \ldots \ldots \ldots \ldots \ldots \ldots$

35 Requisição e resposta no cliente - Teste 1 . . . . . . . . . . . . . 112

36 Diagrama de sequência para Teste $2 \ldots \ldots 113$

37 Requisição e resposta no cliente - Teste 2 . . . . . . . . . . . . . . . 114

38 Requisições 1 e 2 recebidas pelo servidor - Teste $2 \ldots \ldots 115$

39 Requisição e resposta no cliente - Teste 2 . . . . . . . . . . . . . 116

40 Requisição e resposta no cliente - Teste 2 . . . . . . . . . . . 116

41 Diagrama de sequência para Teste $3 \ldots \ldots 117$

42 Requisição e resposta no cliente, e requisição recebida pelo servidor Teste $3 \ldots \ldots \ldots \ldots \ldots \ldots \ldots$

43 Tráfego enviado e recebido - Teste $3 \ldots \ldots$. . . . . . . . . 118

44 Diagrama de sequência para Teste $4 \ldots \ldots$

45 Requisição e resposta no cliente, e requisições recebidas pelo servidor - Teste $4 \ldots \ldots \ldots \ldots \ldots \ldots$ 
46 Tráfego capturado enviado e recebido pelo cliente - Teste 4 . . . . . 121

47 Tráfego enviado pelo cliente para execução da operação - Teste 4 . . . 121

48 Diagrama de sequência para Teste $5 \ldots \ldots 122$

49 Requisição e resposta no cliente, e requisição no servidor - Teste 5 . 122 


\section{LISTA DE TABELAS}

1 Resumo das características do modelo SPI . . . . . . . . . . . . . . . 29

2 Resumo do modelo de dez categorias de Dave Linthicum . . . . . . 30

3 Comparação entre taxonomias NIST, Youseff e Linthicum . . . . . 30

4 Resumo dos modelos de organização de nuvens . . . . . . . . . . . 33

5 Classificação de credenciais para categoria de metadados . . . . . . . 59

6 Classificação de credenciais para categoria de autorizações . . . . . . 60

7 Classificação de credenciais para categoria de obrigações . . . . . . . 60

8 Versões do OpenStack . . . . . . . . . . . . . . . . . . . 87

9 Requisitos funcionais e não funcionais da solução e como eles foram

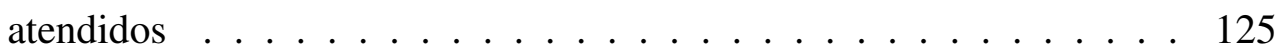

10 Requisitos funcionais e não funcionais da solução e como eles foram

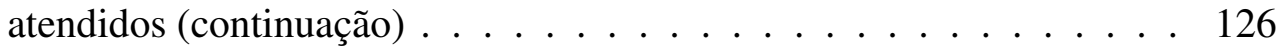




\section{LISTA DE ABREVIATURAS E SIGLAS}

ACM Association for Computing Machinery

API Application Programming Interface

CA Certificate Authority

CaaS Communication as a Service

CMS Credential Management System

CPNI Centre for the Protection of National Infrastructure

CSA Cloud Security Alliance

DaaS Data storage as a Service

DDoS Distributed Denial of Service

DoS Denial of Service

ENISA European Network and Information Security Agency

EPUSP Escola Politécnica da Universidade de São Paulo

HaaS Hardware as a Service

HIPAA Health Insurance Portability and Accountability Act

IaaS Infrastructure as a Service

IEEE Institute of Electrical and Electronics Engineers

LARC Laboratório de Arquitetura e Redes de Computadores

LDAP Lightweight Directory Access Protocol

NIST National Institue of Standards and Technology 
PAM Pluggable Authentication Module

PaaS Platform as a Service

PCI Payment Card Industry

PCS Departamento de Engenharia de Computação e Sistemas Digitais

PKI Public Key Infrastructure

RBAC Role-Based Access Control

SaaS Software as a Service

SAML Security Assertion Markup Language

SGC Sistema de Gerenciamento de Credenciais

SLA Service Level Agreement

SPI SaaS-PaaS-IaaS

SQL Structured Query Language

SSH Secure Shell

SSL Secure Sockets Layer

TGT Ticket Granting Ticket

UC Unique Credential

USP Universidade de São Paulo

VPN Virtual Private Network

XACML eXtensible Access Control Markup Language 


\section{INTRODUÇÃO}

O modelo de computação em nuvem agrega diversas características fundamentais, como escalabilidade, elasticidade e obtenção de recursos de acordo com a demanda (MELL; GRANCE, 2011). Este modelo permite melhorar o aproveitamento dos recursos alocados, reduzindo custos e otimizando a utilização da infraestrutura oferecida. Diversos modos de estruturação e organização da nuvem (nuvens públicas, privadas, híbridas, federações, diferentes tipos de serviços) permitem compor cenários complexos e abrangentes, integrando aplicações e serviços por meio de interfaces transparentes e bem definidas (VAQUERO et al., 2008).

Estes elementos fizeram com que a computação em nuvem ganhasse destaque tanto na academia como no mercado (GIORDANELLI; MASTROIANNI, 2010), com um número cada vez maior de soluções de diversos tipos e propósitos, adotando-se estratégias para oferecer serviços no nível de infraestrutura, plataforma de desenvolvimento e aplicações executadas diretamente na nuvem. Armazenamento, processamento, hospedagem de websites, e-mail e redes sociais são apenas alguns exemplos dos tipos de serviços que podem ser oferecidos por meio da nuvem.

\subsection{Motivação}

Embora o modelo de computação em nuvem mostre-se tecnicamente apto a solucionar diversas questões relacionadas à crescente demanda e disponibilidade de recursos computacionais, alguns percalços impedem sua adoção de maneira mais extensiva. $\mathrm{O}$ 
mais notável destes obstáculos é a segurança dos elementos que compõem o ecossistema da nuvem(ARMBRUST et al., 2010), abrangendo não apenas a infraestrutura oferecida como serviço, mas também a plataforma sobre a qual aplicações são desenvolvidas e as entidades deste ecossistema. Estas entidades incluem o hardware (utilizado para prover os recursos da nuvem), o software (necessário para expor estes recursos por meio de interfaces para usuários, administradores e outros serviços integrados), e os elementos que utilizam estes recursos (BADGER et al., 2011).

Dentre os diversos problemas de segurança estudados em computação em nuvem, questões como isolamento de recursos, confidencialidade e integridade de dados podem ser solucionadas por meio de mecanismos inteligentes de controle de autenticação e autorização (acesso) (CELESTI et al., 2010a). Estes controles podem ser estendidos para todo o ecossistema da nuvem, abrangendo usuários, serviços, recursos físicos e virtuais. Uma maneira de implementar estes mecanismos é utilizando credenciais que concentrem informações sobre estas entidades e seus papéis dentro do contexto da nuvem, estabelecendo as permissões, obrigações e dados relevantes.

\subsection{Objetivos}

Este trabalho tem como objetivo construir uma arquitetura de gerenciamento de credenciais para autenticação e autorização dentro do contexto de computação em nuvem. Adotar uma solução robusta para autenticação e autorização de entidades permite solucionar problemas de isolamento de dados e recursos entre diferentes usuários, além de permitir uma maior integração entre serviços e aplicações. Este tipo de solução também é essencial para cenários que possuem uma maior complexidade inerente, caso de nuvens públicas e híbridas que demandam controles mais efetivos sobre a utilização da nuvem e a administração de sua infraestrutura e das entidades envolvidas.

Dentre objetivos secundários vale destacar a construção de uma taxonomia de ser- 
viços de computação em nuvem e de uma taxonomia de segurança em computação em nuvem, bem como o levantamento dos principais problemas de segurança com base em referências e publicações cientificas.

\subsection{Método}

O método empregado neste trabalho foi o de pesquisa aplicada com base no método Hipotético-Dedutivo, utilizando-se referências da área de pesquisa relacionada ao problema identificado, especificando-se uma hipótese de solução, e posteriormente avaliando tal hipótese por meio da implementação de um protótipo.

Inicialmente foi realizada uma pesquisa conceitual sobre computação em nuvem e segurança neste ambiente. Foi identificada a possibilidade de utilizar credenciais de autenticação e autorização para resolver diversos problemas de segurança relacionados à proteção de dados em ambientes de comunicação não confiáveis, de modo que a pesquisa caminhou para identificação de propostas relacionadas e para a formulação de uma arquitetura e posteriormente solução de autenticação e autorização para computação em nuvem. Com base no modelo proposto foi desenvolvido um protótipo para validação da hipótese formulada, e foram realizados testes deste protótipo em uma nuvem privada. Todo o trabalho de pesquisa, incluindo desde a pesquisa conceitual até a implementação do referido protótipo, foi realizado dentro do contexto de um projeto de pesquisa maior do LARC (Laboratório de Arquitetura e Redes de Computadores) do PCS (Departamento de Engenharia de Computação e Sistemas Digitais) na EPUSP (Escola Politécnica da Universidade de São Paulo), financiado pela Ericsson Telecomunicações do Brasil e com suporte técnico da Ericsson Research na Suécia.

\subsection{Organização do trabalho}

O trabalho foi organizado em sete capítulos além do capítulo introdutório: 
- Capítulo 2 apresenta um breve histórico sobre a tecnologia de computação em nuvem, sua definição, tipos de serviços oferecidos, modelos de organização, e tecnologias relacionadas.

- Capítulo 3 apresenta conceitos de segurança em computação em nuvem, os principais problemas, sugere propostas para classificação e organização dos mesmos, e descreve os resultados do estudo realizado sobre o impacto e a relevância de cada tipo de problema.

- Capítulo 4 apresenta a pesquisa relacionada a identidades e credenciais, incluindo a classificação, o estudo do ciclo de vida destes elementos, e as propostas de arcabouço, arquitetura e implementação para o sistema de gerenciamento de credenciais.

- Capítulo 5 apresenta a proposta de um sistema de gerenciamento de credenciais para computação em nuvem, denominado SGC (Sistema de Gerenciamento de Credenciais) ou CMS (Credential Management System) incluindo o levantamento de requisitos da solução, a descrição da arquitetura da solução, um modelo de implementação da solução, e os trabalhos relacionados.

- Capítulo 6 descreve a implementação do protótipo utilizado para validação da solução proposta.

- Capítulo 7 apresenta os testes realizados de modo a satisfazer os objetivos da pesquisa e os requisitos levantados.

- Capítulo 8 apresenta as considerações finais do trabalho e a produção científica obtida, além de propor possibilidades de trabalhos futuros. 


\section{COMPUTAÇÃO EM NUVEM}

Este capítulo discute o modelo de computação em nuvem considerando sua definição, seu desenvolvimento ao longo dos últimos anos, os tipos de serviços, e os modelos de organização. As seções estão organizadas da seguinte maneira:

- Seção 2.1 apresenta um breve histórico da evolução do conceito, tecnologias, e soluções de computação em nuvem.

- Seção 2.2 apresenta a definição e as características fundamentais de computação em nuvem.

- Seção 2.3 apresenta modelos para classificação dos serviços oferecidos por meio da nuvem.

- Seção 2.4 apresenta modelos de organização da nuvem e seu ecossistema.

- Seção 2.5 apresenta as considerações finais deste capítulo.

\subsection{Histórico}

O modelo de computação em nuvem, embora tenha adquirido maior destaque somente nos últimos anos, tem sua origem paralela à própria concepção da Internet. $\mathrm{O}$ conceito de intergalactic computer network proposto por J. C. R. Licklider (LICKLIDER, 1963) e citado posteriormente por autores como Lawrence Roberts (ROBERTS, 1986) e Judy O’Neill (O’NEILL, 1995), ressalta a necessidade de permitir o acesso de 
um computador a partir de outro de maneira simples, econômica e que viabilize o compartilhamento de recursos. A idéia central de Licklider era melhorar as capacidades humanas por meio da integração cada vez mais próxima entre homem e máquina, conforme proposto em outro de seus artigos (LICKLIDER, 1960), e isto exigiria a criação de uma rede poderosa capaz de processar e trocar informações rapidamente.

Outro ponto importante dentro do contexto de computação em nuvem é o conceito de utility computing, isto é, a computação como uma utilidade tal qual a eletricidade, água, ou qualquer outro tipo de serviço oferecido e precificado de maneira transparente e de acordo com a demanda. Um dos pioneiros nesta área foi o professor John McCarthy, em 1961, quando mencionou a possibilidade de oferecer poder computacional como um serviço assim como telefonia (ABELSON, 1999):

Se os computadores do tipo que tenho preconizado se tornarem o futuro, então a computação pode um dia ser organizada como uma utilidade pública, assim como o sistema de telefonia. A computação como utilidade poderia se tornar a base para uma nova e importante indústria. (MAGOULES, 2009)

Considerando esta perspectiva, recursos como processamento e armazenamento são tratados como grandezas mensuráveis, oferecidas de acordo com as necessidades do usuário e, principalmente, sem os encargos e custos relacionados à aquisição e manutenção de hardware e software de infraestrutura.

Ao longo dos anos o foco das pesquisas e do mercado sempre esteve na Internet e nas tecnologias associadas, e a nuvem era o símbolo utilizado para representá-la em diagramas (KUMAR; CHENG; MCGIBBNEY, 2010) O termo só passou a convergir para o modelo atual de computação distribuída e flexível no fim da década de 1990 com Ramnath Chellapa, definindo a computação em nuvem como um novo paradigma onde as fronteiras computacionais seriam delimitadas não por limites técnicos, mas econômi- 
cos (CHELLAPPA, 1997). Em outras palavras, ao oferecer uma infraestrutura virtualmente infinita para processar e armazenar dados, o fator limitante para a utilização dos seus serviços passa a ser exclusivamente o custo para o usuário final.

A proliferação de serviços oferecidos por meio da Internet foi impulsionada pelo conceito de terminais-cliente (thin clients), isto é, dispositivos e aplicações cliente cada vez mais enxutos oferecendo acesso ubíquo a serviços hospedados em um servidor responsável pelo processamento das tarefas (GIORDANELLI; MASTROIANNI, 2010). Desta forma, o conceito de computação em nuvem vem ganhando cada vez mais força, levando ao surgimento de diversos serviços conforme observado na Figura 1, que resume a evolução da tecnologia de computação em nuvem desde sua concepção nos anos 1960 até a proliferação de serviços nos anos 2000.

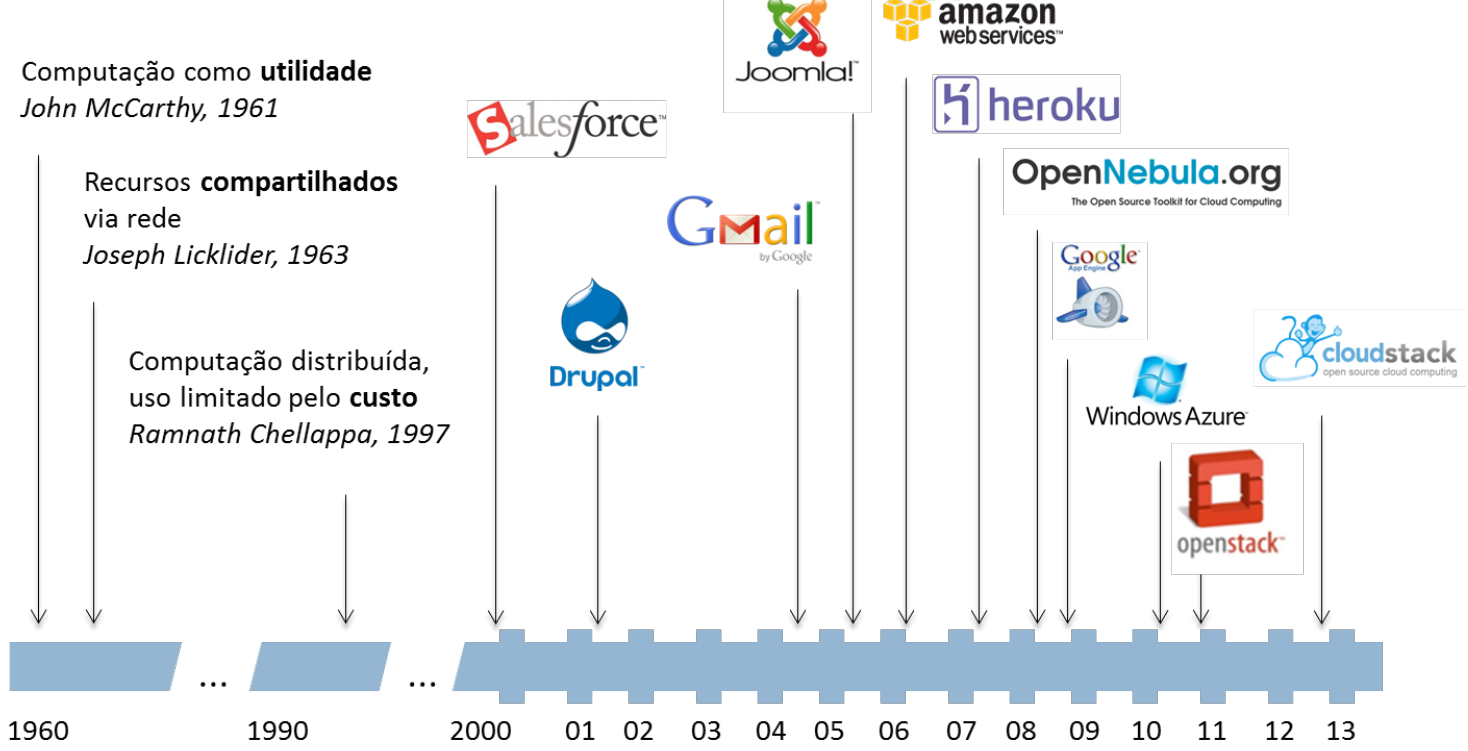

Figura 1: Linha do tempo de evolução do conceito de computação em nuvem e o surgimento de serviços nos anos 2000

Empresas como Salesforce ${ }^{1}$ e Amazon ${ }^{2}$ tem oferecido soluções inovadoras e práticas para distribuição de aplicações e poder computacional, culminando no que denominamos atualmente por SaaS (Software as a Service), PaaS (Platform as a Service) e

\footnotetext{
${ }^{1}$ Www.salesforce.com

${ }^{2}$ aws.amazon.com
} 
IaaS (Infrastructure as a Service).

É possível notar um rápido crescimento da tecnologia principalmente a partir de 2009, fato observado na Figura 2: O gráfico mostra o crescimento de buscas pelos

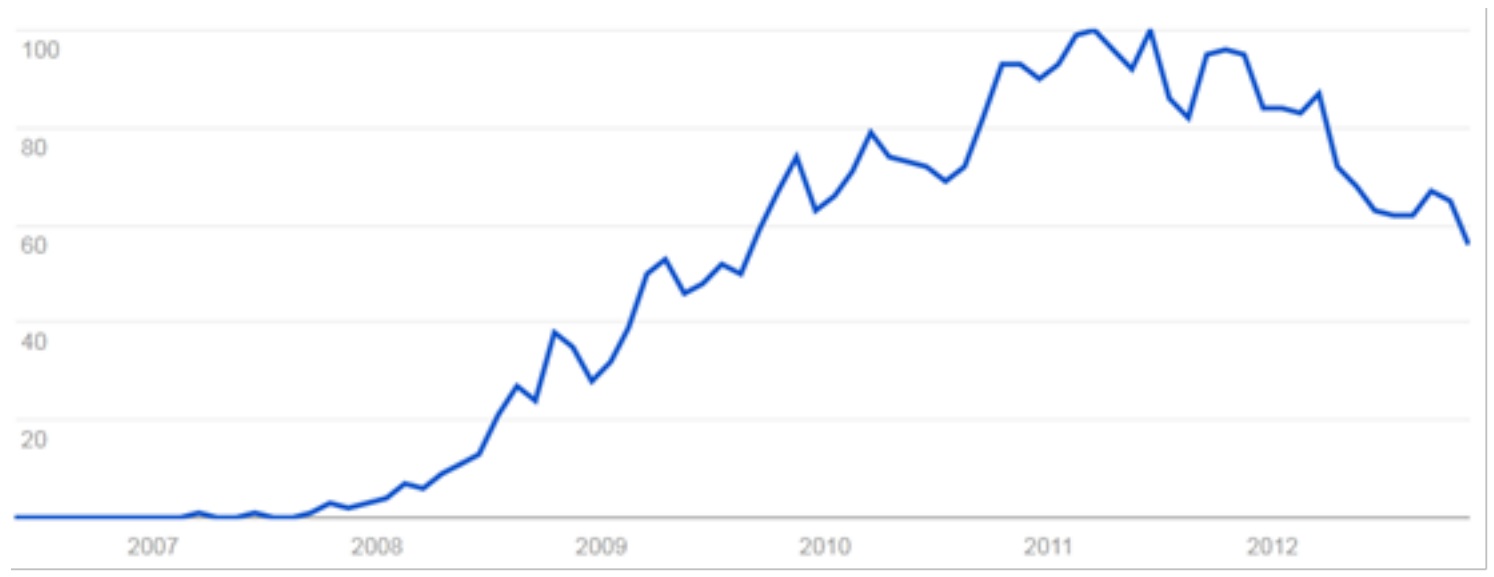

Figura 2: Gráfico gerado a partir da ferramenta Google Trends utilizando o termochave cloud computing

termos relacionados à computação em nuvem a partir de 2007, o notável crescimento entre 2009 e 2010, e o pico de popularidade em 2011. O valor de ordenada 100 representa o volume de pesquisas máximo, definido apenas para estabelecer um patamar superior de comparação. O declínio observado em 2012 está relacionado em parte ao enfraquecimento do clichê (buzzword ${ }^{3}$ ) conforme as idéias e os conceitos amadurecem, tanto em termos de academia como também de aplicações no mercado.

Este comportamento também é verificado no caso de outras tecnologias que começam como protótipos, atingem um pico de promoção exagerada $\left(h_{y p} e^{4}\right)$ e, conforme são mais profundamente pesquisadas pelo meio acadêmico e adotadas em aplicações reais são gradativamente transformadas em soluções de fato. Este ciclo é observado na Figura 3. Conforme a tecnologia amadurece e é adotada pela maioria (incluindo pragmáticos e conservadores) ocorre uma transição de mercado que transforma a hype inicial em produtos e soluções. Com base nas tendências observadas no histórico da

\footnotetext{
${ }^{3}$ Termo utilizado para denominar temas e palavras normalmente pertencentes a um jargão técnico e que são usados fora do seu contexto e de maneira genérica, imprecisa e muitas vezes inapropriada.

${ }^{4}$ Relacionado à temas que recebem grande atenção do público. É derivado da palávra hipérbole (em inglês, hyperbole), uma alusão ao exagero normalmente observado na promoção destes temas.
} 


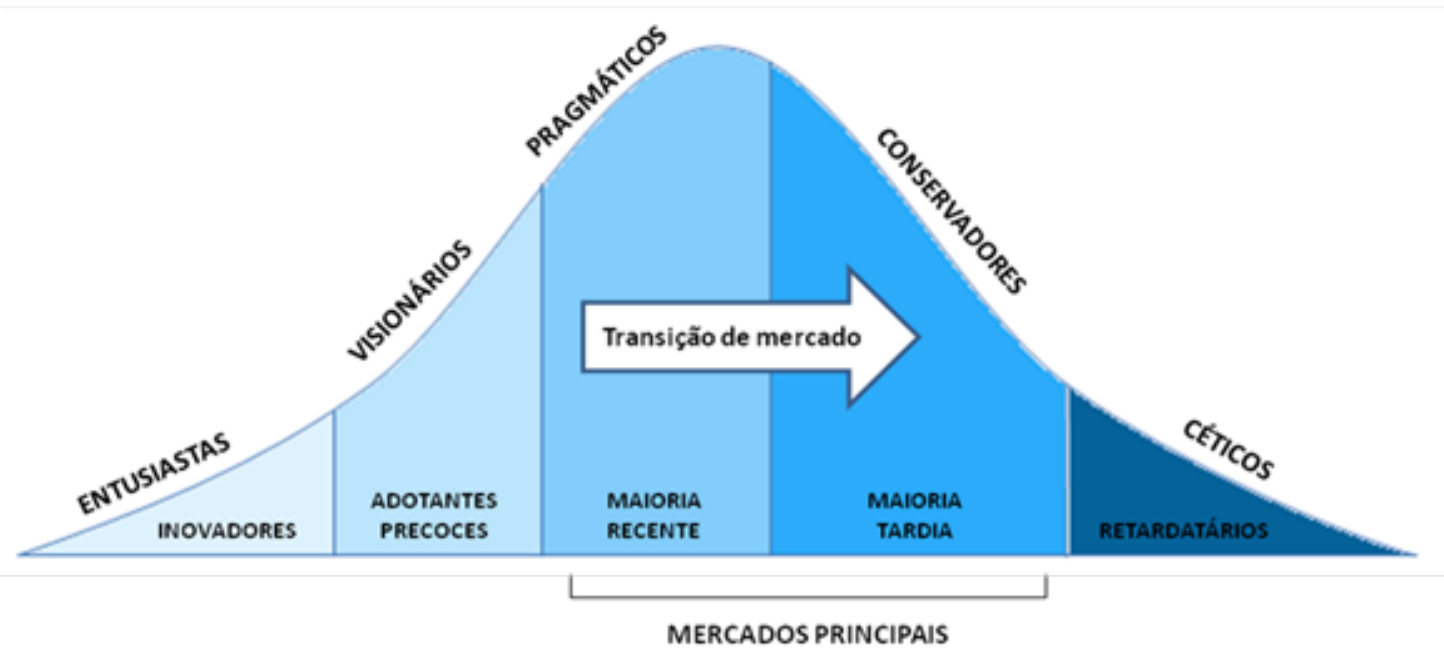

Figura 3: Modelo de ciclo de vida de adoção de tecnologias, baseado em (MEADE; RABELO, 2004)

evolução da computação em nuvem pode-se afirmar que a tecnologia se encontra na transição da terceira fase do ciclo para a quarta, com diversas empresas desenvolvendo e utilizando produtos baseados em nuvem.

\subsection{Características principais}

Diversas publicações científicas, relatórios de entidades e instituições de pesquisa e desenvolvimento oferecem um vasto conjunto de informações que determinam diversas propriedades, métodos de classificação e de utilização que caracterizam a nuvem. O NIST (National Institute of Standards and Technology), órgão americano responsável pela padronização e pelo estabelecimento de métricas em âmbito tecnológico, define a computação em nuvem como um modelo que permite acesso transparente e sob demanda a um conjunto de recursos computacionais configuráveis (redes, servidores, armazenamento, aplicações e serviços) que podem ser facilmente alocados e liberados com mínimo esforço e interação com o provedor de serviços (MELL; GRANCE, 2011). As características apontadas como essenciais neste contexto são:

- Auto-serviço sob demanda: O usuário obtém recursos conforme desejado, sem 
a necessidade de interação humana com o provedor de serviços.

- Acesso via rede: Os recursos e serviços são disponibilizados via rede e acessíveis a partir de plataformas heterogêneas (computadores, notebooks, smartphones) por meio de interfaces padronizadas (navegadores Web, aplicações de linha de comando).

- Compartilhamento: O conjunto de recursos da nuvem é compartilhado por meio de um modelo capaz de permitir diversos usuários sob uma infraestrutura comum (modelo multi-tenant). A localização exata dos recursos não é necessariamente conhecida ou mesmo relevante para o usuário.

- Elasticidade: A quantidade de recursos oferecida pode ser aumentada ou diminuída de maneira automática e imediata, de modo que para os usuários os recursos aparentam ser infinitos, sempre disponíveis e na quantidade adequada às suas necessidades.

- Métricas: Diversos mecanismos de medição são implementados na nuvem para oferecer funcionalidades de balanceamento de carga (de modo que os sistemas sejam capazes de determinar as quantidades ideais de recursos a serem oferecidas para cada usuário) e monitoração (analisando a utilização dos recursos e gerando relatórios de cobrança com base no uso dos serviços).

Estas características são apontadas por outros autores, como (WANG et al., 2008; VAQUERO et al., 2008; ARMBRUST et al., 2010). Sob esta perspectiva a nuvem pode ser representada por um grande aglomerado de recursos facilmente alocáveis e com mecanismos precisos de medição e controle. Diversos usuários acessam o conjunto (pool) de recursos e as quantidades alocadas se adaptam conforme a necessidade de cada um. Para o usuário estas características favorecem a utilização dos recursos computacionais de maneira econômica se comparado com soluções baseadas em um servidor ou um data center local, pois além de evitar desperdícios (por exemplo, manutenção de 
um data center completo com baixo índice de aproveitamento dos recursos), ao adotar uma solução em nuvem o usuário não precisa se preocupar com gastos com a infraestrutura inicial ou sua manutenção, o que pode se tornar extremamente oneroso tanto em termos de tempo quanto custo. Toda a complexidade relacionada ao custeio de equipamentos, atualizações de programas e sistemas operacionais é delegada ao provedor do serviço, e o usuário apenas usufrui das ferramentas e aplicações desejadas.

Outro ponto importante é a adaptação às necessidades do usuário e o foco no desenvolvimento de interfaces adequadas (WANG et al., 2010). Em outras palavras, os serviços oferecidos na nuvem não devem interferir nos hábitos do usuário (por exemplo, sua linguagem de programação preferida, seu sistema operacional e outras ferramentas). $\mathrm{O}$ acesso à nuvem deve ser feito de maneira simples, preferencialmente por meio de uma aplicação cliente já estabelecida no mercado, como um navegador Web (browser), e a qualidade do serviço deve ser mantida com relação ao provisionamento de recursos.

\subsection{Tipos de serviços}

A classificação dos possíveis serviços oferecidos por meio da computação em nuvem é outro tópico que ganhou grande destaque a partir de 2009. Diversas taxonomias e ontologias foram formadas com o objetivo de estabelecer um padrão de categorização de serviços. Esta seção apresenta modelos de classificação conhecidos na academia e no mercado, e também apresenta uma proposta de classificação baseada nos conceitos agregados destes modelos.

\subsubsection{Modelo SPI}

Um dos modelos mais utilizados e difundidos é o apresentado pelo NIST (MELL; GRANCE, 2011), que divide os serviços em três grandes categorias: 
- Software as a Service (SaaS): Aplicações executadas na infraestrutura da nuvem e distribuídas para os usuários sob o modelo multi-tenant, isto é, vários usuários utilizando a mesma instância do serviço. As aplicações normalmente são acessíveis por meio de um terminal-cliente (thin client), como o navegador Web, ou um programa dedicado. O usuário não administra ou controla a infraestrutura da nuvem, incluindo hardware, sistema operacional, além de ferramentas e serviços que suportam a aplicação, estando portanto restrito a realizar modificações dentro do contexto do serviço utilizado (parâmetros de configuração e outros aspectos relacionados).

- Platform as a Service (PaaS): Serviços que permitem ao usuário implementar e distribuir aplicações criadas pelo mesmo ou por terceiros, utilizando linguagens de programação, bibliotecas e outras ferramentas permitidas pelo provedor do serviço. O usuário não possui controle sobre a infraestrutura da nuvem mas pode realizar configurações relacionadas à plataforma de distribuição de aplicações.

- Infrastructure as a Service (IaaS): Recursos infraestruturais oferecidos por meio da nuvem, como armazenamento, processamento, virtualização e outros elementos computacionais. O usuário pode executar quaisquer programas nesta infraestrutura, incluindo sistemas operacionais e outras aplicações, embora ainda não possua controle total sobre a mesma. No entanto, algumas configurações de rede (relacionadas a firewalls, por exemplo) e de armazenamento podem estar disponíveis para modificação.

Este modelo é também denominado Modelo SPI, sigla para as iniciais SaaS, PaaS e IaaS. As principais características (e diferenças) entre os tipos de serviços são resumidas pela Tabela 1 . 
Tabela 1: Resumo das características do modelo SPI

\begin{tabular}{|c|c|c|c|}
\hline Característica & SaaS & PaaS & IaaS \\
\hline Controle sobre parâmetros da aplicação & Sim & Sim & Sim \\
\hline $\begin{array}{l}\text { Controle sobre infraestrutura de software } \\
\text { (serviços e ferramentas de suporte) }\end{array}$ & Não & Sim & Sim \\
\hline $\begin{array}{l}\text { Controle sobre parâmetros de } \\
\text { configuração de hardware }\end{array}$ & Não & Não & Sim \\
\hline $\begin{array}{l}\text { Controle sobre infraestrutura de } \\
\text { hardware }\end{array}$ & Não & Não & Não \\
\hline Público alvo & Usuário final & Desenvolvedores & Administradores \\
\hline Exemplos & $\begin{array}{l}\text { CRM, e-mail, } \\
\text { comunicações, } \\
\text { jogos }\end{array}$ & $\begin{array}{l}\text { Ambiente de } \\
\text { execução, } \\
\text { ferramentas de } \\
\text { desenvolvimento }\end{array}$ & $\begin{array}{l}\text { Máquinas } \\
\text { virtuais, } \\
\text { servidores, } \\
\text { armazenamento }\end{array}$ \\
\hline
\end{tabular}

\subsubsection{Modelo Youseff}

Diversos outros modelos apresentam categorias e conceitos adicionais à classificação em três camadas. Lamia Youseff, Maria Butrico e Dilma da Silva construíram um modelo com seis categorias de serviços (YOUSEFF; BUTRICO; SILVA, 2008).Neste modelo os conceitos de SaaS e PaaS são semelhantes ao do modelo SPI. Já o conceito de IaaS deste modelo é restrito a recursos computacionais, isto é, processamento e virtualização. Os outros elementos infraestruturais são subdivididos em DaaS (Data storage as a Service, tecnologias baseadas em armazenamento e sistemas de arquivos distribuídos), CaaS (Communication as a Service, serviços que oferecem redes de comunicação seguras e com parâmetros de QoS bem definidos) e HaaS (Hardware as a Service, onde o provedor mantém a infraestrutura da nuvem e a oferece como um serviço de terceirização de hardware).

\subsubsection{Modelo Linthicum}

Outro modelo é o de Dave Linthicum (LINTHICUM, 2009) baseado em dez categorias, conforme apresentado na Tabela 2. Embora exiba várias categorias para classificação de serviços esta taxonomia não inclui categorias mais claras para definir serviços de virtualização e processamento remoto (o IaaS original), cobrindo apenas parte dos 
Tabela 2: Resumo do modelo de dez categorias de Dave Linthicum

\begin{tabular}{|c|c|c|}
\hline Tipo & Descrição & Exemplos \\
\hline Armazenamento & $\begin{array}{l}\text { Dados fisicamente remotos porém } \\
\text { logicamente locais }\end{array}$ & Amazon S3, Dropbox \\
\hline Banco de dados & $\begin{array}{l}\text { Serviço de banco de dados remoto e } \\
\text { potencialmente distribuído }\end{array}$ & $\begin{array}{l}\text { Amazon SimpleDB, } \\
\text { Trackvia }\end{array}$ \\
\hline Informações & $\begin{array}{l}\text { Fontes de informações armazenadas na } \\
\text { nuvem e acessíveis por meio de APIs }\end{array}$ & $\begin{array}{l}\text { Ações e dados do mercado } \\
\text { financeiro, previsões } \\
\text { meteorológicas }\end{array}$ \\
\hline Processos & $\begin{array}{l}\text { Serviços capazes de criar fluxos de } \\
\text { processamento ao relacionar diversas } \\
\text { aplicações }\end{array}$ & $\begin{array}{l}\text { Appian Anywhere } \\
\text { ZapThink }\end{array}$ \\
\hline Aplicações & $\begin{array}{l}\text { Software as a Service, aplicações } \\
\text { distribuídas por meio da nuvem }\end{array}$ & Salesforce, Google Apps \\
\hline Plataforma & $\begin{array}{l}\text { Serviço de hospedagem, desenvolvimento } \\
\text { e testes de aplicações }\end{array}$ & $\begin{array}{l}\text { Google App Engine, } \\
\text { Heroku }\end{array}$ \\
\hline Integração & $\begin{array}{l}\text { Integração entre aplicações, controle de } \\
\text { fluxo, EAI distribuída como serviço }\end{array}$ & Amazon SQS \\
\hline Segurança & $\begin{array}{l}\text { Serviços de segurança, como } \\
\text { gerenciamento de identidades }\end{array}$ & Ping Identity \\
\hline Governança & $\begin{array}{l}\text { Administração de outros serviços } \\
\text { oferecidos via nuvem e implantação de } \\
\text { políticas de funcionamento }\end{array}$ & RightScale \\
\hline Testes & $\begin{array}{l}\text { Teste de sistemas desenvolvidos na nuvem } \\
\text { utilizando suítes remotas de testes }\end{array}$ & SOASTA \\
\hline
\end{tabular}

possíveis serviços infraestruturais que podem ser oferecidos na nuvem.

\subsubsection{Comparação dos modelos}

Os modelos estudados foram os mais citados em publicações científicas e em artigos de mercado, como white papers e outras publicações de empresas. Comparando as taxonomias do NIST, Youseff e Linthicum podemos observar algumas interrelações entre as categorias sugeridas, que estão resumidas na Tabela 3. A organização de Dave Linthicum apresenta mais subdivisões para a camada de aplicação porém mostra-se incompleta com relação aos possíveis serviços relacionados a plataformas de desenvolvimento e infraestrutura. A abordagem do autor adota uma perspectiva voltada mais ao mercado do que a propriamente a conceitos técnicos. Já o modelo SPI, embora seja extremamente simples, oferece um arcabouço conciso e prático para organização 
Tabela 3: Comparação entre taxonomias NIST, Youseff e Linthicum

\begin{tabular}{l||l|l}
\hline NIST & $\begin{array}{l}\text { (YOUSEFF; BUTRICO; SILVA, 2008) } \\
\text { Aplicação (SaaS) }\end{array}$ & $\begin{array}{l}\text { (LINTHICUM, 2009) } \\
\text { Informações, Processos, Aplicações, } \\
\text { Integração, Segurança, Governança } \\
\text { Plataforma, Testes }\end{array}$ \\
\hline IaaS & $\begin{array}{l}\text { Ambiente de software (PaaS) } \\
\text { Recursos computacionais (IaaS), } \\
\text { Armazenamento (DaaS), } \\
\text { Comunicações (CaaS), Hardware } \\
\text { (HaaS) }\end{array}$ & Armazenamento, Banco de dados \\
\hline
\end{tabular}

de serviços, características que o transformaram no modelo mais difundido e utilizado em publicações científicas e relatórios técnicos. Por este motivo, o modelo SPI é o adotado como referência ao longo deste trabalho.

\subsubsection{Taxonomia proposta}

Para manter a estrutura básica do modelo SPI e ao mesmo tempo oferecer um modelo de classificação mais preciso (isto é, não tão genérico quanto o modelo SPI) é possível construir uma taxonomia no formato de uma árvore, modelo proposto em (GONZALEZ et al., 2011) e exibido na Figura 4.

A figura mostra algumas das possíveis subcategorias dentro de SaaS, PaaS, e IaaS, que podem ser incluídas na taxonomia. O modelo pode ser livremente estendido para incluir novos serviços sem perder as categorias SPI que constituem o alicerce da classificação. O formato proposto permite trabalhar com uma maior granularidade ao propor soluções relacionadas a diversos aspectos da tecnologia, como segurança e desempenho. Por exemplo, soluções de segurança viáveis para um simples serviço de armazenamento podem ser insuficientes para um serviço mais complexo que ofereça infraestrutura baseada em máquinas virtuais. Segundo o modelo SPI, ambos os cenários estão englobados na categoria IaaS, e no entanto a solução de segurança precisa levar em conta as características de cada caso. O mesmo é observado em outras categorias, como a diferença entre uma aplicação de streaming de vídeo e outra de correio eletrônico. Os requisitos de qualidade de serviço são distintos, visto que no primeiro a 


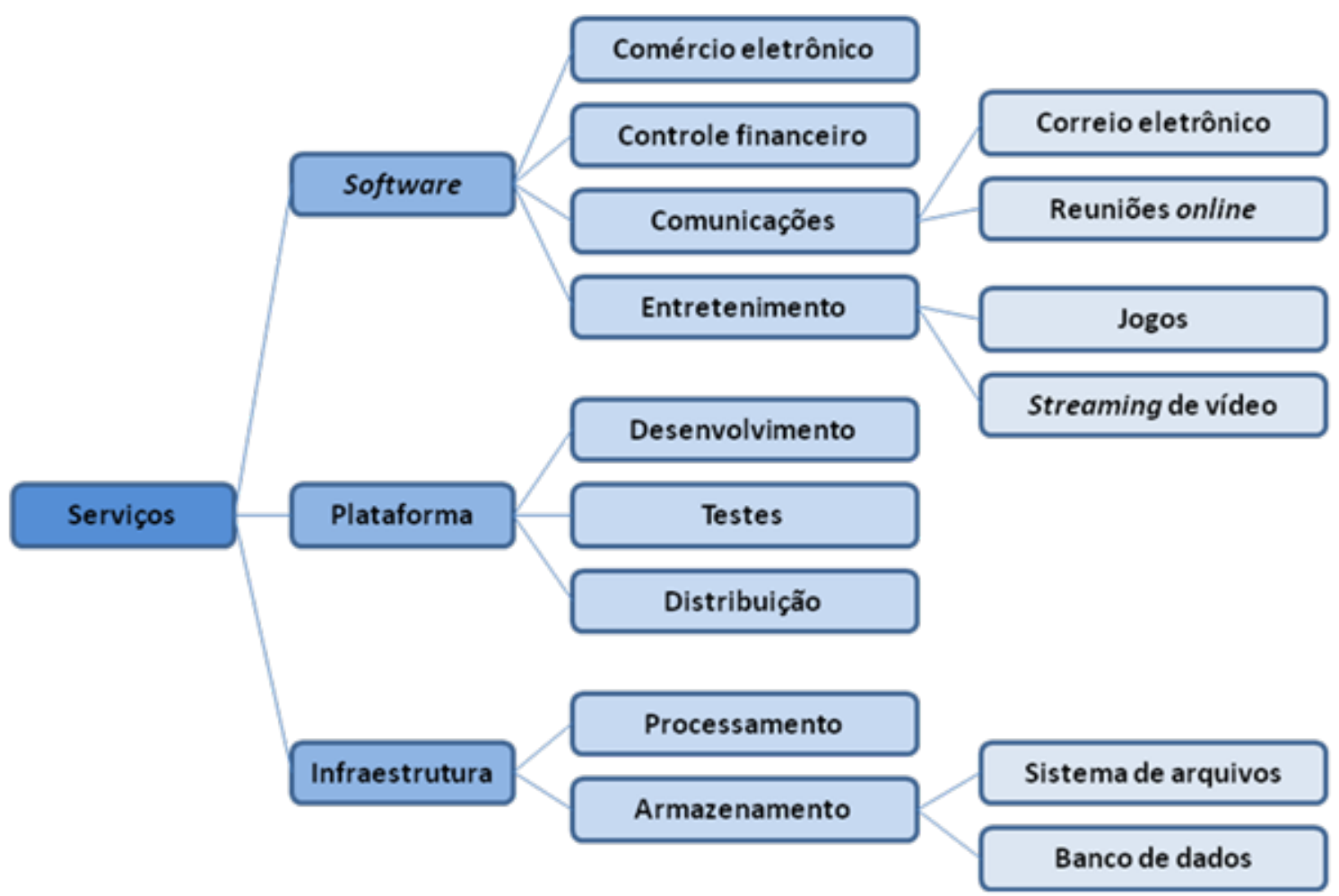

Figura 4: Taxonomia de serviços de nuvem em forma de árvore (GONZALEZ et al., 2011)

entrega imediata é essencial (mesmo que isto incorra em uma ligeira perda de qualidade), enquanto no segundo a integridade é muito mais importante (a perda de alguns bits pode significar a perda total de mensagens ou arquivos).

\subsection{Modelos de organização}

Segundo o NIST (MELL; GRANCE, 2011) uma nuvem pode ser implementada com base em quatro modelos principais de organização:

- Pública: A infraestrutura é oferecida para uso do público geral. A nuvem pode ser controlada e administrada por uma empresa, uma instituição acadêmica ou uma organização governamental.

- Privada: A infraestrutura é de uso exclusivo de uma organização possivelmente composta por múltiplos usuários (devidamente identificados e controlados). A nuvem é controlada pela própria organização ou por um terceiro. 
- Comunitária: A nuvem é oferecida para um grupo de usuários que possuem interesses comuns em termos de utilização, segurança, requisitos de uso e operação, políticas e questões de conformidade. Um bom exemplo é uma nuvem para hospedagem de experimentos científicos que pode ser utilizada por diversas instituições acadêmicas.

- Híbrida: Uma combinação de infraestruturas de nuvens (pública, privada e comunitária) que são entidades únicas mas que possuem elementos de portabilidade, como interfaces e protocolos comuns, que permitem a comunicação entre estes ambientes. Um exemplo é uma infraestrutura com múltiplas nuvens privadas e um mecanismo de balanceamento de carga entre as mesmas.

É possível extrapolar o modelo de nuvem híbrida e considerar um cenário que integre diferentes modelos de computação distribuída, incluindo por exemplo computação em grade (grid computing) e clusters (aglomerados de computadores). A Tabela 4 resume as características dos modelos de organização.

Tabela 4: Resumo dos modelos de organização de nuvens

\begin{tabular}{|c|c|c|}
\hline Model & Definição & Exemplos \\
\hline Pública & $\begin{array}{l}\text { Infraestrutura controlada por uma } \\
\text { organização e disponibilizada para } \\
\text { outras organizações }\end{array}$ & $\begin{array}{l}\text { Distribuição de serviços de uso público, } \\
\text { SaaS }\end{array}$ \\
\hline Privada & $\begin{array}{l}\text { Infraestrutura controlada por uma } \\
\text { organização e disponibilizada } \\
\text { apenas para usuários da mesma }\end{array}$ & $\begin{array}{l}\text { Otimização do uso de recursos internos, } \\
\text { consolidação infraestrutural em larga } \\
\text { escala }\end{array}$ \\
\hline Comunitária & $\begin{array}{l}\text { Infraestrutura controlada e } \\
\text { utilizada por um grupo de } \\
\text { instituições com objetivos comuns }\end{array}$ & $\begin{array}{l}\text { Testbeds e ambientes de experimentação } \\
\text { científica }\end{array}$ \\
\hline Híbrida & $\begin{array}{l}\text { Infraestrutura composta por } \\
\text { múltiplas nuvens }\end{array}$ & $\begin{array}{l}\text { Integração entre nuvens e sistemas } \\
\text { distribuídos, federação, agregação de } \\
\text { infraestruturas }\end{array}$ \\
\hline
\end{tabular}

A partir destes modelos é possível identificar os principais atores no ecossistema da nuvem:

- Provedor da infraestrutura: Responsável por adquirir e manter a infraestrutura que suporta a nuvem. 
- Provedor do serviço: Utiliza a infraestrutura da nuvem para oferecer algum tipo de serviço (em alto nível, caso dos SaaS, ou em mais baixo nível, IaaS).

- Usuário final: Ator que utiliza o serviço oferecido por meio da nuvem, por exemplo uma aplicação para armazenamento de arquivos.

Estes papéis podem se mesclar conforme o modelo de organização adotado. Um modelo privado comumente leva à mistura de todos os papéis (neste caso uma mesma empresa mantém a infraestrutura, implementa a nuvem e os usuários são internos), diferentemente de serviços provenientes de nuvens públicas onde os recursos são compartilhados entre todos os usuários.

\subsection{Considerações do capítulo}

Embora as soluções de computação em nuvem tenham surgido principalmente a partir dos anos 2000, o conceito de oferecer recursos computacionais como utilidade não é novo. Três aspectos podem ser identificados dentre os conceitos sobre computação em nuvm apresentados neste capítulo:

- Características fundamentais: Acesso ubíquo e sob demanda a um (pool) de recursos oferecidos de maneira elástica e controlada por meio de métricas.

- Tipos de serviços: Aplicações (SaaS), plataformas de desenvolvimento (PaaS), recursos computacionais (IaaS).

- Modelos de organização: Nuvens privadas, públicas, comunitárias e híbridas.

Estes aspectos definem o embasamento teórico utilizado ao longo do trabalho. 


\section{SEGURANÇA}

Este capítulo apresenta conceitos de segurança em computação em nuvem, bem como um levantamento de riscos, ameaças e vulnerabilidades que constituem desafios para o estabelecimento da tecnologia como uma solução confiável e robusta. Com base nestes conceitos é criada uma classificação e posteriormente uma taxonomia para organizar estes problemas de segurança de modo a facilitar seu entendimento e identificação de áreas de estudo. Por fim é feita uma análise quantitativa destes problemas com foco na diferenciação entre referências que mencionam os problemas e outras que apresentam soluções, permitindo portanto comparar o impacto de cada problema e o quão estudado e resolvido ele está.

O capítulo está organizado da seguinte maneira:

- Seção 3.1 descreve o modelo proposto de classificação de problemas de segurança em computação em nuvem.

- Seção 3.2 apresenta a taxonomia proposta para estudo dos problemas de segurança em computação em nuvem.

- Seção 3.3 discute a análise de problemas e soluções de segurança com base no levantamento bibliográfico realizado.

- Seção 3.4 apresenta as considerações finais do capítulo. 


\subsection{Classificação proposta}

O primeiro passo da pesquisa é a definição dos riscos, ameaças e vulnerabilidades que representam os principais problemas de segurança encontrados na nuvem. Neste conjunto foram encontrados problemas já existentes em outras tecnologias e também problemas novos, derivados principalmente das soluções de virtualização utilizadas, bem como o conceito de compartilhamento de recursos e multi-tenancy. Sob esta perspectiva, diversas referências (SIMMONDS; REZEK; REED, 2011; CATTEDDU; HOGBEN, 2009; CPNI, 2010; ARCHER et al., 2010; ALVA et al., 2013; MARKIEWICZ, 2008; ROSS et al., 2010; ROSS et al., 2012; ROSS et al., 2009; ROSS et al., 2013; DAVIS, 2010) relacionam estes problemas, bem como o impacto destes problemas na utilização de tecnologias de cloud computing e, portanto, o impacto destes problemas sobre a adoção da computação em nuvem pela academia e pelo mercado. Os problemas apresentados nestas referências podem ser agrupados em sete categorias principais (GONZALEZ et al., 2011): segurança de rede, interfaces, segurança de dados, virtualização, governança, conformidade e questões legais. Um resumo destas categorias é ilustrado pela Figura 5.

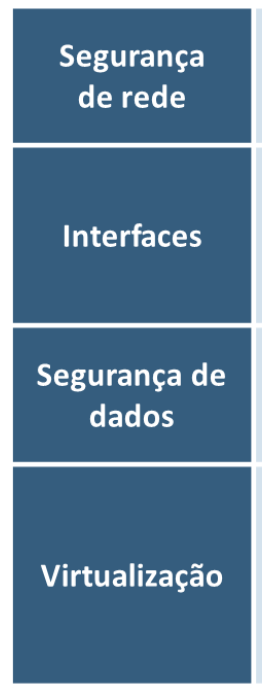

Transferências
Firewall
Configurações de segurança
API
Administração
Usuário
Autenticação
Criptografia
Redundância
Descarte
Isolamento
Vulnerabilidades do hypervisor
Vazamento de dados
Identificação de máquinas virtuais
Ataque entre máquinas virtuais

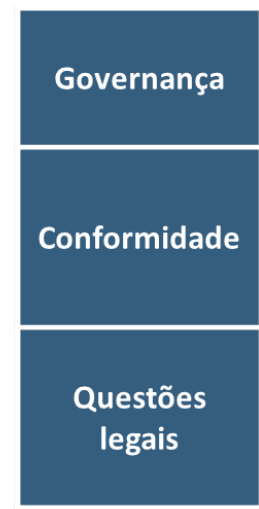

Controle de dados Controle da segurança Lock-in Nível de serviço (SLA) Disponibilidade Auditoria Conformidade de serviço Localização dos dados E-Discovery Privilégio do provedor Legislações

Figura 5: Resumo das categorias de segurança em computação em nuvem

Estas categorias são analisadas nas subseções de 3.1.1 à 3.1.7. 


\subsubsection{Segurança de rede}

A segurança da rede está relacionada a problemas associados à rede de comunicações utilizada para transmitir dados e informações, bem como elementos de processamento e armazenamento da nuvem. Um cenário ideal deveria configurar o serviço de nuvem como uma extensão das configurações internas do usuário (TOMPKINS, 2009), adotando as mesmas medidas de proteção e precauções de segurança e permitindo estender estratégias locais para os recursos e processos remotos (JENSEN et al., 2009). Dentro deste contexto, os principais pontos identificados foram:

- Transferências: Arquiteturas distribuídas, compartilhamento de recursos em larga escala e sincronização de máquinas virtuais implicam em um maior fluxo de dados na nuvem, o que requer a utilização de mecanismos de proteção destas informações (por exemplo, por meio de VPNs) contra ataques de sniffing (interceptação e análise de tráfego), spoofing (personificação ou imitação de uma entidade legítima), man-in-the-middle (também relacionado à interceptação de dados), e side-channel (ataque aos canais de comunicação permitindo vazamento de dados).

- Firewall: Proteção da infraestrutura do provedor da nuvem contra ataques externos e também internos (TRENDMICRO, 2010). Estes mecanismos também permitem o isolamento, filtragem granular de endereços e portas de acesso, prevenção de ataques de negação de serviço (Denial of Service, DoS) e detecção de procedimentos de análise de segurança (probing). Esforços para o desenvolvimento de soluções de firewall consistentes para o ambiente de nuvem (GENOVESE, 2009; HULME, 2011) revelam a importância de adaptar soluções já existentes em outros ambientes (distribuídos ou não).

- Configurações de segurança: Configurações de protocolos, sistemas e tecnologias de modo a oferecer níveis de segurança e privacidade. 


\subsubsection{Interfaces}

Problemas relacionados às interfaces oferecidas pelo serviço para que usuários, administradores, e elementos programáticos possam interagir com a nuvem. Dentre estes problemas pode-se destacar:

- API: Interfaces programadas (recurso essencial para PaaS e IaaS) que permitem o acesso a recursos virtualizados e sistemas em geral devem ser protegidas contra uso malicioso (DAVESLAB, 2009; ROSE, 2009; BALKAN, 2008).

- Administração: Permite controle remoto da nuvem e de seus usuários, máquinas e outras entidades importantes. Também oferece os principais mecanismos para gerenciamento de recursos em um IaaS, do desenvolvimento e plataforma de implementação de um PaaS, ou as aplicações e respectivas configurações em um SaaS.

- Usuário: Interface oferecida para o usuário final para utilização dos recursos e ferramentas oferecidos na nuvem (o serviço propriamente dito), o que requer a adoção de medidas de segurança adequadas (SALESFORCE, 2011; ESPINER, 2007; YEE, 2007; SALESFORCE, 2013).

- Autenticação: Mecanismos necessários para permitir o acesso à nuvem (LI et al., 2009). A maioria dos serviços utiliza métodos baseados em contas simples com usuário e senha (KAUFMAN; VENKATAPATHY, 2010), e portanto são vulneráveis a diversos tipos de ataques (MCMILLAN, 2010; MILLS, 2010; ARRINGTON, 2010; BOSCH, 2009; WESTERVELT, 2010) cujas consequências são aumentadas pelo modelo multi-tenant e o compartilhamento de recursos inerente à nuvem. 


\subsubsection{Segurança de dados}

Segurança de dados pode ser entendida como a proteção de dados com relação à confidencialidade, disponibilidade, e integridade (conceitos aplicáveis não somente dentro do contexto de aplicações na nuvem, mas qualquer tipo de serviço baseado na manipulação de dados e infomações em geral).

- Criptografia: Prática essencial para proteção de dados sigilosos (MUSTHALER, 2009) contra leitura e manipulação indevida, largamente empregada em serviços e exigida por diversos padrões legais e de mercado (YAN; RONG; ZHAO, 2009).

- Redundância: Mecanismo para evitar perda de dados e garantir disponibilidade de serviços. A maioria dos modelos de negócios depende da tecnologia de informação para a realização de suas atividades e processos (TECH, 2010; LYLE, 2011). Portanto, ao menos as informações críticas de négocio devem ser protegidas em termos de integridade e disponibilidade.

- Descarte: O descarte ou remoção de dados deve ser completo e definitivo (DORION, 2010). Resquícios de dados podem ser encontrados em servidores e instâncias virtuais, o que pode constituir um sério problema de segurança caso as informações sejam sigilosas e possam, de alguma forma, ser indevidamente recuperadas (MOGULL, 2009).

\subsubsection{Virtualização}

Técnicas de virtualização são empregadas para dividir e organizar os recursos físicos da infraestrutura da nuvem, que podem ser distribuídos e compartilhados entre vários clientes implementando-se arquiteturas complexas com capacidade de oferecer serviços e executar aplicações. As principais questões de segurança relaciondas à virtualização são: 
- Isolamento: Apesar de existir uma divisão lógica dos recursos de cada máquina virtual, o recurso físico (hardware) é o mesmo. Consequentemente é possível explorar brechas de segurança nos elementos que garantem esse isolamento lógico, levando a problemas de vazamento de dados e ataques de uma máquina virtual para outra (RISTENPART et al., 2009). O conceito de isolamento pode ser aplicado em diversos níveis de granularidade, desde máquinas virtuais a processos e elementos de armazenamento.

- Vulnerabilidades do hypervisor: O hypervisor é o principal elemento de software para virtualização de infraestruturas computacionais. Soluções para manter cada unidade virtual isolada e protegida ainda são escassas, demandando mais pesquisas na área para garantir este nível de segurança.

- Vazamento de dados: Ao explorar vulnerabilidades do hypervisor e outros elementos que fazem parte do gerenciamento da nuvem e dos recursos virtualizados, é possível acessar dados de outros usuários e máquinas e portanto afetar a integridade e confidencialidade dos mesmos (BAKSHI; YOGESH, Feb.; JAEGER; SAILER; SREENIVASAN, 2007). O vazamento de dados pode ocorrer por meio da exploração de falhas de segurança no software responsável pela orquestração da nuvem, permitindo por exemplo que um usuário possa capturar credenciais de outros usuários, obtendo acesso aos dados destes.

- Identificação de máquinas virtuais: Falta de controles para identificação (autenticação e autorização) de máquinas virtuais e outros elementos (ou entidades) da nuvem (KRAUTHEIM, 2009).

- Ataques entre máquinas virtuais: Também denominados cross-VM attacks, são tentativas de obter dados privilegiados sobre outras máquinas (utilização de recursos como processamento, memória e armazenamento), abrindo caminho para ataques de vazamento de dados e de negação de serviço (denial of service). 
Uma possibilidade deste tipo de ataque é a criação sucessiva de máquinas virtuais em uma mesma máquina física até que o espaço de memória passe a ser compartilhado (RAJ et al., 2009; JIN; HUH, 2011).

\subsubsection{Governança}

Problemas relacionados à perda de controle administrativo e de segurança ao utilizar soluções baseadas em nuvem (CHOW et al., 2009; SADEGHI; SCHNEIDER; WINANDY, 2010).

- Controle dos dados: Mover os dados para a nuvem significa perder autonomia sobre os mesmos. Diversos mecanismos são oferecidos pelos serviços para que o usuário tenha um certo nível de controle sobre seus arquivos e informações, mas o controle nunca é tão abrangente quanto na utilização local.

- Controle da segurança: A utilização de soluções em nuvem também acarreta na perda de controle sobre os níveis de segurança adotados e as respectivas configurações.

- Lock-in: Existe uma potencial dependência em relação aos serviços oferecidos por uma nuvem. Ao adotar um serviço de nuvem todo um modelo de negócio passa a depender deste serviço (BRISCOE; MARINOS, 2009). Caso este serviço seja descontinuado ou migrado, são observadas diversas consequências em relação aos dados e processos de uma empresa ou do usuário em geral.

\subsubsection{Conformidade}

Problemas relacionados às obrigações contratuais estabelecidas para um serviço e seus usuários, assim como diversos requisitos de funcionamento e acordos de nível de serviço. Existem, portanto, questões inerentes aos requisitos de conformidade com níveis de serviço, disponibilidade, transparência e auditoria (BRANDIC et al., 2010). 
- Nível de serviço (SLA): Os SLAs (Service Level Agreements) estabelecem políticas relacionadas a requisitos de disponibilidade do serviço e dos dados, procedimentos de segurança a serem adotados e possíveis relações com requisitos legais (ANDRZEJAK; KONDO; YI, 2010; VAN; TRAN; MENAUD, 2009; ALHAMAD; DILLON; CHANG, 2010; FITO; GOIRI; GUITART, 2010).

- Disponibilidade: Interrupções no fornecimento de um serviço não são exclusivas de um ambiente de nuvem. Por seguir um modelo de utilidade pública, um serviço oferecido por meio da infraestrutura da nuvem pode sofrer problemas e ser interrompido, assim como um serviço de eletricidade ou água. A dependência entre serviços da nuvem torna este problema ainda mais grave (GONG et al., Sept.), à medida que um SaaS pode utilizar recursos de infraestrutura de outro serviço de IaaS (WINTERFORD, 2011; CLARKE, 2011; SHANKLAND, 2011). Este tipo de problema sugere a necessidade de implementar mecanismos de tolerância e recuperação de falhas, permitindo por exemplo redundância também nas aplicações cliente.

- Auditoria: Está relacionada a análises de segurança e disponibilidade de serviço baseadas em políticas de auditoria pré-estabelecidas. Métodos transparentes e eficazes são necessários para analisar as condições de serviço (GADIA, 2009; PROTIVITI, 2012), e constituem requisitos contratuais e legais básicos. Interfaces de programação (APIs) podem ser utilizadas para automatizar parte das tarefas de auditoria, medições e contabilidade (PEARSON, 2009; MARSTON et al., 2011).

- Conformidade de serviço: Problemas relacionados às obrigações contratuais estabelecidas para um serviço e seus usuários, assim como diversos requisitos de funcionamento e acordos de nível de serviço (SLAs) são definidos e respeitados. 


\subsubsection{Questões legais}

Como aspectos relacionados a requisitos legais em geral, pode-se identificar:

- Localização dos dados: A localização precisa dos dados na nuvem é incerta, não apenas em relação aos próprios recursos físicos de um data center como também a distribuição desses recursos em provedores de serviços de nuvem dispersos geograficamente, em diferentes estados, países, e continentes. Cada região tem sua jurisdição em relação a crimes digitais e legislação referente, gerando conflitos ao mover dados de uma localização geográfica para outra (AGARWAL, 2010).

- E-Discovery: Como resultado de uma decisão judicial, os dispositivos de armazenamento e processamento de um serviço podem ser recolhidos para análise forense para auxílio em uma investigação criminal ou algum evento do gênero. Contudo, todos os usuários do serviço cujos dados estão armazenados nestes dispositivos terão sua confidencialidade comprometida (HUNTER, 2011; NELSON; SIMEK, 2011; BENTLEY, 2009).

- Privilégio do provedor: O provedor do serviço tem controle parcial ou total sobre sua infraestrutura, de modo que usuários internos maliciosos podem conduzir atividades que comprometam a integridade e confiabilidade do serviço como um todo, colocando em risco a confidencialiade dos dados dos usuários (ZIERICK, 2011; DINOOR, 2010).

- Legislações: Problemas legais relacionados a novos conceitos e paradigmas introduzidos pelas tecnologias de computação em nuvem (PAVOLOTSKY, 2010; GRAY, 2013). 


\subsection{Taxonomia proposta}

As categorias de segurança propostas podem ser resumidas pela taxonomia de segurança apresentada na Figura 6, que resume as categorias e subcategorias apresentadas.

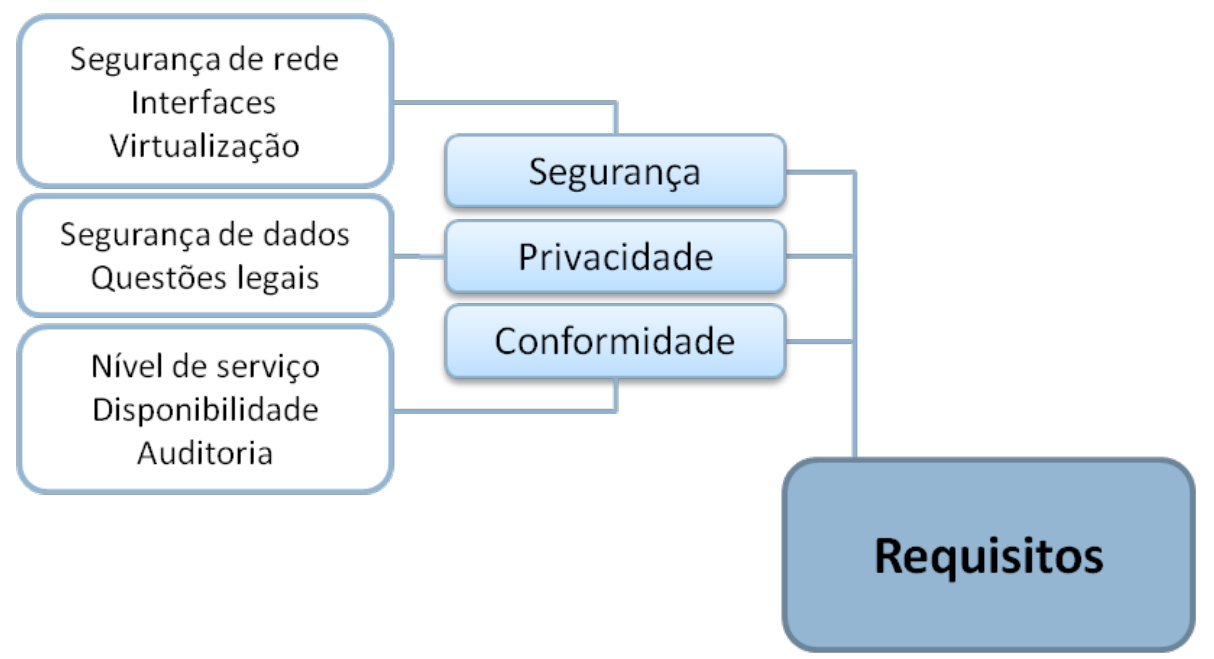

Figura 6: Proposta de classificação de problemas de segurança em computação em nuvem

A classificação dos problemas é baseada em três níveis principais:

- Segurança: Categoria relacionada a problemas da infraestrutura da nuvem, como transmissão de informações, interfaces entre o serviço e seus usuários e administradores e vulnerabilidades associadas às tecnologias de virtualização empregadas para distribuir e compartilhar os recursos da infraestrutura da nuvem.

- Privacidade: Categoria relacionada principalmente à proteção dos dados dos usuários (como informações sigilosas, relatórios de atividades e históricos) e os desdobramentos de decisões legais sobre a privacidade dos usuários e do modo como o serviço opera.

- Conformidade: Categoria relacionada aos problemas de disponibilidade, confiabilidade, respeito às políticas de uso e distribuição de recursos, mecanismos de 
contabilidade e controle de uso.

\subsection{Análise}

Com base nas categorias e taxonomia propostas é possível organizar e direcionar os esforços de pesquisa de modo a atender à demanda da academia e do mercado em relação à categorização e classificação de problemas inerentes ao ambiente de computação em nuvem. Utilizando esta classificação é possível analisar as publicações do mercado e da academia e verificar quais os problemas mais frequentemente mencionados, quais estão sendo ou já foram solucionados e quais ainda se encontram em uma fase de maturação, aguardando mais pesquisas e desenvolvimento de protótipos e arquiteturas.

Foi conduzida uma pesquisa envolvendo mais de duzentas referências da academia (publicações do IEEE, ACM, Springer, WebScience e SciPress), organizações de pesquisa (SANS Institute, CSA, NIST, ENISA, Gartner Group, KVM.org, OpenGrid, OpenStack, OpenNebula) e mercado (white papers, manuais, entrevistas e conteúdo digital de empresas como Ericsson, IBM, Xerox, Cisco, VMware, Xen, Citrix, EMC, Microsoft e Salesforce). Cada referência foi analisada com o objetivo de identificar quaisquer problemas de segurança em computação em nuvem mencionados, assim como soluções para os mesmos. As subseções 3.3.1 e 3.3.2 mostram os resultados desta pesquisa.

\subsubsection{Problemas}

Os resultados obtidos a partir da pesquisa de referências sobre problemas de segurança em computação em nuvem podem ser observados na Figura 7.

Os três principais problemas identificados com mais citações são relacionados a questões legais, conformidade de serviço e perda de governança sobre os dados e con- 


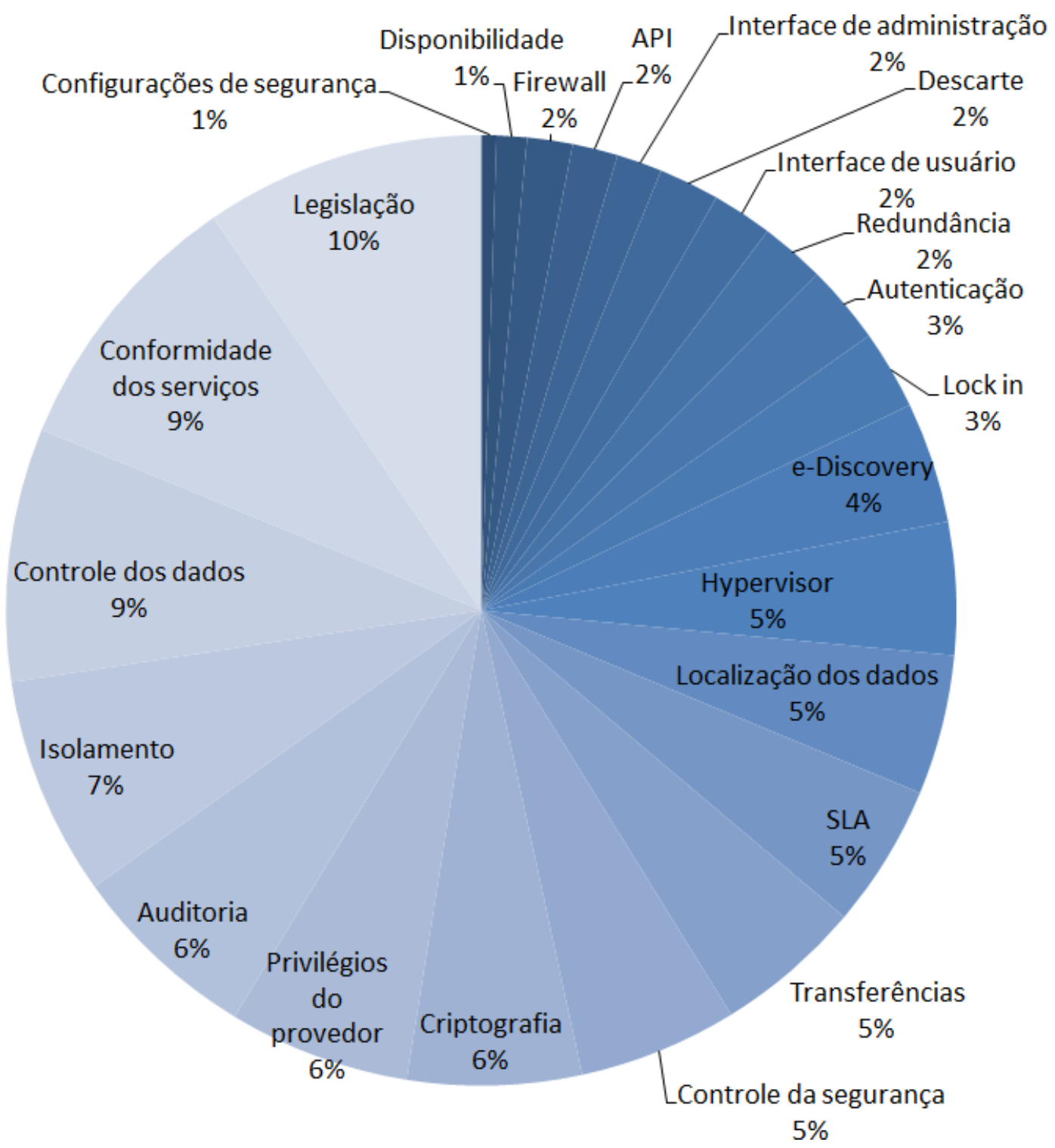

Figura 7: Gráfico relativo aos problemas de segurança em computação em nuvem

figurações relacionadas, somando quase um terço das citações encontradas. O principal problema técnico encontrado é o de isolamento dos dados e recursos, com $7 \%$ das citações. Os problemas menos citados são relacionados a questões de configuração de serviços, disponibilidade, proteção contra intrusões e segurança das interfaces de serviço.

Agrupando os problemas por meio das categorias propostas obtemos o gráfico que pode ser observado na Figura 8.

Neste gráfico fica clara a predominância de citações relacionadas a problemas le- 


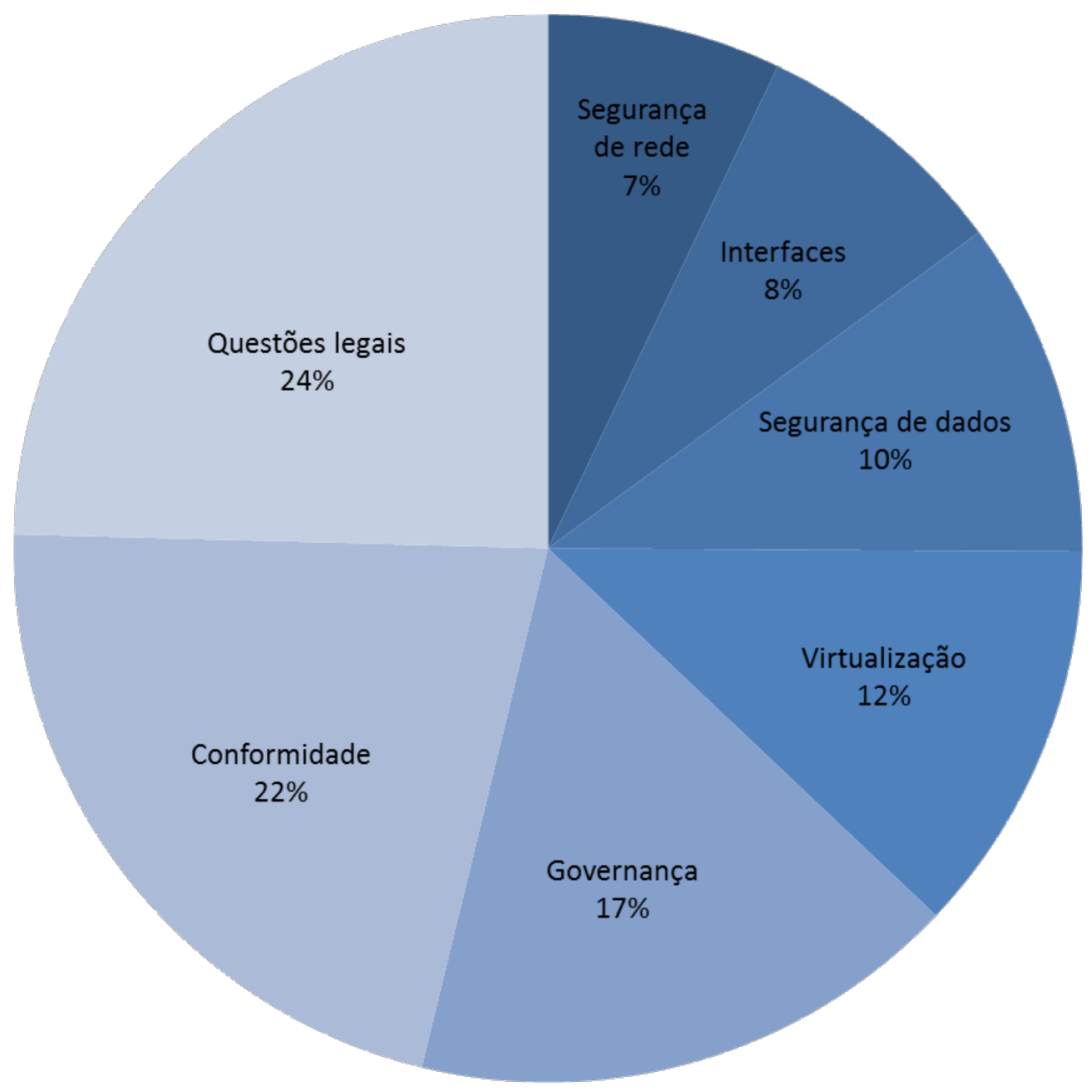

Figura 8: Gráfico relativo aos problemas de segurança com categorias agrupadas

gais, conformidade e perda de controle sobre a infraestrutura e sobre o modo como os dados são administrados na nuvem. Dentre as questões técnicas a de maior impacto é a de virtualização, com $12 \%$ das citações. Ao todo estes problemas mais relacionados às tecnologias utilizadas correspondem a 37\% do total de citações.

\subsubsection{Soluções}

Para a análise de soluções foi adotada a mesma estratégia, isto é, a análise das referências buscando menções sobre soluções para os problemas de segurança destacados. Os resultados são apresentados na Figura 9. Verificou-se aqui que o número de citações de soluções para problemas legais ou de conformidade também representam uma grande porcentagem das referências analisadas. Embora exista uma grande preo- 


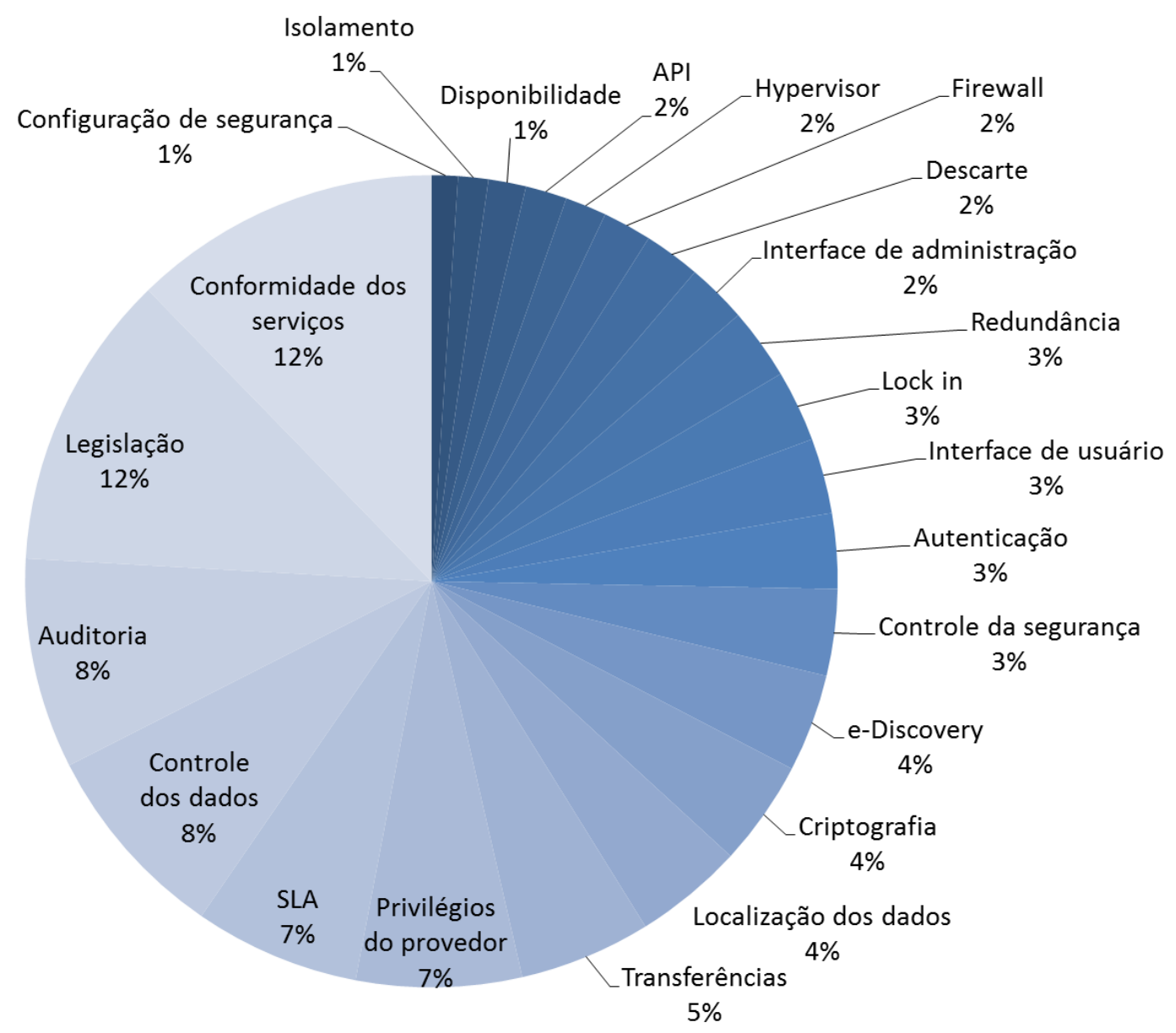

Figura 9: Gráfico relativo às soluções de segurança em computação em nuvem

cupação com estes problemas, também há um grande trabalho já em andamento para suprir as necessidades nestas áreas.

O mesmo não ocorre com as questões técnicas mencionadas anteriormente. Questões relacionadas à virtualização, isolamento de recursos e vulnerabilidades ainda são pouco exploradas. Em outras palavras, problemas como este e outros recebem atenção considerável porém são pouco explorados em termos de pesquisa e desenvolvimento.

Agrupando os resultados da referida pesquisa obtem-se o gráfico apresentado na Figura 10. Fica clara a distinção entre a quantidade de citações de problemas e de soluções para cada grande categoria. Enquanto na análise de problemas a categoria virtualização correspondia a $12 \%$ das citações, em termos de soluções a mesma categoria apresenta apenas 3\%, o que representa uma diferença considerável. Já outras 


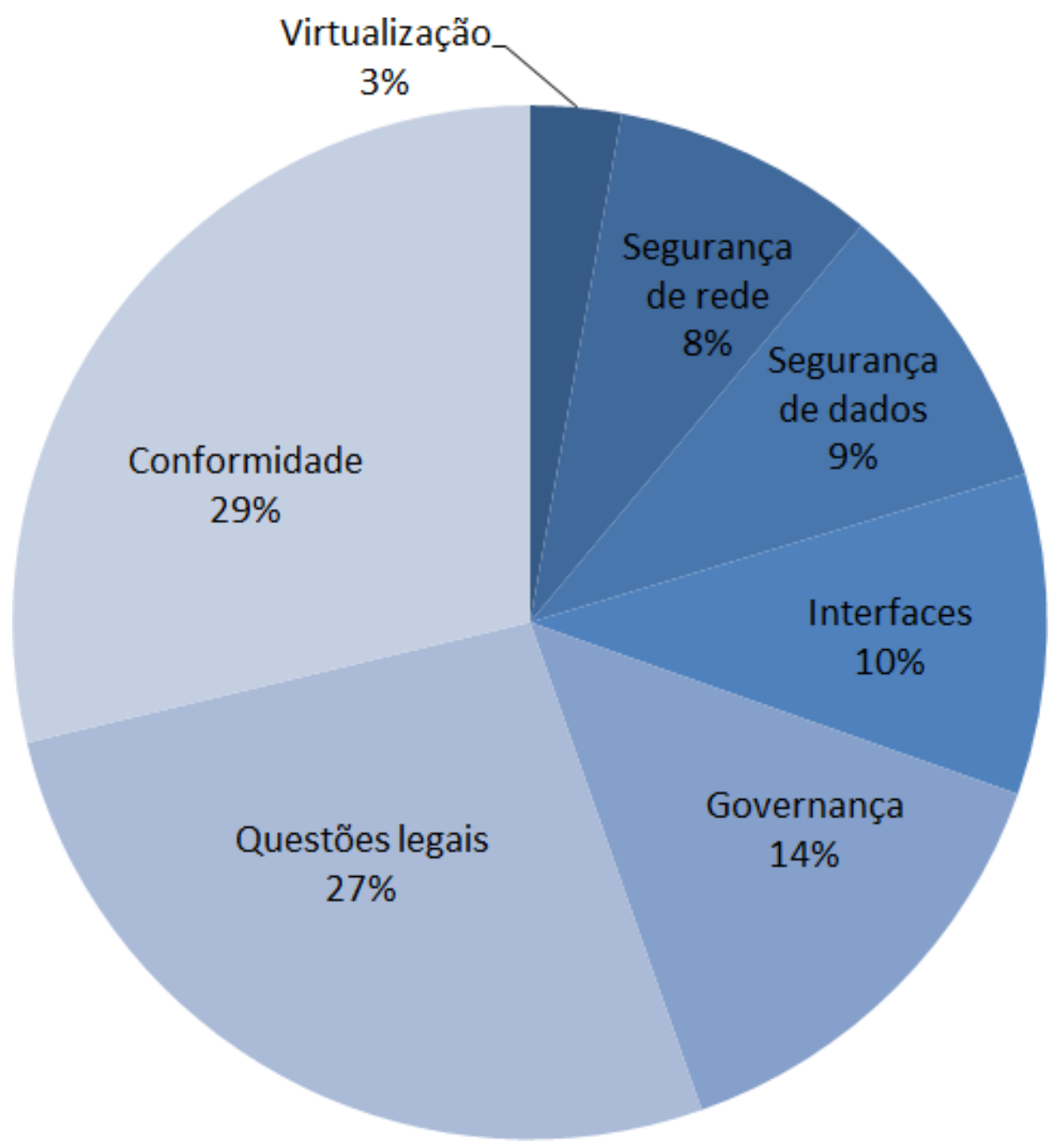

Figura 10: Gráfico relativo às soluções de segurança com categorias agrupadas

categorias apresentaram um percentual maior de soluções do que de problemas, o que leva à conclusão de que estas áreas estão sendo ativamente exploradas não apenas pela academia, mas também por soluções de mercado já existentes e utilizadas.

\subsubsection{Comparação}

Para comparar os resultados de cada análise (de problemas e de soluções) foram gerados gráficos que revelam a discrepância entre citações de cada tipo. O gráfico para as categorias completas é observado na Figura 11. Os valores nos eixos correspondem à quantidade de citações (de problemas ou soluções) para uma determinada categoria.

Com relação aos tons de cinza: 


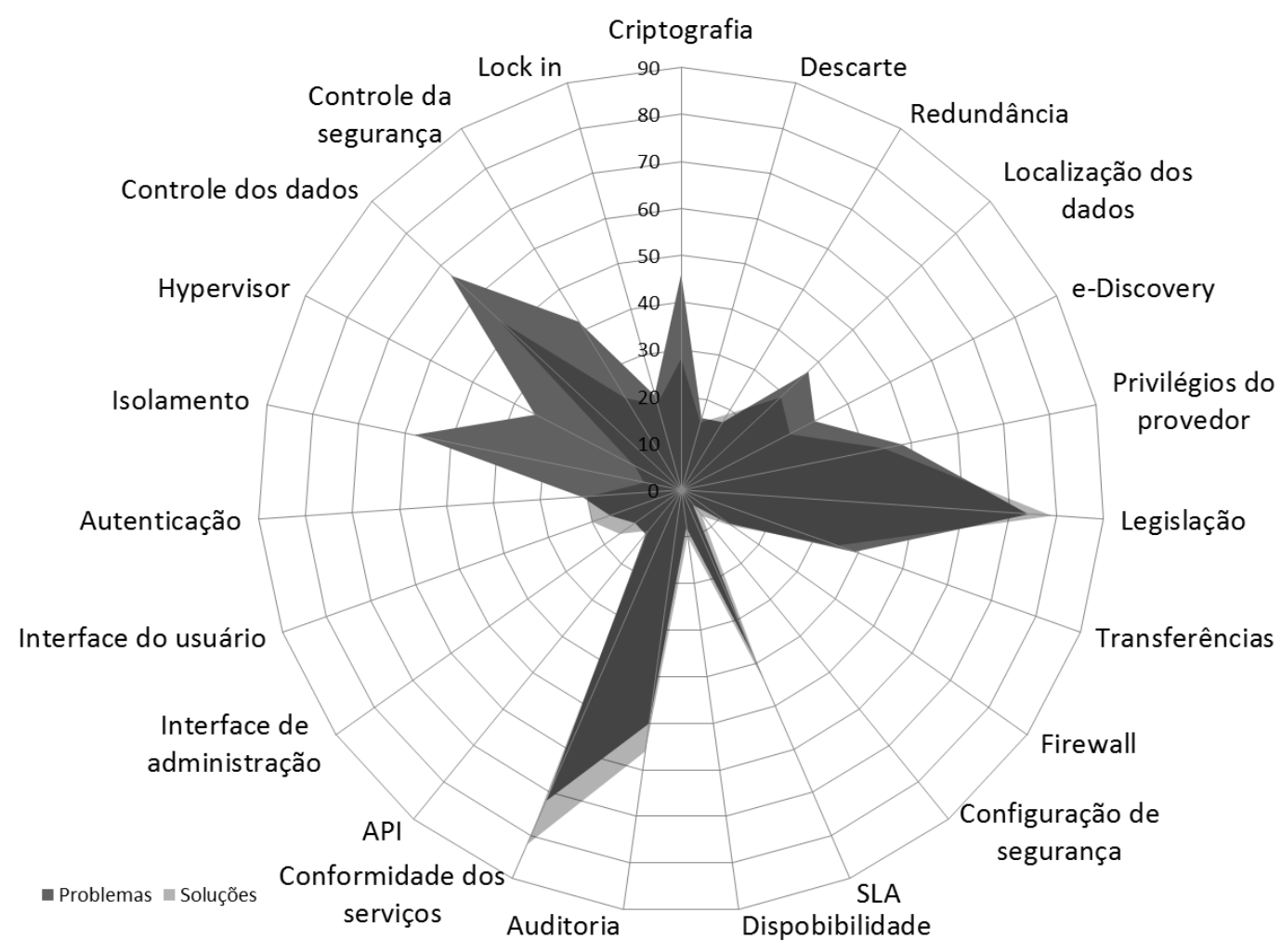

Figura 11: Gráfico de comparação entre problemas e soluções

- Em cinza claro estão as citações de soluções.

- Em cinza médio estão as citações de problemas.

- Em cinza escuro estão as áreas onde ocorre sobreposição.

Deste modo:

- Áreas com predominância do cinza claro representam áreas onde existem mais citações retratando problemas na categoria do que soluções propriamente ditas. Tratam-se portanto de áreas que ainda precisam ser pesquisadas e novas soluções precisam ser desenvolvidas.

- Áreas com predominância do cinza médio indicam categorias com mais indicações de soluções do que de problemas. São categorias que já possuem uma grande base de conhecimento desenvolvida, bem como soluções já sendo utilizadas ativamente. 


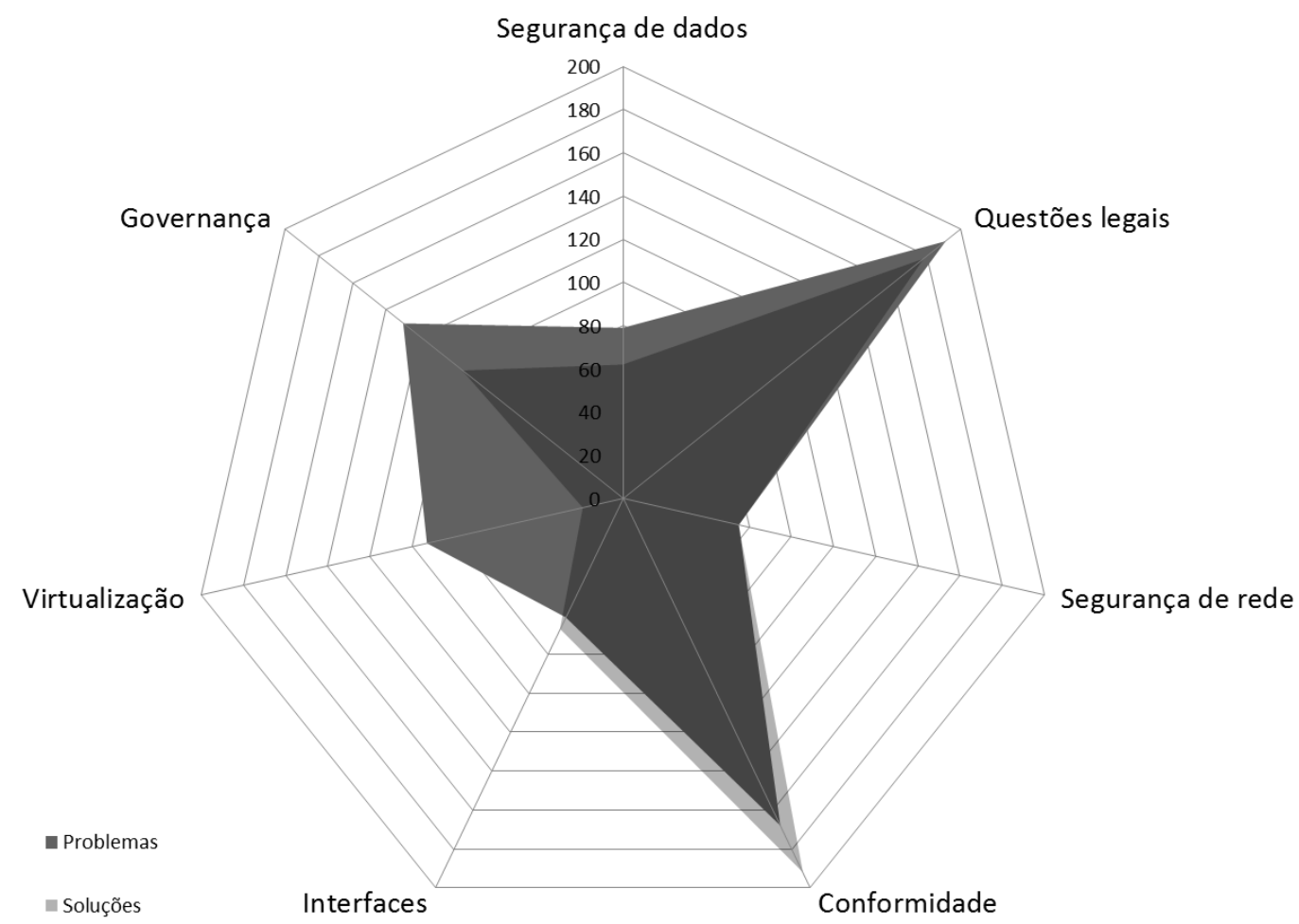

Figura 12: Gráfico de comparação entre problemas e soluções com categorias agrupadas

- Áreas com predominância do cinza escuro indicam equilíbrio entre citações, portanto são categorias que estão relativamente encaminhadas em termos de pesquisas, embora as soluções ainda não estejam tão bem consolidadas quanto no caso anterior.

Com estas informações, pode-se inferir que categorias como conformidade de serviço, questões legais e níveis de serviço possuem uma grande base de conhecimento existente, com equilíbrio ou até mesmo vantagem no número de citações sobre soluções do que de citações de problemas. Já algumas áreas técnicas, como isolamento de dados e recursos, vulnerabilidades de aplicações de virtualização e controles de segurança precisam receber atenção para que os problemas sejam resolvidos adequadamente.

Agrupando as categorias obtem-se os resultados observados na Figura 12. Novamente tem-se um grande volume de citações nas áreas de conformidade e ques- 


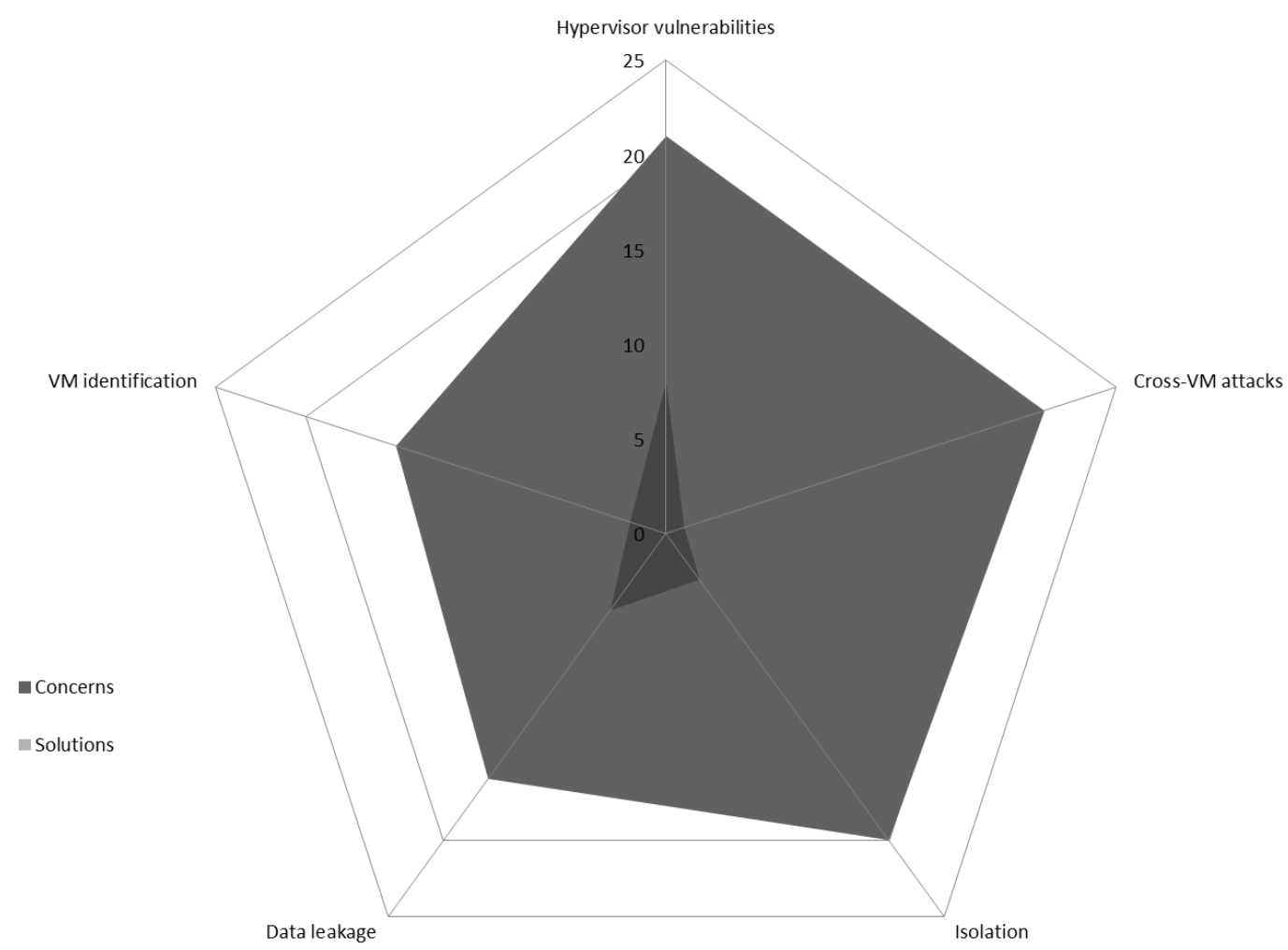

Figura 13: Comparação entre problemas e soluções para a categoria de virtualização

tões legais, porém observa-se equilíbrio entre citações relacionadas a problemas e soluções. Já questões técnicas (agrupadas essencialmente na categoria de virtualização) apresentam uma grande área clara, o que indica a necessidade de maiores pesquisas nestas áreas.

Para especificar melhor quais são as áreas dentro de virtualização a serem exploradas, foi conduzida uma nova análise focando na subdivisão das categorias de virtualização (vulnerabilidades do hypervisor, ataques entre máquinas virtuais, isolamento, vazamento de dados e identificação de máquinas virtuais). Os resultados são observados na Figura 13. As subcategorias com mais citações de soluções são as de vazamento de dados, hypervisor e isolamento. Já questões relacionadas à identificação de entidades dentro da nuvem (autenticação, autorização e contabilidade) e ataques entre máquinas virtuais são os assuntos menos explorados, embora exibam grande quantidade de citações de problemas (em cinza claro). Com base na análise realizada fica clara a necessidade de pesquisar e desenvolver soluções robustas para os problemas 
relacionados às tecnologias de virtualização utilizadas na computação em nuvem, especialmente no que tange a identificação e controle de uso de recursos e restrições de acesso à serviços por parte de usuários e administradores.

\subsection{Considerações do capítulo}

O início da pesquisa sobre segurança em computação em nuvem consistiu em levantar os principais problemas de segurança indicados por referências tanto da academia como do mercado. Com base nos conceitos levantados foi proposto um modelo de classificação para estes problemas, bem como uma taxonomia para organizar estes conceitos. A partir desta base de conhecimento foi realizado um estudo aprofundado sobre as questões de segurança encontradas em diversas publicações de diferentes tipos, focando não apenas nos problemas, mas também nas soluções ou nas sugestões de pesquisa em cada área. O resultado final são os gráficos comparando a quantidade de problemas e soluções encontrados ao longo do levantamento bibliográfico realizado.

A partir dos gráficos é possível concluir que problemas relacionados às tecnologias de virtualização representam o principal obstáculo técnico à adoção de tecnologias de nuvem em geral. Uma busca mais minuciosa focando nestes problemas permitiu verificar que questões de isolamento de máquinas virtuais, vazamento de dados, e ataques entre máquinas de uma mesma nuvem são os principais pontos a serem considerados na pesquisa desta dissertação. 


\section{CREDENCIAIS}

Como visto no capítulo 3, segurança é um fator essencial para consolidar a tecnologia de computação em nuvem como uma solução que promova a integração de serviços e recursos por meio de múltiplas nuvens e outros ambientes distribuídos (ARMBRUST et al., 2010). É importante garantir a privacidade e isolamento de dados e recursos considerando diversos níveis de granularidade, funcionalidades que podem ser atendidas por meio de mecanismos adequados de autenticação e autorização (LI et al., 2009; JANSEN, 2011). Conforme observado na análise de segurança apresentada em 3.3, questões relacionadas à identificação e controle de recursos e de entidades constituem problemas expressivos no ambiente de nuvem, embora ainda apresentem pouca pesquisa e desenvolvimento.

Considerando a evolução natural da tecnologia e a contínua integração de serviços, torna-se necessário desenvolver soluções consistentes para nuvens integradas (CELESTI et al., 2010a), permitindo o isolamento de recursos e portanto a administração dos mesmos e de seus usuários. Entretanto, soluções de administração de identidades (identity management, IdM) existentes focam principalmente nas interações entre usuários e serviços, tratando com menor relevância outras entidades, como máquinas virtuais e recursos computacionais (processamento, armazenamento). Um arcabouço abrangente para autenticação e autorização permite desenvolver mecanismos mais precisos e confiáveis para gerenciamento da nuvem.

Este capítulo apresenta a pesquisa relacionada aos mecanismos de autenticação e 
autorização baseadas em credenciais, com foco em computação em nuvem, onde se faz necessário prover serviços de segurança, privacidade, e confidencialidade englobando entidades diversas, como é o caso das máquinas virtuais.

- Seção 4.1 apresenta conceitos e definições relacionados aos elementos do ecossistema da nuvem, como entidades, atributos, identidades e credenciais.

- Seção 4.2 apresenta a classificação (resumida e completa) de credenciais.

- Seção 4.3 apresenta os ciclos de vida de credenciais e identidades.

- Seção 4.4 apresenta o arcabouço completo para estudo e desenvolvimento de soluções em gerenciamento de credenciais para computação em nuvem.

- Seção 4.5 apresenta as considerações finais do capítulo.

\subsection{Definições}

Diversas definições válidas podem ser encontradas para os conceitos de identidade e credencial. Muitas até mesmo se sobrepõem, visto que as informações que ambas representam estão intimamente relacionadas. Fato é que várias referências consideram identidades como um tipo de credencial (MACGREGOR; DUTCHER; KHAN, 2006; REID et al., 2003)

\subsubsection{Levantamento de definições}

A seguir são apresentadas algumas possíveis definições de identidade e credencial. É importante ressaltar que as definições foram extraídas de diferentes referências provenientes de diferentes contextos e não são específicas para computação nuvem (isto, contudo, não significa que as definições não sejam aplicáveis neste contexto).

Como exemplos de definições de identidade, podem-se citar: 
- Representação computacional de uma entidade física ativa (um usuário humano, um sistema ou um dispositivo de rede) ou agente programático (processo, serviço) (BENANTAR, 2005).

- Representação digital de informações sobre um indivíduo específico ou organização (BERTINO; TAKAHASHI, 2010).

- Representação parcial de uma pessoa em um contexto ou papel específico (PFITZMANN; HANSEN, 2010).

- Informação fundamental para atribuição de privilégios (BISHOP, 2004).

- Informação suficiente sobre uma entidade para identificá-la em um contexto particular (ITU-T, 2009).

Como definições de credencial, podem-se mencionar:

- Conjunto de dados que fornece evidências sobre afirmações relativas a uma identidade (BERTINO; TAKAHASHI, 2010).

- Coleção de atributos de identidade e asserções sobre um sujeito específico, emitidos por um provedor de identidades, também referido como provedor de credenciais (BERTINO; TAKAHASHI, 2010).

- Termo genérico para dados utilizados para verificar a identidade de uma entidade, que pode ser um servidor, cliente ou serviço (BREZAK et al., 2007).

- Evidências emitidas por uma entidade (provedor) sobre outra (usuário) relativas à autorizações ou reputação (CAMENISCH et al., 2005).

- Documentos cuja função primária é associar um conjunto de atributos com os elementos identificadores de um sujeito (MACGREGOR; DUTCHER; KHAN, 2006). 


\subsubsection{Definições consolidadas}

Estes conceitos podem ser consolidados por meio das seguintes definições adotadas:

- Entidade: Elemento do ecossistema da nuvem (BADGER et al., 2011) (de uma perspectiva alto nível, como serviços, clientes e provedores; ou de uma perspectiva de baixo nível, como máquinas virtuais e processos computacionais).

- Atributo: Característica ou informação que seja inerente a uma entidade ou que a qualifique.

- Identidade: Representação única de uma entidade física ou lógica no contexto da nuvem.

- Credencial: Coleção de atributos relativos a uma entidade específica.

A relação entre entidades, identidades, seus atributos e as credenciais associadas é ilustrada pela Figura 14. Este modelo considera que a identidade é unica para uma entidade. Contudo, em determinados cenários isto não é verificado, se por exemplo o usuário possuir contas distintas para cada serviço utilizado. Neste caso existem múltiplas representações digitais da mesma entidade.

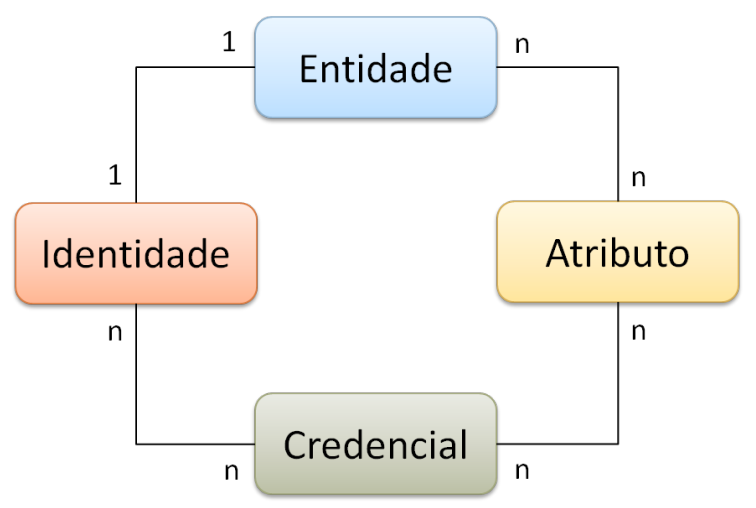

Figura 14: Proposta de modelo entidade-relacionamento para entidades, identidades, atributos e credenciais 
Também é possível a existência de credenciais compartilhadas por várias entidades. Por exemplo, se um recurso específico pode ser acessado por vários usuários simultaneamente, a autorização pode ser realizada de duas maneiras:

- Uma credencial separada é emitida para cada usuário.

- Uma credencial compartilhada é criada e replicada para todos usuários.

No primeiro caso o controle é mais preciso, consequentemente torna-se mais fácil criar políticas de acesso e revogar permissões separadamente. Por outro lado, se as políticas são as mesmas para todos os usuários então faz sentido criar uma credencial compartilhada. Se as diretivas de controle de acesso forem alteradas apenas uma credencial precisa ser atualizada. Contudo, com uma credencial compartilhada é mais difícil criar políticas para um usuário específico sem afetar os outros.

\subsection{Classificação}

Credenciais podem ser utilizadas para representar um vasto conjunto de informações sobre uma entidade, desde atributos que a descrevem, ações que ela pode realizar, e regras que ela deve seguir. Estas informações podem ser resumidas pelas seguintes categorias propostas:

- Metadado: Credenciais utilizadas para armazenar informações sobre a própria entidade, como atributos para sua identificação, migração entre nuvens, registros sobre alterações no ciclo de vida, indicações de utilização e de propriedade.

- Autorização: Credenciais estabelecendo as ações que a entidade pode executar, os recursos que ela pode acessar e quaisquer vantagens que ela pode usufruir.

- Obrigação: Credenciais definindo as regras e políticas que uma entidade deve seguir dentro do contexto da nuvem, incluindo obrigações financeiras, legais e operacionais. 
Um conjunto mais abrangente de possíveis tipos de credenciais é proposto pelas Tabelas 5, 6 e 7. Estas categorias são baseadas na publicação NIST SP 800-103 (MACGREGOR; DUTCHER; KHAN, 2006), uma ontologia que não cobre apenas credenciais digitais (utilizadas em sistemas computacionais), mas qualquer tipo de credencial física existente (carta de motorista, documentos de registro nacional). As tabelas apresentam o nome da categoria (em alguns casos adaptado ao contexto da nuvem), a definição original da categoria, exemplos, e uma proposta de definição e exemplos adaptados ao contexto de computação em nuvem. Esta classificação facilita a identificação dos tipos de informação que devem ser representados de acordo com os requisitos do serviço prestado dentro do contexto da nuvem em termos de confiabilidade, privacidade e segurança de infraestrutura.

Um resumo das categorias de credencial propostas pode ser observado na Figura 15. Uma credencial representa um conjunto de atributos sobre uma entidade, e portanto

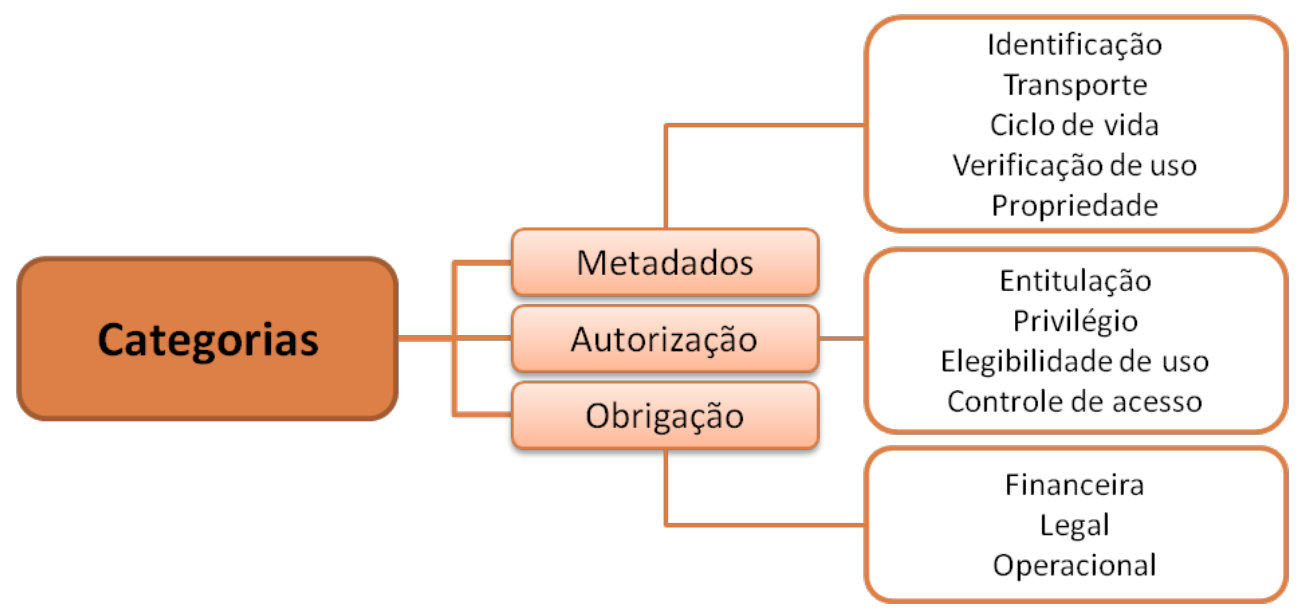

Figura 15: Proposta de classificação de credenciais

pode incorporar elementos de mais de uma categoria. Um exemplo real é a carta de motorista, que além de estabelecer um tipo de privilégio (o de poder dirigir) também pode ser utilizada como identificação (metadados). No contexto da nuvem um possível exemplo é um certificado em XML contendo informações sobre uma máquina virtual (unicamente representando-a dentro do sistema) e também com políticas de controle de acesso para usuários. 
Tabela 5: Classificação de credenciais para categoria de metadados

\begin{tabular}{|c|c|c|c|}
\hline Categoria & Definição & Exemplos & Contexto da nuvem \\
\hline Identificação & $\begin{array}{l}\text { Documento emitido } \\
\text { para propósitos } \\
\text { específicos mas que } \\
\text { também pode ser } \\
\text { utilizado como } \\
\text { identificação de uma } \\
\text { entidade }\end{array}$ & $\begin{array}{l}\text { Registro } \\
\text { nacional, cartão } \\
\text { inteligente, carta } \\
\text { de motorista, } \\
\text { passaporte }\end{array}$ & $\begin{array}{l}\text { Informação que identifica de } \\
\text { maneira única uma entidade, } \\
\text { como informações de } \\
\text { autenticação de usuários e } \\
\text { descrição de máquina virtual }\end{array}$ \\
\hline Transporte & $\begin{array}{l}\text { Identificação para } \\
\text { viagens, utilizado } \\
\text { por linhas aéreas, } \\
\text { imigração e } \\
\text { alfândega }\end{array}$ & $\begin{array}{l}\text { Passaporte, visto, } \\
\text { comprovante de } \\
\text { embarque }\end{array}$ & $\begin{array}{l}\text { Informação utilizada para } \\
\text { transporte ou migração da } \\
\text { entidade (entre nuvens ou dentro } \\
\text { da mesma nuvem), como } \\
\text { especificação de máquina virtual } \\
\text { para replicá-la em outro domínio }\end{array}$ \\
\hline $\begin{array}{l}\text { Ciclo } \\
\text { de vida }\end{array}$ & $\begin{array}{l}\text { Documentos } \\
\text { emitidos em eventos } \\
\text { importantes, como } \\
\text { nascimento, } \\
\text { casamento ou morte }\end{array}$ & $\begin{array}{l}\text { Certificado de } \\
\text { nascimento, de } \\
\text { morte }\end{array}$ & $\begin{array}{l}\text { Controles sobre criação, } \\
\text { atualização, e destruição da } \\
\text { entidade }\end{array}$ \\
\hline $\begin{array}{l}\text { Verificação } \\
\text { de uso }\end{array}$ & $\begin{array}{l}\text { Documentos que } \\
\text { indicam se uma } \\
\text { pessoa está } \\
\text { empregada } \\
\text { (legalmente ou não) }\end{array}$ & $\begin{array}{l}\text { Cartão de } \\
\text { identificação de } \\
\text { empregado, } \\
\text { identificação } \\
\text { militar }\end{array}$ & $\begin{array}{l}\text { Informação sobre emprego (uso) } \\
\text { atual da entidade, indicando } \\
\text { atividades e especializações }\end{array}$ \\
\hline Propriedade & $\begin{array}{l}\text { Documentos que } \\
\text { comprovam a } \\
\text { relação entre uma } \\
\text { pessoa e um país ou } \\
\text { estado (cidadania) }\end{array}$ & $\begin{array}{l}\text { Passaporte, } \\
\text { certificado de } \\
\text { naturalização, } \\
\text { identificação de } \\
\text { cidadão }\end{array}$ & $\begin{array}{l}\text { Informação sobre proprietário } \\
\text { original da entidade, como } \\
\text { informações sobre origem da } \\
\text { máquina virtual (útil ao migrá-la } \\
\text { para outros domínios, } \\
\text { principalmente para auditoria e } \\
\text { contabilidade) }\end{array}$ \\
\hline
\end{tabular}

\subsection{Ciclo de vida}

O ciclo de vida de uma credencial pode ser organizado por meio do processo representado pelas seguintes funções propostas:

- Criar: Criação de uma credencial utilizando atributos validados por uma autoridade confiável.

- Guardar: Armazenamento da credencial em uma base de dados, arquivo em disco ou apenas em memória, dependendo da implementação do sistema de gerenciamento de credenciais utilizado. 
Tabela 6: Classificação de credenciais para categoria de autorizações

\begin{tabular}{|c|c|c|c|}
\hline Categoria & Definição & Exemplos & Contexto da nuvem \\
\hline Entitulação & $\begin{array}{l}\text { O portador pode } \\
\text { receber um } \\
\text { benefício }\end{array}$ & $\begin{array}{l}\text { Cartão de plano de } \\
\text { saúde }\end{array}$ & $\begin{array}{l}\text { Entidade pode receber certos } \\
\text { serviços ou benefícios baseados em } \\
\text { regras, como análises periódicas de } \\
\text { segurança, contabilidade e auditoria }\end{array}$ \\
\hline Privilégio & $\begin{array}{l}\text { O portador é } \\
\text { qualificado para } \\
\text { exercer uma } \\
\text { atividade }\end{array}$ & $\begin{array}{l}\text { Carta de motorista, } \\
\text { licença } \\
\text { profissional, }\end{array}$ & $\begin{array}{l}\text { Entidade é qualificada para realizar } \\
\text { ações restritas, como utilizar } \\
\text { recursos de alta performance ou ter } \\
\text { prioridade no uso de recursos de } \\
\text { rede }\end{array}$ \\
\hline $\begin{array}{l}\text { Eligibilidade } \\
\text { de uso }\end{array}$ & $\begin{array}{l}\text { O portador pode } \\
\text { ser legalmente } \\
\text { empregado }\end{array}$ & $\begin{array}{l}\text { Carteira de } \\
\text { trabalhador }\end{array}$ & $\begin{array}{l}\text { Entidade pode ser utilizada em } \\
\text { certas operações (uma máquina } \\
\text { virtual pode acessar recursos de } \\
\text { nuvens públicas externas) }\end{array}$ \\
\hline $\begin{array}{l}\text { Controle de } \\
\text { acesso }\end{array}$ & $\begin{array}{l}\text { Concede } \\
\text { permissão à } \\
\text { edifícios e } \\
\text { instalações }\end{array}$ & $\begin{array}{l}\text { Identificação de } \\
\text { empresa, federal } \\
\text { ou militar }\end{array}$ & $\begin{array}{l}\text { Controles básicos para autorização } \\
\text { de entidades, como credenciais para } \\
\text { utilizar interfaces administrativas de } \\
\text { um serviço }\end{array}$ \\
\hline
\end{tabular}

Tabela 7: Classificação de credenciais para categoria de obrigações

\begin{tabular}{|c|c|c|c|}
\hline Categoria & Definição & Exemplos & Contexto da nuvem \\
\hline Financeira & $\begin{array}{l}\text { Documentos para } \\
\text { realização de } \\
\text { transações } \\
\text { financeiras }\end{array}$ & $\begin{array}{l}\text { Cartão de crédito, } \\
\text { comprovante de } \\
\text { conta de banco }\end{array}$ & $\begin{array}{l}\text { Informações para transações } \\
\text { dentro da nuvem, como } \\
\text { contabilidade e restrições de } \\
\text { uso }\end{array}$ \\
\hline Legal & $\begin{array}{l}\text { Documentos } \\
\text { indicando obrigações } \\
\text { legais do portador }\end{array}$ & $\begin{array}{l}\text { Documento de } \\
\text { alistamento } \\
\text { militar }\end{array}$ & $\begin{array}{l}\text { Obrigações legais de uma } \\
\text { entidade, como condições e } \\
\text { restrições de uso }\end{array}$ \\
\hline Operacional & $\begin{array}{l}\text { Regras operacionais } \\
\text { de um negócio ou } \\
\text { organização }\end{array}$ & $\begin{array}{l}\text { Diretivas de } \\
\text { tempo de } \\
\text { trabalho, } \\
\text { utilização de } \\
\text { recursos } \\
\text { (impressora) }\end{array}$ & $\begin{array}{l}\text { Condições de operação a serem } \\
\text { satisfeitas, como limitações de } \\
\text { tempo e uso de recursos }\end{array}$ \\
\hline
\end{tabular}

- Usar: Verificação do valor ou apenas da existência de uma credencial para executar uma operação que exija algum tipo de autenticação ou autorização.

- Atualizar: Alteração das informações ou reemissão integral da credencial, por exemplo, caso as restrições de controle de acesso tenham sido mudadas.

- Revogar: Invalidação de uma credencial sem removê-la do sistema, por exemplo, após sua expiração.

- Arquivar: Arquivamento da credencial em uma unidade de armazenamento se- 
parada para auditoria e contabilidade, ou ainda para deixá-la em um estado inativo até que a entidade relacionada peça sua reativação.

- Destruir: Destruição completa e definitiva da credencial, bem como qualquer informação relacionada à mesma, visando evitar inconsistências entre informações do sistema.

Este processo é ilustrado pela Figura 16. Após criada a credencial é armazenada para que possa ser utilizada por outros sistemas. A operação de uso da credencial pode ser uma simples verificação da existência da mesma, ou pode incluir a leitura de seu conteúdo e comparação com alguma política de restrição de uso de recursos, por exemplo. Uma credencial armazenada no sistema também pode ser atualizada em caso de alterações nos atributos que ela representa.

Finalmente, quando a credencial não é mais necessária ou se torna inválida (após expiração ou período de não utilização) ela é revogada, e portanto não pode ser utilizada para autenticação e autorização até que seja reativada ou reemitida. O estado de revogação é transitório (o que é representado pela linha tracejada), e a credencial é arquivada ou destruída. A transição final (estado de destruição para estado de criação) não é de fato implementada em soluções reais, mas os atributos de uma credencial destruída podem ser reutilizados para criar uma nova, dando continuidade ao ciclo.

Se comparado com o ciclo de vida de uma credencial, o ciclo para uma identidade pode ser simplificado, apresentando menos estados e transições conforme observado na Figura 17. A identidade é única para uma entidade em um contexto específico, e os atributos utilizados para gerá-la representam um conjunto suficiente de características que permitem autenticar a entidade. É importante que estes atributos sejam perenes de modo a evitar interpretações errôneas ao utilizar a identidade, caso contrário a identidade deixa de ser confiável. Deste modo, operações para atualizar ou recriar uma identidade teoricamente não são necessárias, já que os atributos utilizados para criá-la 
também não mudam.

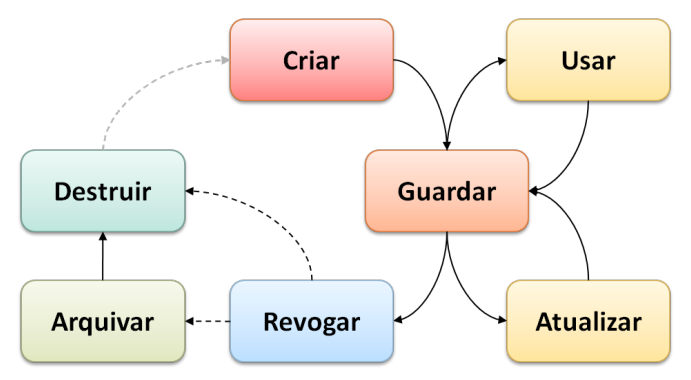

Figura 16: Proposta de ciclo de vida para credenciais

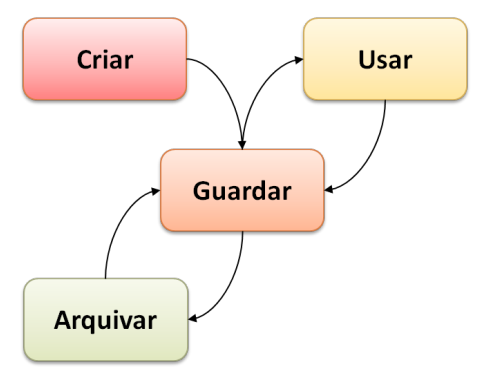

Figura 17: Proposta de ciclo de vida para identidades

Outro ponto importante é que mesmo se uma entidade deixa de ser ativa (uma máquina virtual que foi permanentemente excluída do sistema, por exemplo), ainda é necessário guardar informações sobre a mesma para funções de auditoria e consistência de $\log s$ de sistema e de utilização do mesmo. Caso contrário as informações sobre o uso de recursos dentro do sistema tornam-se inválidas, fazendo referência a elementos que não estão mais registrados no sistema. Isto também é importante para evitar a reutilização de uma velha identidade (reusando atributos identificadores) para uma nova entidade, forçando o sistema a sempre criar uma nova identidade.

Um resumo do ciclo de vida de credenciais e identidades é observado na Figura 18. A identidade é vista como uma especialização da credencial e seu ciclo de vida possui menos estados do que o de uma credencial. Na prática, alterações nas informações que compõem a identidade de uma entidade do ecossistema devem ser interpretadas como uma oportunidade para rever as políticas de emissão de identidades. Em caso de necessidade real de modificar algum atributo identificador é necessário reemitir a identidade e provavelmente verificar se as outras identidades também precisam ser atualizadas. 


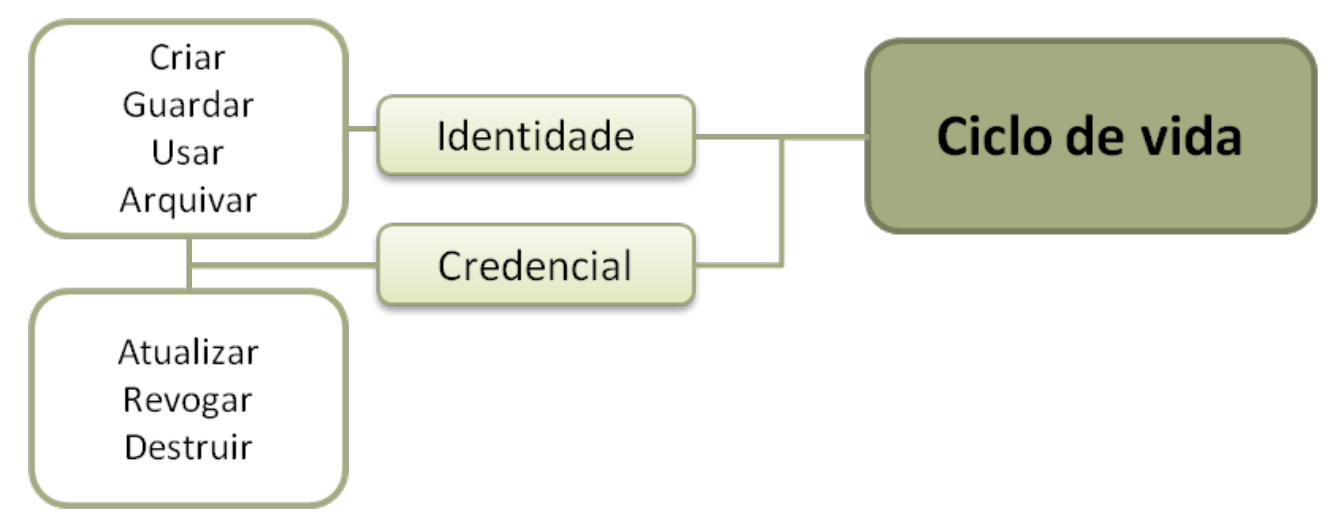

Figura 18: Resumo da proposta de organização de ciclo de vida de credenciais e identidades

\subsection{Arcabouço proposto}

Sistemas e serviços baseados em computação em nuvem exigem um sistema de administração de credenciais para oferecer mecanismos confiáveis de autenticação e autorização. Para desenvolver ou adotar um sistema deste tipo é necessário considerar os seguintes pontos:

1. Tipo de informação representada pela credencial. Este item está intimamente relacionado à classificação de credenciais apresentada na seção 4.2. As categorias fornecem a visão geral necessária para decidir como representar as políticas de autorização, obrigações que devem ser atendidas e informações que devem ser mantidas sobre a entidade. Por meio da classificação também é possível agrupar atributos, reduzindo o número de credenciais e portanto simplificando a solução como um todo.

2. Tipo de serviço que será oferecido. Isto influencia o foco do sistema de gerenciamento de credenciais. Em um SaaS o usuário possui pouco ou nenhum privilégio sobre a administração ou configuração da infraestrutura da nuvem. Isto permite a criação de credenciais com foco nas interfaces de comunicação entre serviço e cliente, e protegendo contra usuários externos maliciosos. Credenciais específicas para proteção da infraestrutura podem ser simplificadas. Já 
em serviços PaaS e IaaS o cliente utiliza recursos diretamente da infraestrutura, consequentemente o usuário malicioso já pode estar dentro da nuvem. Neste caso é importante desenvolver controles para isolamento e contra o vazamento de dados ou escalada de privilégios.

3. A organização da nuvem em termos de arquitetura e ecossistema. Isto afeta o modo como as credenciais são geradas e distribuídas. Nuvens privadas são ambientes mais restritos e controlados, portanto o emissor de credenciais pode ser uma entidade centralizada e a administração destas credenciais é feita dentro de um escopo fechado. Em contrapartida, nuvens públicas e comunitárias são compartilhadas por muitos usuários e empresas, portanto é necessário estabelecer uma terceira parte confiável para gerar e administrar credenciais. Por fim, nuvens híbridas são composições de várias nuvens, portanto é necessário estabelecer uma relação de confiança entre os emissores e gerenciadores de credenciais de cada nuvem, bem como quaisquer outras autoridades importantes.

4. Requisitos de segurança, privacidade e conformidade de serviço. Este item engloba o que o sistema de gerenciamento de credenciais deve atender em termos de segurança infraestrutural, privacidade de dados e informações sigilosas, e conformidade com níveis de serviço acordados (SLA). Por exemplo, requisitos legais como legislações específicas para uma localidade (estado ou país) sugerem a criação de credenciais de controle. O conhecimento destes requisitos permite reduzir a quantidade e complexidade das credenciais necessárias, evitando a criação de controles desnecessários e portanto otimizando o funcionamento do sistema.

5. As entidades que serão administradas em termos de autenticação e autorização. Isto define os elementos do ecossistema que deverão ser identificados e controlados. Este item tem impacto direto nos tipos de credenciais a serem usadas e é influenciado pelo tipo de serviço oferecido. Em um IaaS existe uma necessidade 
maior de controlar elementos infraestruturais, como máquinas virtuais, processos e elementos de armazenamento. Já em um SaaS o acesso a estes recursos é limitado pelas interfaces do serviço, portanto o foco passa a ser o usuário.

6. O ciclo de vida de identidades e credenciais. Isto afeta os mecanismos e políticas do sistema de gerenciamento de credenciais, visto que cada estado e transição do ciclo de vida deve ser cuidadosamente desenvolvido e controlado para evitar problemas relacionados à replicação incorreta de credenciais ou utilização de credenciais expiradas. Os mecanismos de revogação, arquivamento e destruição são essenciais para evitar tais problemas.

Os pontos apresentados podem ser resumidos pelo arcabouço proposto na Figura 19 (GONZALEZ et al., 2013). A classificação de credenciais é a apresentada na seção 4.2.

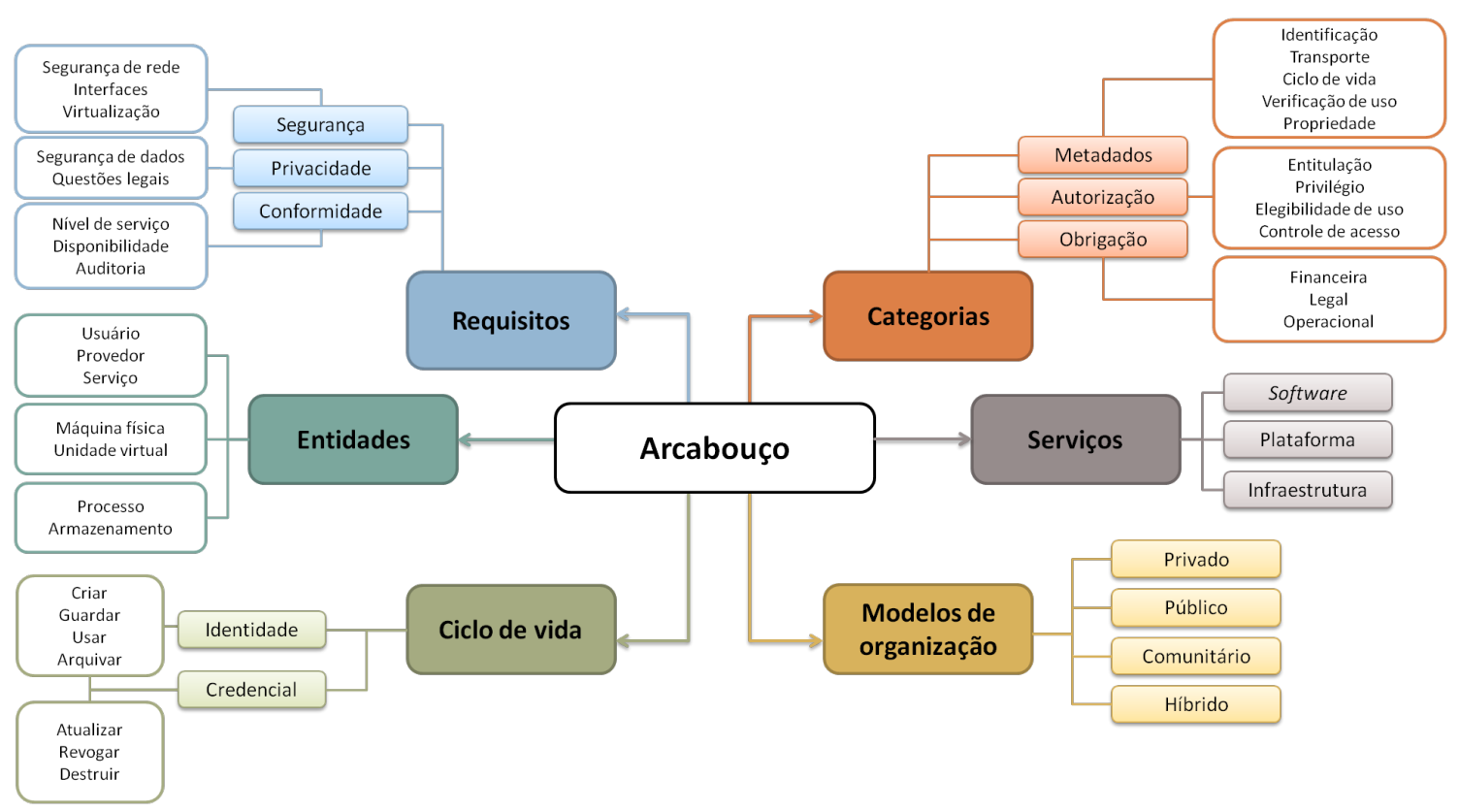

Figura 19: Proposta de arcabouço de gerenciamento de credenciais

O modelo de organização de nuvem e de tipos de serviços é baseado na referência do NIST (MELL; GRANCE, 2011). Os requisitos de segurança são baseados nas referências (JANSEN; GRANCE, 2011; SIMMONDS; REZEK; REED, 2011; CATTEDDU; HOGBEN, 2009) e na organização apresentada em (GONZALEZ et al., 2011) e consolidada em (GONZALEZ 
et al., 2012). O conceito de entidades é proveniente da seção 4.1, e os ciclos de vida de 4.3 .

O arcabouço visa facilitar o estudo dos mecanismos de autenticação e autorização baseados em credenciais. Ao consolidar as diversas definições e conceitos necessários para compreender o gerenciamento de credenciais, o modelo também permite comparar os diferentes requisitos para este tipo de solução ao alterar seus elementos. Por exemplo, se um ambiente de testes científicos baseado em nuvem privada for migrado para uma nuvem comunitária (para ser agregar usuários de outras universidades e permitir o compartilhamento de recursos), existem diversas decisões relacionadas à administração de credenciais. Questões relacionadas a como as universidades irão estabelecer uma relação de confiança entre as autoridades que emitem credenciais de modo que seja possível oferecer o conjunto compartilhado de recursos mantendo privilégios e obrigações. Se as universidades estão em países diferentes, quais são as implicações legais para permitir esta integração infraestrutural. Devido à agregação de recursos, que tipos de credenciais devem ser criadas tanto para controle do hardware físico como de plataformas virtualizadas. Estas decisões dependem dos pontos tratados pelo arcabouço, assim como outros requisitos não relacionados à segurança, como requisitos de negócio e políticos.

\subsection{Considerações do capítulo}

O levantamento de problemas de segurança culminou na identificação de alguns pontos fundamentais a serem pesquisados e resolvidos. Em particular, problemas de isolamento de usuários, recursos, mecanismos de controle de acesso e autenticação são pontos que podem ser tratados por soluções baseadas em credenciais, que permitem guardar informações sobre as entidades da nuvem, além de suas permissões e obrigações dentro da mesma. O passo seguinte foi realizar um estudo teórico sobre credenciais, visando estabelecer uma definição concreta do que é uma identidade e uma 
credencial. Posteriormente foi proposto um modelo de classificação de credenciais baseado em conceitos identificados no levantamento bibliográfico realizado. Outros pontos estudados foram o ciclo de vida das credenciais e quais as variáveis que afetam uma solução de autenticação e autorização baseada em credenciais.

Por fim, o estudo foi concluído com a elaboração de um arcabouço que reúne os principais pontos a serem considerados ao desenvolver ou adotar uma solução de credenciais para nuvem. Itens como os requisitos de segurança, privacidade, e conformidade, bem como o tipo de serviço trabalhado, o modelo de organização da nuvem, os tipos de credenciais necessárias, as entidades a serem controladas, e o ciclo de vida destas credenciais, constituem os fatores fundamentais que definem o modo de funcionamento e a abrangência de um sistema de gerenciamento de credenciais. 


\section{SISTEMA DE GERENCIAMENTO DE CREDENCIAIS}

O levantamento bibliográfico revelou a necessidade de propor mecanismos robustos e transparentes para oferecer maior controle sobre o acesso aos recursos da nuvem por parte de seus usuários. Com base no estudo teórico realizado acerca do conceito de credenciais, identidades, e mecanismos de autenticação e autorização, a pesquisa passou a focar na proposta de solução de gerenciamento de credenciais para ambientes de computação em nuvem. Este capítulo apresenta a proposta de Sistema de Gerenciamento de Credenciais (SGC) ou Credential Management System (CMS).

O capítulo está organizado da seguinte maneira:

- Seção 5.1 apresenta os requisitos do SGC.

- Seção 5.2 apresenta a visão geral da proposta de arquitetura do SGC.

- Seção 5.3 apresenta o modelo de implementação do SGC, detalhando cada um dos módulos especificados pela arquitetura.

- Seção 5.4 apresenta os trabalhos relacionados à proposta de SGC.

- Seção 5.5 apresenta as considerações finais do capítulo.

\subsection{Especificação de requisitos}

Para o desenvolvimento do SGC é considerado um ambiente de computação em nuvem, o que estabelece algumas premissas para o cenário: 
- Características fundamentais de uma nuvem: O ambiente de computação em nuvem subentende um conjunto de recursos físicos e virtuais compartilhados, elásticos, e acessíveis por meio de interfaces transparentes via rede.

- Funções básicas para controle de autenticação e autorização: Deve ser possível controlar o acesso aos recursos da nuvem por parte dos usuários, caso contrário torna-se inviável implementar um sistema de gerenciamento de credenciais que não consiga estabelecer uma camada de controle entre os usuários e a nuvem.

\subsubsection{Requisitos funcionais}

Como requisitos funcionais do SGC foram identificados:

1. Proibir por padrão o tráfego de dados às claras (sem proteção). Um requisito opcional dentro deste contexto é permitir que este parâmetro seja configurável no SGC, representando uma política geral caso políticas mais específicas não estejam definidas.

2. Permitir envio de dados às claras desde que o SGC seja explicitamente configurado, por meio de controle manual (override) ou baseado em políticas (regras específicas para determinados tipos de tráfego, diferenciando por exemplo um tráfego de controle de um tráfego de vídeo ou o conteúdo de uma página).

3. Evitar de realizar modificações nas aplicações originais nas quais o SGC será inserido. O SGC provê mecanismos de autenticação e autorização para outros sistemas, e portanto é importante que estes sistemas não precisem ser modificados ou adaptados ao SGC.

4. Evitar duplicação de informações sobre usuários e outras entidades da nuvem. O SGC deve estar integrado ao sistema administrado para obter informa- 
ções sobre estas entidades, guardando informações adicionais internamente caso necessário.

5. Toda entidade do sistema administrado deve ser/estar autenticada pelo SGC, a não ser que o SGC seja explicitamente configurado para não fazê-lo. Em outras palavras, uma entidade sem uma identidade válida e reconhecida pelo SGC não pode interagir com a nuvem.

6. Toda operação entre entidades deve ser/estar autorizada pelo SGC, a não ser que o SGC seja explicitamente configurado para não fazê-lo. Em outras palavras, toda operação dentro da nuvem deve ser autorizada pelo SGC, não podendo ser possível por exemplo utilizar comandos da aplicação original para evitar o controle do SGC.

7. O SGC deve oferecer interfaces para que as operações de autenticação e autorização possam ser delegadas para outros sistemas ou soluções, caso isto seja importante para o funcionamento da aplicação original. Em outras palavras, o SGC deve implementar estes mecanismos, porém também deve permitir que estas operações sejam realizadas por outra aplicação.

8. SGCs de diferentes aplicações ou nuvens devem estabelecer uma relação de confiança, permitindo a integração de serviços e compartilhamento de informações de autenticação e autorização.

9. O SGC deve implementar mecanismos de single sign-on, permitindo que a entidade não precise passar várias vezes pelo mesmo processo de autenticação (ou que uma mesma operação precise ser autorizada várias vezes durante sua execução).

10. O SGC deve oferecer mecanismos para controle de expiração de credenciais. 
11. Não permitir o reuso de credenciais expiradas.

12. Regras de autorização devem ser baseadas na identidade ou nos papéis da entidade.

13. O SGC deve se integrar com outros serviços da nuvem para obter informações sobre pontos de acesso da nuvem. Isto permite obter um mapa dos serviços oferecidos pela nuvem, favorecendo a integração com os mesmos.

\subsubsection{Requisitos não funcionais}

Além dos requisitos funcionais, foram definidos para o SGC os seguintes requisitos não funcionais:

1. Permitir que um número mínimo desejável de usuários possa utilizar o SGC simultaneamente, tendo como limite mínimo operacional um total de dois usuários da nuvem e dois serviços distintos.

2. Minimizar o overhead do SGC, isto é, tempo em excesso destinado às funções do SGC em si, e não da operação original realizada.

3. Evitar que o modo de funcionamento da aplicação original seja modificado, permitindo que o usuário desta aplicação não precise modificar o modo como ele trabalha, ou como seus programas e scripts funcionam. Em outras palavras, maximizar a transparência.

\subsection{Descrição da arquitetura proposta}

Com base nos requisitos levantados, as seguintes funcionalidades devem ser implementadas pelo SGC:

- Autenticação: Corresponde ao serviço de identificação de entidades do sistema. 
- Autorização: Implica na verificação da validade de uma operação dentro da nuvem, exercendo-se o controle de acesso aos recursos e serviços oferecidos.

- Contabilização: Controla o uso de recursos da nuvem com base nas requisições efetuadas para o SGC.

- Tratamento de entrada: Recebe requisições de autenticação, autorização, registro de novas entidades, dentre outras operações implementadas pelo SGC. Também é a porta de entrada da solução de gerenciamento de credenciais.

- Tratamento de saída: Envia requisições para outros serviços, constituindo portanto o principal elemento de integração com outros serviços da nuvem.

- Comprovação: Responsável por comprovar a validade dos atributos utilizados ao emitir uma nova credencial.

- Emissão: Cria novas credenciais com base na informação sobre a entidade e os atributos adequados.

- Controle: Controle principal do SGC, orquestrando as operações de autenticação e autorização.

Cada uma destas funcionalidades são implementadas em módulos individuais que constituem o núcleo do SGC. Para garantir a proteção dos dados ao longo de sua transferência é necessário prover mecanismos de segurança a partir da aplicação cliente. Para isso é proposta a implementação de uma camada intermediária (middleware) que realize a integração e proteção entre a aplicação original e o SGC. A integração de todos estes elementos é ilustrado pela Figura 20.

A aplicação original foi dividida em cliente original e servidor original, o que pressupõe que o usuário tem acesso a uma aplicação cliente (client-side) que faz requisições para uma aplicação servidor (server-side). O middleware deve se integrar a ambas partes, portanto é necessário desenvolver um cliente SGC e um servidor SGC. 


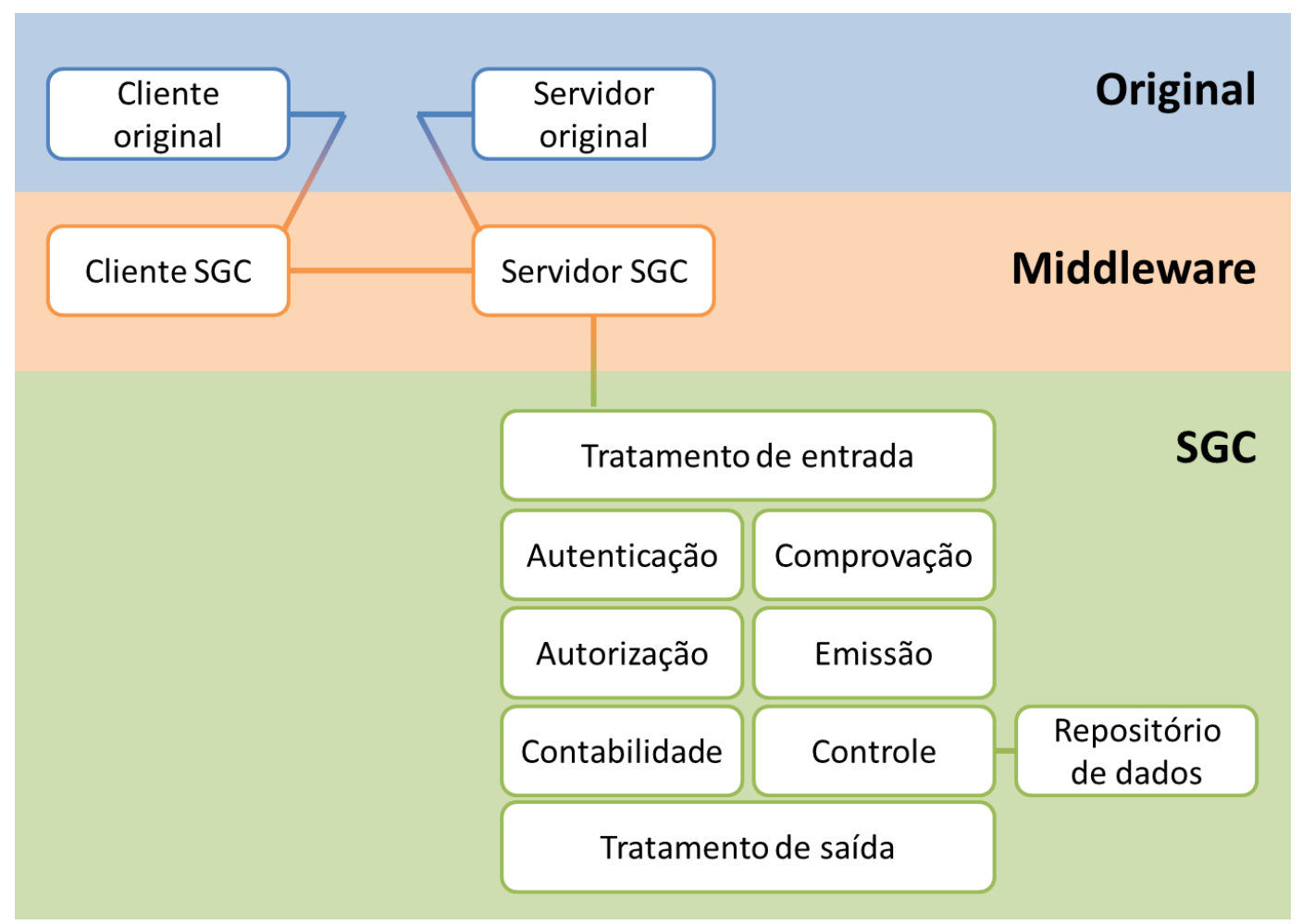

Figura 20: Arquitetura do Sistema de Gerenciamento de Credenciais

As requisições feitas pelo cliente original são interceptadas pelo cliente SGC, que envia a requisição para o servidor SGC. Este, por sua vez, encaminha a requisição para o SGC propriamente dito, onde serão realizadas as operações de autenticação do requisitante e autorização da operação. O resultado da operação é devolvido ao servidor SGC, que encaminha este resultado para o servidor original. Cada operação é registrada (logada) dentro do banco de dados do SGC, permitindo portanto realizar a contabilidade do uso de recursos e serviços com base nas requisições realizadas pelas entidades.

Caso a operação envolva o cadastro de uma nova identidade ou a emissão de uma credencial, os módulos de emissão e comprovação também serão acionados. O SGC dispõe de um repositório de dados, onde são armazenadas as informações sobre as entidades da nuvem e as credenciais emitidas. Conforme estudo realizado sobre o ciclo de vida de credenciais, é importante armazenar estas credenciais mesmo após sua expiração visando manter a integridade do registro das operações do sistema. 


\subsection{Implementação da solução}

Esta seção apresenta detalhes sobre cada um dos módulos especificados na arquitetura do SGC. A implementação pode ser dividida em dois conjuntos de módulos: o middleware e o SGC propriamente dito, denominado SGC central.

\subsubsection{Middleware}

O middleware é composto por dois módulos fundamentais: o cliente SGC e o servidor SGC. Estes elementos têm duas atribuições principais:

- Interceptação: As requisições enviadas do cliente original devem ser interceptadas pelo cliente SGC e posteriormente tratadas pelo SGC central.

- Proteção: O cliente e o servidor SGC devem estabelecer um canal seguro de comunicação para troca de credenciais e outras informações confidenciais, tais como senhas e atributos da entidade. O canal seguro pode ser estabelecido por meio de diversas técnicas disponíveis, como túneis SSH ou uma solução própria de encriptação.

Conforme já mencionado, a proteção dos dados pode ser implementada por meio de técnicas diretas de encriptação, portanto sua implementação é relativamente simples. Por outro lado, a interceptação das requisições exige alto nível de integração entre a aplicação cliente original e o cliente SGC, o que é conflitante com o requisito funcional 3 (evitar modificações nas aplicações originais). Dois modos de integração podem ser implementados:

- Ativo: A interceptação ocorre de maneira ativa, isto é, o cliente original passa a enviar os dados e requisições para o cliente SGC.

- Passivo: A interceptação ocorre de maneira passiva, isto é, o cliente original 
continua enviando dados e requisições para o servidor original, porém este tráfego é desviado para o cliente SGC.

O modo ativo pode ser facilmente implementado, porém exige modificação na aplicação cliente original e potencialmente no servidor original (caso esta mudança implique em alteração em algum protocolo de comunicação). Já o modo passivo exige manipulação de pacotes e fluxo de dados, porém evita ao máximo qualquer tipo de modificação na aplicação original, até mesmo na configuração da mesma.

\subsubsection{SGC}

O SGC pode ser implementado em dois conjuntos de módulos:

- Núcleo (core): Concentra as funcionalidades de autenticação, autorização, contabilidade, geração de credenciais, e controle da operação do SGC como um todo. Em termos da arquitetura proposta, isto representa a união dos módulos centrais da arquitetura.

- Interface: Concentra as funcionalidades de comunicação com a aplicação original e quaisquer outros serviços aos quais o SGC esteja integrado. Considerando a arquitetura proposta, tais funcionalidades são implementadas pelos módulos de tratamento de entrada e saída.

Tanto a autenticação das entidades como a autorização de operações é feita com base em credenciais (lembrando que a identidade é um tipo específico de credencial). Como as entidades administradas pelo SGC são provenientes de uma nuvem ou sistema já existente, informações sobre estas entidades podem ser encontradas nas bases de dados desta nuvem ou sistema. O SGC deve portanto dispor de interfaces para obter estas informações, evitando a duplicação de informações. 
O controle do SGC deve focar nas credenciais emitidas, garantindo a integridade e consistência da base de dados. Credenciais expiradas devem ser invalidadas e arquivadas para futuras consultas. O acesso ao repositório de dados (que pode ser um banco, um arquivo, ou uma região de memória) é intermediado pelo módulo de controle.

\subsection{Trabalhos relacionados}

Esta seção apresenta os trabalhos relacionados à proposta de sistema de gerenciamento de credenciais. Os trabalhos foram organizados em duas subseções:

1. Tecnologias consolidadas, apresentando soluções conhecidas e utilizadas em aplicações reais, específicas ou não para nuvem.

2. Publicações, discorrendo sobre publicações recentes na área de gerenciamento de credenciais, autenticação, e autorização.

Foram utilizadas como ferramentas principais de pesquisa a busca convencional do Google $^{1}$, a busca especializada em publicações científicas ${ }^{2}$, o SciVerse Scopus ${ }^{3}$, e o Portal Periódicos da CAPES ${ }^{4}$. Os resultados das buscas foram analisados por ordem de relevância (para identificar as publicações mais importantes da área) e por data de publicação (para encontrar as mais recentes).

\subsubsection{Tecnologias consolidadas}

Dentre as tecnologias relacionadas estudadas, foram selecionadas as que mais influenciaram nas decisões de idealização da solução proposta. As tecnologias selecionadas são apresentadas nas subseções a seguir.

\footnotetext{
${ }^{1}$ http://google.com/

${ }^{2}$ http://scholar.google.com/

${ }^{3}$ http://www.scopus.com/

${ }^{4} \mathrm{http}: / /$ periodicos.capes.gov.br/
} 


\subsubsection{PKI}

Infraestrutura de Chaves Públicas (Public Key Infrastructure), é um conjunto composto por elementos de hardware, software, políticas, regras, e entidades administradas. Também são definidos métodos para permitir a interação entre estas entidades de maneira segura por meio de certificados, que são criados e administrados pela infraestrutura (ADAMS; LLOYD, 2002). O objetivo principal é permitir o estabelecimento de canais de comunicação seguros em uma rede inerentemente insegura, permitindo a identificação correta de um usuário por meio dos certificados emitidos por uma autoridade confiável. A autoridade certificadora (também denominada certificate authority, ou simplesmente CA) emite e verifica os certificados digitais. A CA possui uma chave privada (que não é disponibilizada para outros usuários ou entidades), que é utilizada para assinar (ou gerar) chaves públicas para outros usuários. Os usuários também possuem uma chave pública e uma privada. Chaves públicas permitem encriptar mensagens de maneira assimétrica, exigindo a chave privada para decodificar o conteúdo. Desta forma, para encriptar uma mensagem para ser enviada para um usuário, a mensagem é encriptada utilizando a chave pública deste usuário. Posteriormente a mensagem é decriptada pelo usuário por meio de sua chave privada.

O PKI foca essencialmente na identificação de usuários e na proteção de mensagens e dados trocados entre estes usuários. O SGC possui um escopo maior, englobando a identificação de entidades em geral e administrando credenciais para controle de acesso aos recursos e serviços da nuvem. Contudo, o SGC pode utilizar técnicas de PKI para estabelecer o canal seguro de comunicação entre as entidades da nuvem, especialmente para a execução de operações administrativas, como cadastro de usuários e criação de grupos de segurança. Outro ponto é o estabelecimento de uma relação de confiança entre a autoridade certificadora e os demais elementos pertencentes ou que utilizam a infraestrutura.

Com relação à organização dos elementos da PKI são identificados cinco elemen- 
tos principais: a autoridade certificadora (CA), a autoridade registradora (RA, responsável pela verificação da identidade dos usuários utilizando informações provenientes da CA), um diretório central para armazenar as chaves geradas, um sistema de administração dos certificados, e um elemento de validação dos certificados. O SGC concentra estas responsabilidades e permite a interação entre SGCs de diferentes nuvens e sistemas, permitindo a integração dos mesmos de maneira transparente.

\subsubsection{Kerberos}

Kerberos ${ }^{5}$ é um protocolo de autenticação que também visa estabelecer comunicações seguras em ambientes inseguros, principalmente para aplicações baseadas no modelo cliente/servidor. Kerberos foi criado pelo MIT como uma solução para problemas de segurança relacionados à utilização de canais inseguros de comunicação e à necessidade de confiar nos usuários e provedores dos serviços. A primeira etapa de utilização da solução é a autenticação do usuário (normalmente por meio do nome do usuário e senha, mas também podendo utilizar uma chave pública). Ao utilizar um serviço o cliente envia uma mensagem às claras contendo sua identificação para o servidor de autenticação (AS). A chave secreta e a senha do usuário não são enviadas. O AS verifica se o cliente está cadastrado na base de dados e pode devolver a seguintes mensagens: 1) Uma chave de sessão encriptada utilizando a chave secreta do usuário, que é gerada pelo AS com base na senha deste usuário; ou 2) um ticket que permite gerar tickets (também denominado Ticket Granting Ticket, TGT), que é protegido pela chave secreta do sistema de emissão de tickets (Ticket Granting Service, TGS). Ao receber uma destas mensagens o cliente decripta o conteúdo e finaliza o estabelecimento da conexão com o serviço, podendo executar operações sem a necessidade de uma nova negociação de chaves (considerando o tempo de expiração da chave obtida).

Uma das principais limitações do Kerberos é a existência de um ponto único co-

\footnotetext{
${ }^{5}$ http://web.mit.edu/kerberos/
} 
mum de falha (single point of failure). O servidor central responsável pela administração de chaves e tickets deve estar sempre presente, de modo que quando este servidor está indisponível nenhum usuário consegue utilizar o sistema. No caso do SGC o serviço central é o SGC servidor. O SGC middleware sempre intercepta as requisições e envia para o SGC servidor, e caso este não esteja funcionando adequadamente a requisição será descartada.

Outro ponto importante com relação ao Kerberos é a necessidade de kerberizar a aplicação, isto é, modificar o código da aplicação para que as chamadas às bibliotecas do Kerberos sejam efetuadas. Esta operação pode ser extremamente complexa ou até mesmo impossível, no caso de aplicações de código fechado. O SGC evita ao máximo modificações na aplicação cliente, transferindo toda a complexidade de implementação para o SGC.

\subsubsection{Publicações}

Dentre os diversos trabalhos estudados foram escolhidos os dois que mais influenciaram na definição e especificação da solução de gerenciamento de credenciais.

(CELESTI et al., 2010b) foca em cenários de nuvem complexos, como nuvens heterogêneas e federadas (ambientes também denominados InterClouds). O modelo distingue dois tipos de nuvem: home cloud (nuvem doméstica) e foreign cloud (nuvem externa). Supõe-se que a nuvem doméstica está saturada em termos de uso de recursos, portanto novas requisições de recursos são encaminhadas para a nuvem externa. Os principais requisitos levantados pela solução incluem a capacidade de estabelecer sessões duradouras (single sign-on), evitando que seja necessário efetuar as etapas de autenticação e autorização diversas vezes, e o estabelecimento de uma terceira parte confiável que ofereça serviços de identificação. Isto permite integrar as duas nuvens, permitindo que usuários de uma nuvem consigam realizar operações na outra, desde que ambas as nuvens confiem nas informações provenientes dessa terceira parte con- 
fiável. Ambos os requisitos são similares com o que é proposto no SGC. A implementação da proposta foi feita utilizando SAML (Security Assertion Markup Language), que permite definir regras de acesso em formato XML.

(LI et al., 2009) ressalta a necessidade de autenticar tanto usuários como serviços da nuvem. A proposta dos autores é baseada no modelo IBHMCC (Identity-Based Hierarchical Model for Cloud Computing) para geração de chaves e assinaturas, e o protocolo desenvolvido é comparado com o SAP (SSL Authentication Protocol). O SGC, por sua vez, possui políticas de acesso baseadas em regras tanto no lado cliente como no servidor, de modo que o usuário pode definir quais operações devem ser protegidas, e o administrador da nuvem pode definir as permissões e obrigações de cada usuário da sua nuvem. O SGC possui suporte tanto a credenciais baseadas em identidade como também em papéis e atributos.

\subsection{Considerações do capítulo}

Este capítulo apresentou a arquitetura do Sistema de Gerenciamento de Credenciais. A solução foi dividida em duas partes principais: um middleware para estabelecer a comunicação segura entre a aplicação cliente e o servidor; e o SGC central que oferece os mecanismos de autenticação e autorização. O middleware pode ser implementado por meio de duas técnicas: ativo, onde há modificação da aplicação cliente para que o tráfego seja enviado para o cliente SGC; e passivo, onde as aplicações originais não são modificadas e o fluxo é desviado do seu caminho original para o cliente SGC.

A arquitetura do SGC compreende elementos para autorizar operações e entidades da nuvem, para contabilizar o uso de recursos da nuvem, para receber requisições de autenticação, autorização, e registro de novas entidades, para enviar requisições para outros serviços, para comprovar a validade dos atributos utilizados durante a emissão de uma credencial, e para emitir de fato a credencial. 


\section{IMPLEMENTAÇÃO}

Este capítulo apresenta a implementação do protótipo. O capítulo está organizado da seguinte forma:

- Seção 6.1 apresenta a Infraestrutura, serviços fundamentais para o funcionamento da nuvem, tal como gerenciamento de máquinas virtuais e usuários.

- Seção 6.2 apresenta o SGC cliente, interface transparente para interceptação e proteção do tráfego entre aplicação cliente e servidor.

- Seção 6.3 apresenta o SGC servidor, componentes executados em paralelo aos serviços de infraestrutura de nuvem.

- Seção 6.4 apresenta as limitações da implementação.

- Seção 6.5 apresenta as considerações do capítulo.

\subsection{Infraestrutura}

Bibliotecas de virtualização como a libvirt ${ }^{1}$ oferecem uma camada de programação em alto nível para administração de máquinas virtuais, permitindo gerenciar o estado das mesmas e controlar o acesso aos seus recursos. Desta forma é possível desenvolver uma camada extra de abstração para integrar as funcionalidades de controle

\footnotetext{
${ }^{1}$ http://libvirt.org/
} 
de máquinas virtuais às funcionalidades do SGC (autenticação de entidades e autorização de operações). Entretanto, diversas ferramentas (muitas gratuitas e de código aberto) já oferecem este tipo de solução, disponibilizando um conjunto de serviços que cuidam de diversos aspectos do gerenciamento (ou orquestação) de nuvens. Ferramentas deste tipo incluem o OpenStack ${ }^{2}$, OpenNebula ${ }^{3}$, e Eucalyptus ${ }^{4}$. Todos são projetos de código aberto visando oferecer ferramentas para orquestração de nuvens.

Para escolher uma das soluções foi realizada uma pesquisa sobre cada um dos projetos visando levantar informações relacionadas à estabilidade, qualidade do código, comunidade (tamanho, atividade), dentre outros fatores. A pesquisa foi realizada principalmente utilizando a ferramenta Ohloh.net ${ }^{5}$, que permite analisar e comparar projetos de código aberto. Já na página inicial são mostrados os dez projetos mais ativos (em termos de número contribuições, isto é, commits de código). Os resultados são apresentados na Figura 21. Dentre os projetos de administração de nuvens o único que aparece na lista é o OpenStack, com uma taxa de atualização similar a de outros projetos de código aberto bastante populares, como o Mozilla Firefox (navegador Web), KDE e GNOME (bibliotecas gráficas e conjuntos de aplicações para ambiente Linux).

Comparando OpenStack, OpenNebula, e Eucalyptus (a comparação pode ser reproduzida por meio do link ${ }^{6}$ ), todos os projetos são classificados como projetos de atividade muito alta (very high). A quantidade de contribuidores considerando todo o tempo de vida dos projetos, no entanto, é expressivamente maior no OpenStack (1387 desenvolvedores) do que no OpenNebula ou Eucalyptus (20 e 74 desenvolvedores, respectivamente). O número de commits do OpenStack e do Eucalyptus é parecido (aproximadamente 76 mil em ambos), enquanto no OpenNebula é menor (aproximadamente 7400).

\footnotetext{
${ }^{2}$ http://www.openstack.org/

${ }^{3}$ http://opennebula.org/

${ }^{4} \mathrm{http}: / /$ www.eucalyptus.com/

${ }^{5}$ http://www.ohloh.net/

${ }^{6}$ http://www.ohloh.net/p/compare?project_0=OpenStack\&project_1=OpenNebula\&project_2=Eucalyptus
} 


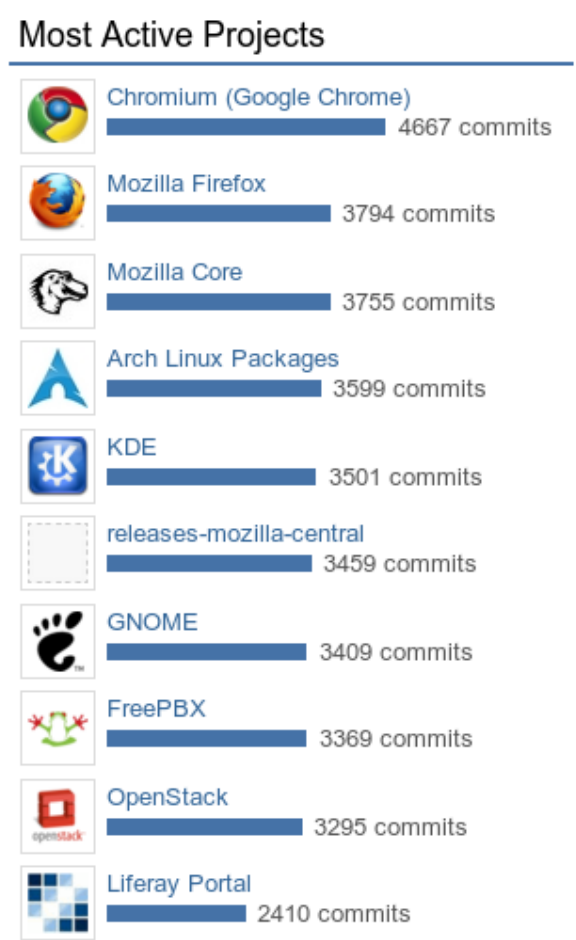

Figura 21: Lista dos projetos mais ativos segundo o site Ohloh.net. Dados obtidos em 19/08/2013.

Analisando os últimos 12 meses, o OpenStack contou com 1083 contribuidores ativos contra 11 do OpenNebula e 55 do Eucalyptus. O número de commits do OpenStack foi de mais de 30 mil, enquanto o do OpenNebula foi de aproximadamente 2 mil e o do Eucalyptus 18 mil. A diferença em termos de atividade de projeto fica ainda mais clara ao analisar os últimos 30 dias, com o OpenStack com mais de 300 contribuidores ativos contra 6 do OpenNebula e 14 do Eucalyptus. Isto mostra que a comunidade desenvolvedora do OpenStack é maior e mais ativa do que as comunidades dos outros projetos.

As Figuras 22 e 23 resumem a comparação entre o OpenStack, OpenNebula, e Eucalyptus. O crescimento do número de contribuidores do projeto OpenStack é nítido, principalmente a partir de 2012 com o lançamento da versão Essex, que trouxe melhorias significativas nos serviços existentes e também adicionou funcionalidades de segurança. Já analisando o número de atualizações no código observa-se equilíbrio entre OpenStack e Eucalyptus, enquanto o OpenNebula permaneceu ao longo do 
Number of contributors who made changes to the project source code each month.

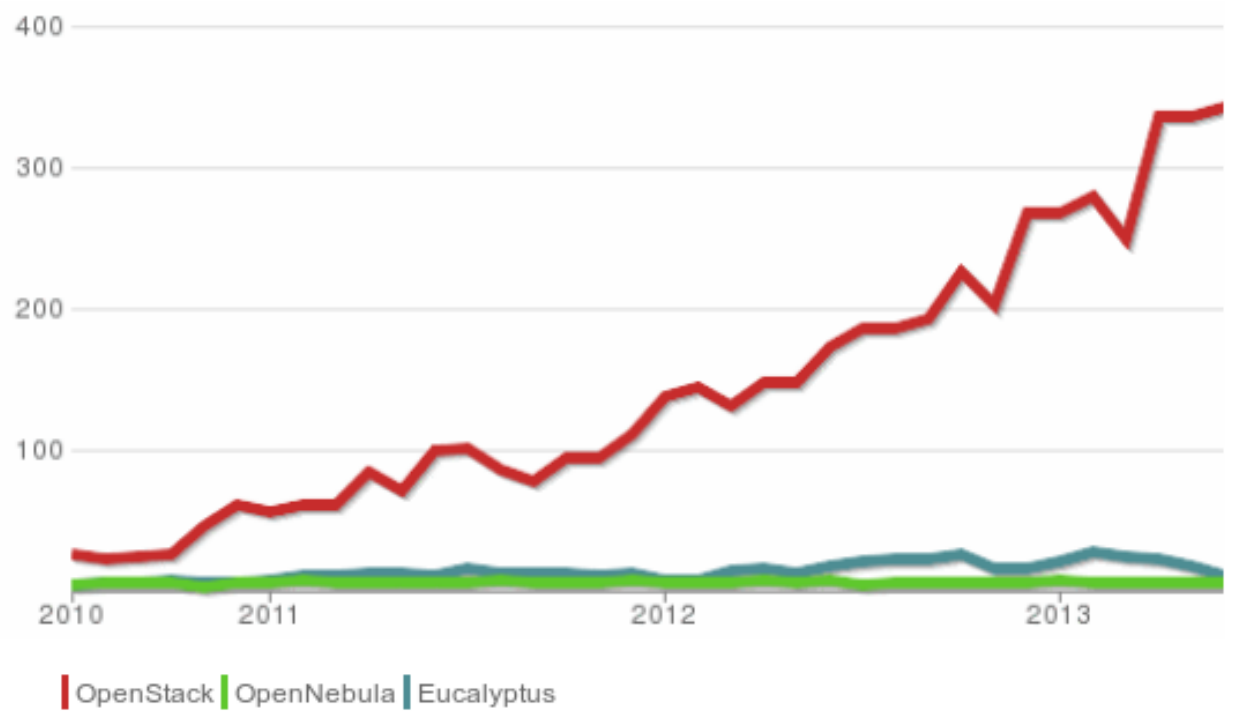

Figura 22: Comparação do número de contribuidores (desenvolvedores) dos projetos OpenStack, OpenNebula, e Eucalyptus. Dados obtidos em 19/08/2013.

Number of commits made to the project source code each month.

$$
5,000
$$

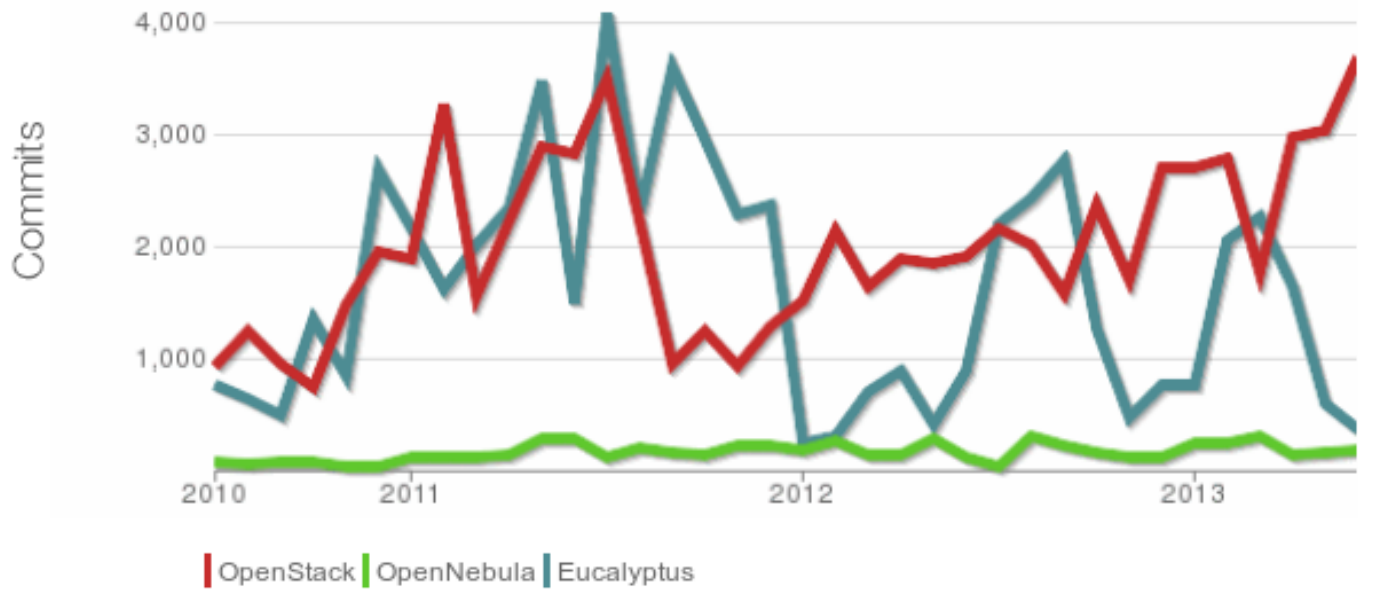

Figura 23: Comparação do número de contribuições (commits) dos projetos OpenStack, OpenNebula, e Eucalyptus. Dados obtidos em 19/08/2013.

tempo com menos atualizações.

A comunidade do OpenStack pode ser comparada com a de projetos muito maiores e mais populares, como o Linux Kernel e o KVM (virtualização). Analisando os últimos 30 dias, o número de contribuidores ativos do OpenStack foi 338, enquanto o do Linux Kernel foi 310 contribuidores, e o do KVM 177 contribuidores. A quantidade 
Number of contributors who made changes to the project source code each month.

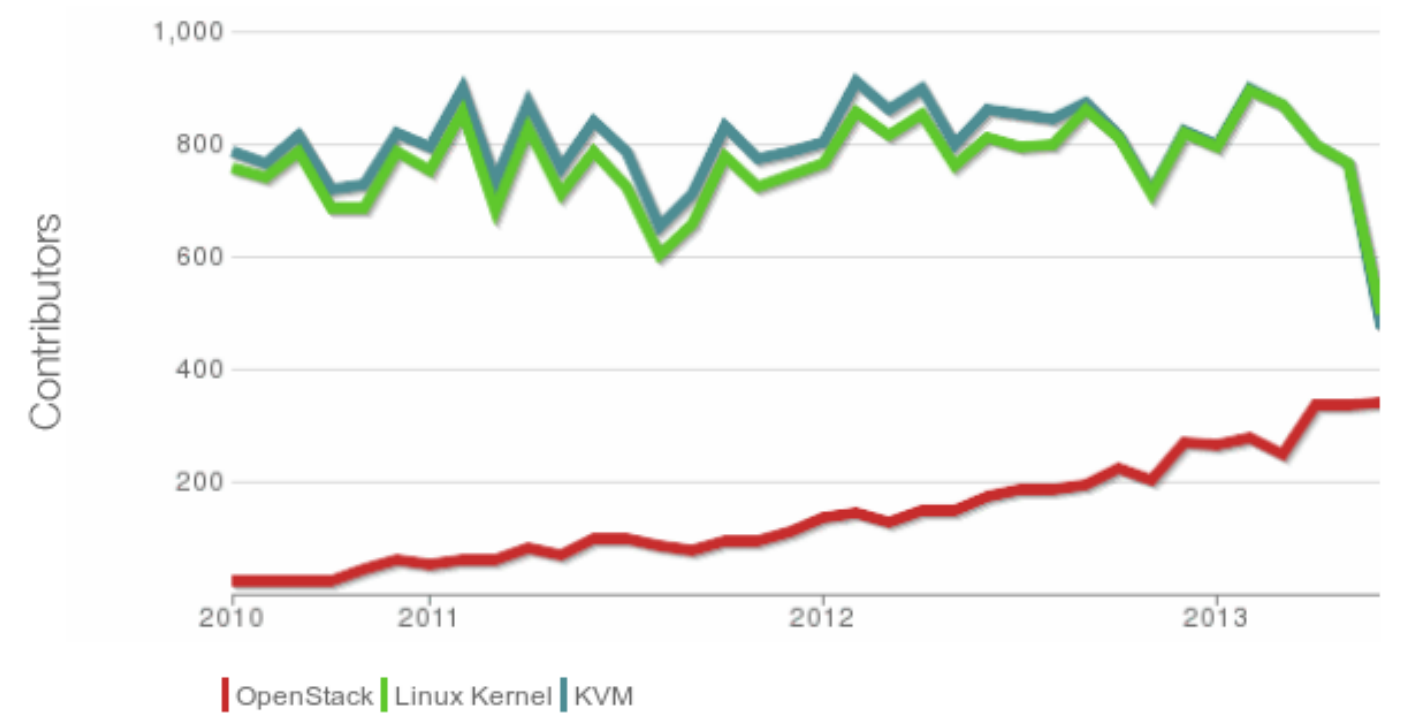

Figura 24: Comparação do número de contribuidores (desenvolvedores) dos projetos OpenStack, Linux Kernel, e KVM. Dados obtidos em 19/08/2013.

Number of commits made to the project source code each month.

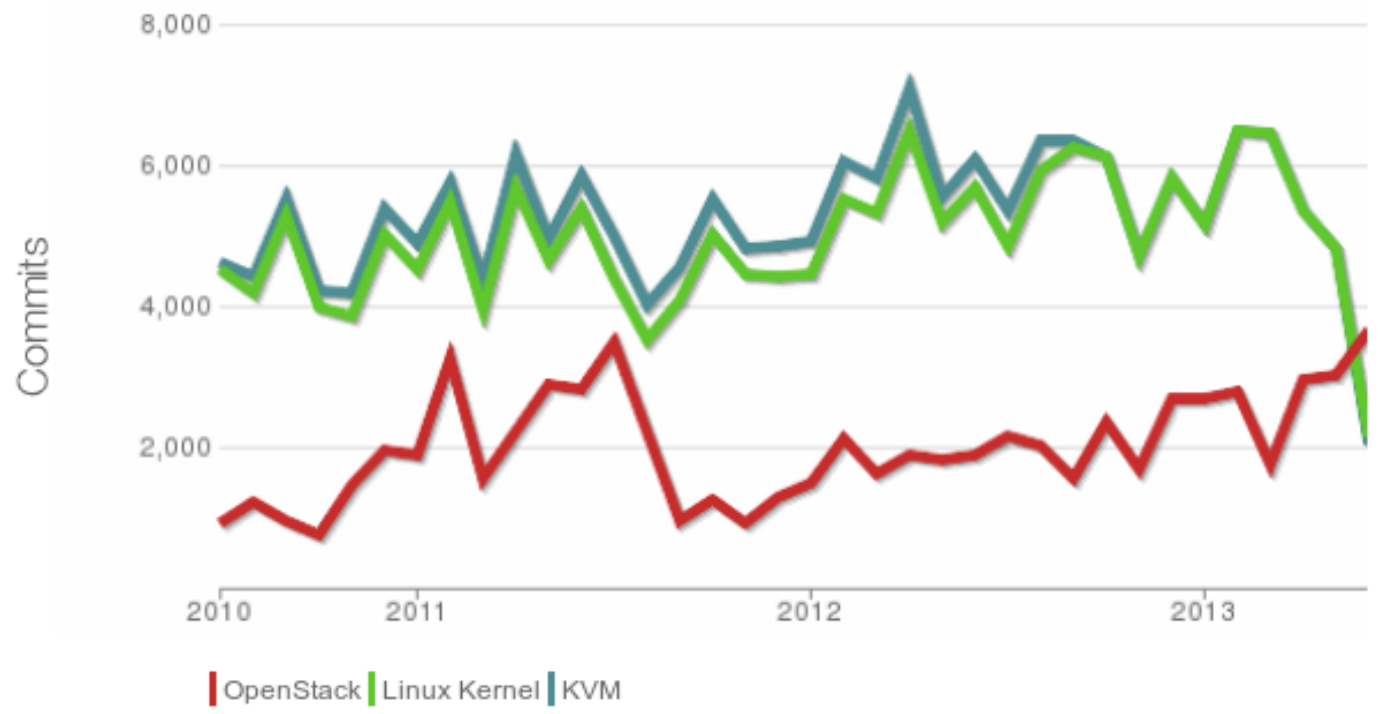

Figura 25: Comparação do número de contribuições (commits) dos projetos OpenStack, Linux Kernel, e KVM. Dados obtidos em 19/08/2013.

de commits do OpenStack foi de 3295 contra 855 do Linux Kernel e 445 do KVM.

As Figuras 24 e 25 resumem a comparação entre o OpenStack, o Linux Kernel e o KVM. Embora o Linux Kernel e o KVM sejam projetos muito maiores, tanto em termos de contribuidores, quantidade de código escrito e testado, número de usuários, 
e atividade dos projetos (comunidade), o OpenStack vem crescendo rapidamente enquanto o Linux Kernel e o KVM permanecem estacionados, com uma notável queda nos últimos meses.

Com base nestes dados conclui-se que o OpenStack constitui uma solução adequada a ser adotada para construir a infraestrutura da nuvem sobre a qual serão instalados os módulos do SGC. Por ter uma taxa de atualização maior e por contar com uma comunidade maior e mais ativa, é possível encontrar mais facilmente suporte técnico e documentação para resolução de quaisquer problemas encontrados durante instalação e uso da solução.

\subsubsection{OpenStack}

O OpenStack é um conjunto de serviços de código aberto para construir nuvens, permitindo configurar e administrar máquinas virtuais, armazenamento, e redes. Sua primeira versão, codinome Austin, foi lançada em outubro de 2010. A versão estável atual (20/08/2013) é a sétima, de codinome Grizzly. A Tabela 8 tem mais informações sobre as versões do OpenStack.

Tabela 8: Versões do OpenStack

\begin{tabular}{l|l}
\hline Codinome & Data da última atualização \\
\hline Austin & Outubro 2010 \\
Bexar & Fevereiro 2011 \\
Cactus & Abril 2011 \\
Diablo & Janeiro 2012 \\
Essex & Outubro 2012 \\
Folsom & Abril 2013 \\
\hline Grizzly & Junho 2013 \\
\hline
\end{tabular}

A versão utilizada na pesquisa foi a Essex, lançada pela primeira vez em Abril de 2012. As modificações presentes nesta versão podem ser encontradas na página de Release Notes ${ }^{7}$.

\footnotetext{
${ }^{7}$ https://wiki.openstack.org/wiki/ReleaseNotes/Essex
} 
Cada nova versão do OpenStack adiciona funcionalidades na forma de serviços. Cada serviço é responsável por uma determinada tarefa que compõe a orquestração da nuvem como um todo. Na versão Essex os principais serviços são:

- Keystone: Serviço de identificação de usuários e autorização de operações. A identidade dos usuários é gerada quando o usuário é cadastrado na nuvem OpenStack, e a autorização é baseada em tokens, chaves com validade limitada.

- Glance: Serviço de administração de imagens. Estas imagens são utilizadas para subir máquinas virtuais de maneira prática e dinâmica, permitindo replicar máquinas e criar pools de recursos.

- Nova: Serviço de administração de máquinas virtuais. Controla o estado das máquinas, oferece meios para acessá-las e para controlar este acesso.

\subsubsection{Keystone: Visão geral}

Todos os serviços do OpenStack precisam de algum meio para realizar a autenticação dos usuários. Com a consolidação do Keystone, serviços como Glance e Nova passaram a utilizá-lo para guardar informações sobre os usuários e identificá-los adequadamente. O Keystone também emite tokens para a utilização do serviço, constituindo portanto um sistema básico de autorização de operações.

O Keystone está organizado em quatro serviços:

- Identity: Cuida da validação de identidades dos usuários, grupos de trabalho (tenants), e papéis (roles) dos usuários. O serviço de identidade oferece uma interface básica (CRUD, create, read/retrieve, update, delete) para administrar estas informações, que podem estar armazenadas em um banco de dados próprio ou por meio de outra solução, como LDAP. 
- Token: Cuida da geração e distribuição de tokens, que permitem a autenticação de requisições provenientes de usuários da nuvem já validados por meio do serviço de identidade.

- Catalog: Cuida do registro de pontos de oferecimento de serviço (endpoints), isto é, locais (endereços URL) em que os serviços do OpenStack (não só o Keystone, mas qualquer serviço válido) podem ser acessados.

- Policy: Cuida da definição de políticas de acesso aos serviços e operações.

O armazenamento das informações sobre os elementos administrados pelo Keystone e a representação dos dados relativos ao serviço podem ser feitos por meio dos seguintes métodos:

- KVS Backend: Interface simples baseada em chaves primárias armazenadas em memória. O método KVS (Key-Value Store) do Keystone utiliza a implementação de dicionários do Python, di ct ${ }^{8}$.

- SQL Backend: Interface baseada em banco de dados SQL (Structured Query Language), utilizando a biblioteca SQLAlchemy do Python. Esta interface permite utilizar diversas soluções de banco de dados, como SQLite ${ }^{9}$ e MySQL ${ }^{10}$. A inicialização do banco é realizada por meio do comando db_sync, que define o esquema de organização do banco (tabelas e campos adequados).

- PAM Backend: Interface PAM (Pluggable Authentication Module) extremamente simples, provendo uma relação um para um entre usuários e grupos de trabalho e definindo um usuário root com poderes administrativos totais sobre a nuvem.

\footnotetext{
${ }^{8}$ http://docs.python.org/2/library/stdtypes.html\#mapping-types-dict

${ }^{9} \mathrm{http}: / /$ www.sqlite.org/

${ }^{10} \mathrm{http}: / /$ www.mysql.com/
} 
- Templated Backend: Interface que utiliza modelos para definição de variáveis e parâmetros de configuração do serviço. Em linhas gerais, esta interface permite definir macros e mecanismos para interpretação de código e configurações, provendo meios para que estas configurações sejam definidas de maneira dinâmica.

- LDAP Backend: Interface LDAP (Lightweight Directory Access Protocol) que organiza usuários e grupos de trabalho em subárvores separadas. Papéis são armazenados dentro dos grupos de trabalho.

Cada serviço dentro do Keystone pode utilizar diferentes métodos de representação de dados. Por exemplo, o serviço de identificação pode armazenar seus dados por meio da interface SQL, enquanto o serviço de políticas trabalha com a interface baseada em modelos (templates).

O modelo de dados do Keystone está baseado em seis tipos de dados:

- User: Usuário, possui informações para identificação e está associado a um ou mais grupos de trabalho.

- Tenant: Grupo de trabalho, define uma unidade de propriedade e pode conter vários usuários.

- Role: Papel, define características inerentes a um usuário dentro de um grupo de trabalho.

- Token: Identifica uma permissão de execução de operação associada a um usuário.

- Extras: Permite definir características extras de um usuário dentro de um grupo de trabalho.

- Rule: Regras, definem requisitos para execução de determinadas operações dentro da nuvem. 
A autorização de execução de uma operação é definida de duas maneiras: por meio de regras ou por meio de soluções RBAC (Role-Based Access Control). O mecanismo RBAC, segundo a documentação ${ }^{11}$, ainda não está implementado. Já o esquema de regras é aplicado por meio de chamadas à função policy_api .enforce ( ) .

\subsubsection{Keystone: Middleware}

O Keystone conta com um middleware responsável pela implementação de uma camada transparente de autenticação, utilizada pelos projetos e serviços do OpenStack. O middleware funciona como um proxy, interceptando requisições HTTP realizadas pelo usuário e adicionando cabeçalhos HTTP adequados. Ao interceptar a requisição o middleware limpa quaisquer informações de autenticação para evitar falsificação de informações. Posteriormente ele coleta o token a partir dos cabeçalhos existentes, valida este token, e prossegue com a execução normal da operação. Possíveis mensagens de erro incluem HTTPUnauthorized, caso a operação não tenha sido autorizada, e HTTPServiceUnavailable, caso o serviço não tenha sido encontrado ou não esteja disponível.

\subsubsection{Keystone: Requisitos e utilização}

Como pré-requisitos, a documentação do Keystone ${ }^{12}$ recomenda a instalação do serviço nos seguintes sistemas operacionais:

- Ubuntu 11.10 ou superior.

- Fedora 15 ou superior.

- Mac OS X Lion (10.7) ou superior.

Com relação às ferramentas para instalação, o Keystone requer:

\footnotetext{
${ }^{11} \mathrm{http}: / /$ docs.openstack.org/developer/keystone/architecture.html

${ }^{12} \mathrm{http} / / /$ docs.openstack.org/developer/keystone/setup.html
} 
- Git ${ }^{13}$ : Sistema de versionamento, permite o download do código fonte dos serviços e aplicações cliente do OpenStack. Necessário para obter ou atualizar a base de código do Keystone.

- Setuptools ${ }^{14}$ : Facilita a obtenção e instalação de pacotes Python. Boa parte do OpenStack (incluindo o Keystone) é codificada em Python.

- Pip ${ }^{15}$ : Ferramenta para instalação e administração de pacotes Python. O pip oferece uma camada de abstração para facilitar a instalação de aplicações escritas em Python, operando de maneira similar à ferramentas como aptitude ${ }^{16} \mathrm{e}$ apt-get ${ }^{17}$.

O código do Keystone pode ser obtido via git por meio do seguinte comando: \$ git clone https://github.com/openstack/keystone.git

O comando irá criar uma pasta key s tone contendo o conteúdo obtido do servidor de código.

Após a instalação é necessário configurar os serviços do OpenStack para utilizar o Keystone como solução de identificação. Durante a configuração inicial do Keystone é necessário definir um admin_token, uma chave administrativa para controle do serviço. Posteriormente são criados os usuários, grupos de trabalho, e papéis destes usuários dentro de cada grupo de trabalho. Finalmente os serviços OpenStack são registrados dentro da base de dados do Keystone, bem como informações para acessar estes serviços (endpoints).

\footnotetext{
${ }^{13} \mathrm{http}: / /$ git-scm.com/

${ }^{14}$ https://pypi.python.org/pypi/setuptools

${ }^{15}$ https://pypi.python.org/pypi/pip

${ }^{16}$ http://packages.debian.org/sid/aptitude

${ }^{17}$ https://wiki.debian.org/Apt
} 


\subsubsection{Keystone: Limitações}

Embora o serviço Keystone do OpenStack ofereça mecanismos de autenticação de usuários, duas limitações fundamentais foram identificadas:

- Texto às claras: Por padrão, todas as interações entre serviços do OpenStack ocorrem por meio da troca de informações em texto às claras, isto é, sem emprego de mecanismos de encriptação.

- Transparência: A integração entre os serviços e o Keystone não é totalmente transparente, exigindo configuração manual de arquivos que definem parâmetros de conexão e autenticação de usuários e operações.

Com relação ao envio de texto às claras, a Figura 26 mostra um exemplo de envio de comando para criação de uma máquina virtual utilizando o serviço Nova do OpenStack. Executando o comando em modo debug é possível observar o que de fato

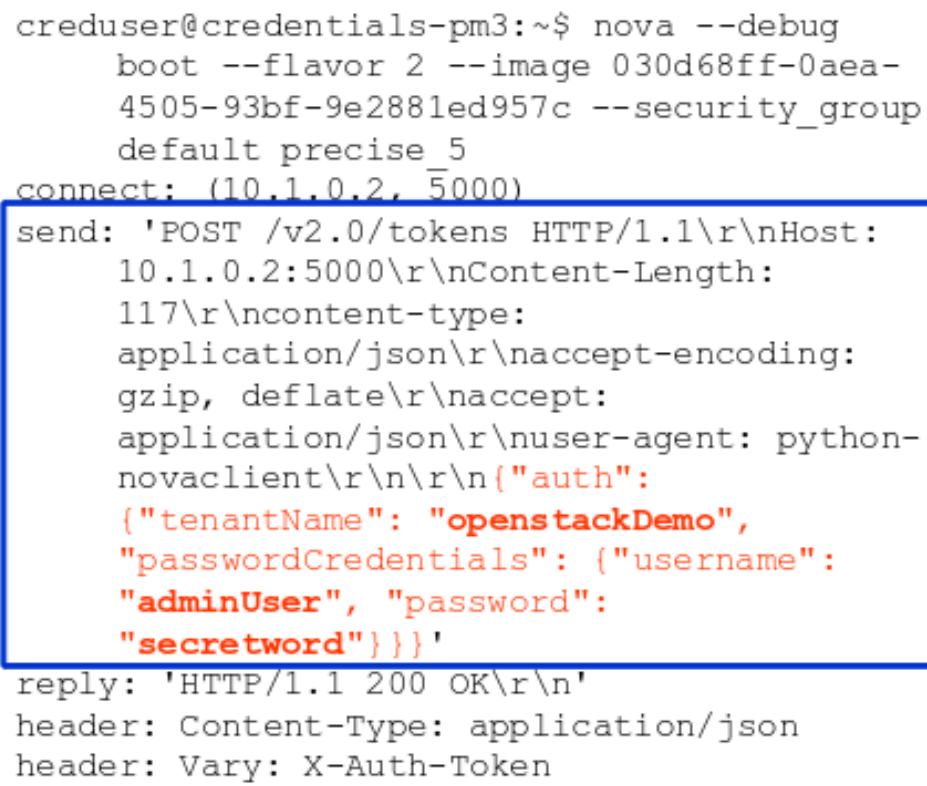

Figura 26: Comando enviado pelo cliente em modo debug, com destaque para as informações confidenciais sendo enviadas por meio de um canal inseguro.

é enviado juntamente à requisição. É possível observar informações sobre o grupo de trabalho ao qual o usuário pertence, bem como o nome deste usuário e a sua senha. 
tema de credenciais.

O SGC cliente é executado na mesma máquina ou dispositivo onde estão as aplicações cliente da nuvem, isto é, aplicações que permitem acessar os serviços de criação de máquinas virtuais ou de administração de usuários. Utilizando o OpenStack Essex como exemplo, temos as seguintes aplicações principais:

- keystone_client: Cliente do Keystone, permite enviar comandos para listar e modificar informações sobre usuários, grupos de trabalho, e papéis destes usuários.

- glance_client: Cliente do Glance, permite subir e modificar imagens de discos virtuais.

- nova_client: Cliente do Nova, permite criar e controlar as máquinas virtuais que compõem a nuvem.

Uma possível solução para evitar tráfego desprotegido entre estas aplicações cliente e os serviços correspondentes é a utilização de tunelamento. Entretanto, estabelecer um túnel permanente entre cliente e servidor faz com que todo o tráfego seja encriptado, o que nem sempre é desejável. A encriptação dos dados é importante no caso de informações confidenciais sobre o usuário, como senha e credenciais. Entretanto, ao subir uma imagem de disco (que pode ser relativamente grande, na ordem de dezenas ou centenas de gigabytes), é melhor proteger apenas os dados do usuário que está executando a operação, e não a operação como um todo (incluindo a imagem de disco adicionada). Logo, a proteção deve ser seletiva, variando de acordo com o tipo de operação realizada.

Para manter a transparência ao usuário e implementar o mecanismo de proteção seletiva, o protótipo desenvolvido implementa um desvio de execução das requisições provenientes dos serviços do OpenStack. O SGC cliente possui uma aplicação prin- 
cipal codificada em Python, cms_client, que implementa a lógica de encriptação seletiva baseada em políticas. As políticas são definidas em um arquivo policies, que possui o seguinte formato:

keystone user-create

keystone user-list

glance index

Cada linha representa uma regra indicando os comandos que devem ser protegidos, isto é, completamente encriptados. Neste exemplo, devem ser completamente protegidas as operações de criação e listagem de usuários via Keystone, e a listagem de imagens de disco via Glance. Outras operações, como a adição de imagens de disco via Glance (comando glance add) ou a criação de máquinas virtuais via Nova (comando nova boot) serão parcialmente protegidas (apenas dados do requisitante serão protegidos - a imagem adicionada ou a máquina virtual criada não serão encriptadas ao longo do canal de comunicação).

O desvio de execução em si é implementado por meio de links simbólicos (symbolic links). Estes links funcionam como atalhos convencionais, que ao serem acessados redirecionam comandos para a aplicação para a qual o link aponta. No protótipo foram criados três links simbólicos, um para cada aplicação cliente (keystone_client, glance_client, nova_client). Os três links apontam para o SGC cliente, cms_client. Assim, quando o usuário executa um comando em uma destas aplicações clientes, o executável que será de fato chamado é o cms_client. O fluxo de execução é desviado para o cms_client, que analisa a requisição, verifica o arquivo de políticas, determina se a operação deve ser completamente ou apenas parcialmente protegida, e prossegue da maneira adequada. As aplicações cliente originais são escondidas em um diretório dentro do SGC, e são acionadas após a conclusão das etapas de autenticação e autorização.

O preparo do ambiente para utilização do SGC cliente é feito por meio de um simples instalador que prepara os links simbólicos, move as aplicações cliente originais 
para uma subpasta do SGC, e instala o executável do SGC cliente. Com relação ao arquivo de políticas, caso esteja vazio todas as operações serão executadas por meio de meios convencionais, sem o emprego do canal seguro. Deste modo o sistema irá se comportar como o sistema original, neste caso como uma nuvem OpenStack padrão.

\subsection{SGC servidor}

No lado servidor o SGC recebe requisições do SGC cliente para autorização de operações. A autenticação de usuários é feita utilizando as informações provenientes da base de dados do Keystone, e portanto foi desenvolvida uma integração entre o Keystone e o SGC.

O sistema de tokens do Keystone foi mantido, porém os tokens são criados e trocados sempre por meio do canal seguro. Nas operações parcialmente protegidas, o token é criado manualmente por meio do comando keystone token-get. O comando exige a passagem de usuário e senha, portanto é vital enviar a requisição por meio do canal seguro. Após criado o token é enviado juntamente com a requisição, que neste modo é enviada às claras. Para evitar reuso do token ele é manualmente removido da base de dados do Keystone por meio de uma aplicação auxiliar cms_delete_token.

Já em operações totalmente protegidas, toda a interação é realizada por meio do canal seguro, portanto não é necessário implementar estes mecanismos manuais. Ao ser executada por meio do canal seguro, a requisição é enviada de maneira integral para o servidor e só é interpretada na máquina onde os serviços estão em execução. É necessário portanto ter uma cópia das aplicações cliente no lado servidor, pois são estas aplicações cliente que de fato executam os comandos. Como os comandos são enviados para a própria máquina os dados não trafegam por canais inseguros, permanecendo na interface de loopback da máquina de serviços. Deste modo, para roubar os dados 
do usuário o atacante precisaria comprometer a máquina do serviço, o que significa comprometer a infraestrutura da nuvem (tarefa mais complexa do que atacar apenas um cliente).

O SGC servidor recebe dois tipos de requisições: requisições de autorização e requisições de operação. As requisições de autorização são sempre provenientes de um cliente SGC, são recebidas por meio do canal seguro, e contém dados sobre o requisitante, sobre o serviço, e sobre a operação. Com base nestes dados o SGC servidor analisa um arquivo de políticas de controle de acesso, policies.py. O arquivo é um código Python contendo dicionários relacionando nomes de usuário, serviços, e operações. São definidos três tipos de regras:

- Regras específicas: Regras específicas para uma determinada operação de um determinado serviço.

- Regras gerais: Regras gerais para um serviço, utilizadas quando uma regra específica de operação não é encontrada.

- Regra padrão: Regra padrão, utilizada quando nenhuma outra regra é encontrada.

Um exemplo de arquivo de políticas é:

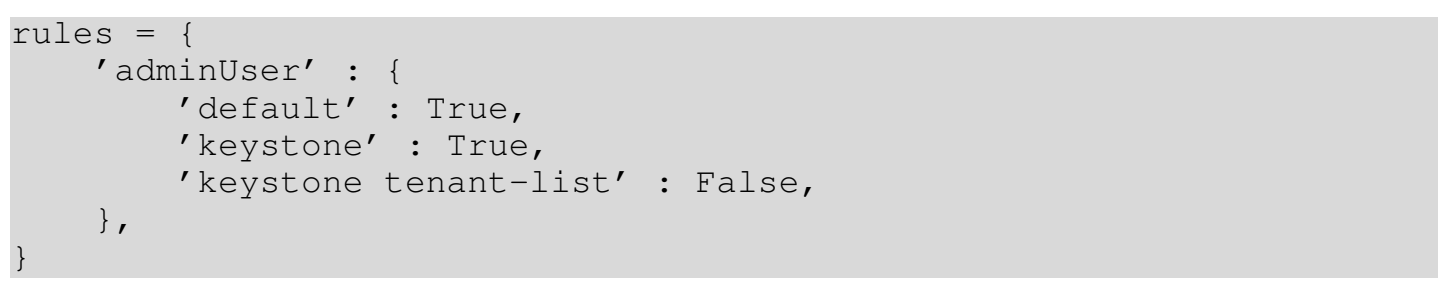

O valor final das regras é True (autorizado) ou False (não autorizado). Neste exemplo caso o usuário adminUser tente executar o comando keystone tenant-list o pedido será negado. Já qualquer outra requisição para o serviço Keystone será validada. Se o usuário tentar criar uma máquina virtual por meio do comando nova boot o sistema de autorização irá utilizar a regra default, que no caso é de confir- 
mação de autorização. Vale observar que estas regras são definidas na máquina do serviço, portanto o arquivo não pode ser acessado ou modificado pelos usuários da nuvem. Somente o administrador da nuvem pode alterar estas configurações.

Com a confirmação de autorização o SGC servidor gera uma credencial de uso único (UC). A UC é armazenada na base de dados do SGC, implementada de maneira simples na forma de um arquivo onde cada linha é uma UC. Um exemplo de arquivo contendo UCs é:

\begin{tabular}{|c|c|c|c|c|c|c|}
\hline $5-27$ & & & & tenant-Ins & & 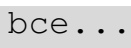 \\
\hline $05-27$ & $14: 39: 39$ & dminUser & keystone & tenant-list & True & 970. \\
\hline $013-05-27$ & $14: 41: 42$ & adminUser & keystone & tenant-list & False & $\mathrm{b} 48$ \\
\hline $013-05-27$ & $14: 43: 04$ & leUser & keystone & tenant-list & None & $d f 9$. \\
\hline $5-27$ & $14: 45: 06$ & adminUser & keystone & tenant-list & Done & $4 \mp 0$ \\
\hline $013-05-27$ & $14: 45: 49$ & adminUser & keystone & tenant-list & True & ebc \\
\hline $5-27$ & $14: 46: 20$ & adminUser & keystone & tenant-list & False & $7 e e$ \\
\hline $5-27$ & $14: 46$ & adminUser & keystone & tenant-list & True & 289. \\
\hline$-05-27$ & $14: 47: 47$ & adminUser & keystone & user-list & Done & $6 \mathrm{cb}$ \\
\hline $3-05-27$ & $15: 55$ & adminUser & keystone & user-list & True & 167 \\
\hline $3-05-27$ & $15: 56: 00$ & adminUser & keystone & tenant-list & False & $84 \mathrm{c}$ \\
\hline $3-05-27$ & $16: 02: 51$ & adminUser & keystone & user-list & Done & 335 . \\
\hline $3-05-27$ & $16: 08$ & adminUser & keystone & tenant-list & False & f93. \\
\hline$-05-27$ & $16: 16: 0$ & adminUser & glance & index & False & $\mathrm{cd} 2$ \\
\hline $3-05-27$ & $16: 16: 14$ & adminUser & glance & index & True & C 96. \\
\hline
\end{tabular}

A UC inclui informações sobre a data e a hora que requisição foi emitida (na forma de um timestamp), o usuário que realizou a requisição, o serviço utilizado, a operação desejada, o status da operação, e uma chave que representa a UC. O status da operação pode ser: 1) True, caso tenha sido autorizada; 2) False, caso não tenha sido autorizada; 3) None, caso tenha ocorrido algum erro (usuário não cadastrado no SGC, por exemplo); e 4) Done, caso a operação já tenha sido realizada. Após executar a operação a UC é consumida, não podendo ser reutilizada.

Após a etapa de autorização o SGC servidor recebe requisições de operação. A requisição de operação é uma requisição HTTP proveniente dos clientes originais (escondidos) relacionados ao serviço desejado. Após recebida a requisição é analisada visando identificar o serviço e operação desejados. Com estas informações é possível ler o arquivo de UCs para verificar se a operação foi autorizada ou não, e também se já foi consumida. 


\subsection{Limitações da implementação}

A principal limitação da implementação é o modo como as credenciais são definidas, baseadas sempre nas informações dos usuários. Em outras palavras, o protótipo implementa um esquema de credenciais baseadas em identidades (identity-based credentials), adequada para nuvens públicas utilizadas por usuários individuais porém não eficiente para oferecer mecanismos de autenticação e autorização para grupos de trabalho. Neste caso seria melhor implementar um sistema baseado em papéis (role-based credentials) ou atributos (attribute-based credentials), visto que papéis e atributos podem ser compartilhados por vários usuários.

Outra limitação é a dependência de tecnologias específicas para implementar alguns módulos da solução. O canal seguro, por exemplo, foi implementado utilizando túneis $\mathrm{SSH}^{18}$. O acordo de chaves é configurado manualmente no cliente e no servidor, de modo que a comunicação entre SGC cliente e servidor é feita de maneira transparente. Uma implementação mais completa do SGC pode incluir outros mecanismos para troca de chaves e para proteção dos dados trafegados.

Com relação à implementação o SGC servidor é executado em uma thread única, sem paralelização. Deste modo, em caso de requisições simultâneas existe a formação de uma fila de espera até que todas as requisições sejam tratadas. Uma melhoria simples neste sentido é a utilização de threads, o que pode ser implementado facilmente por meio do módulo multiprocessing do Python.

\subsection{Considerações do capítulo}

Este capítulo apresentou detalhes sobre a implementação do Sistema de Gerenciamento de Credenciais. Três itens principais foram ressaltados: 1) a infraestrutura da nuvem, baseada em OpenStack; 2) o SGC cliente, responsável pela criação do canal

\footnotetext{
${ }^{18}$ http://www.openssh.org/
} 
seguro de comunicação mantendo a transparência da solução; e 3) o SGC servidor, responsável por todo o mecanismo de autenticação e autorização provido pelo SGC. O SGC foi implementado essencialmente em Python, o que permite desenvolver módulos flexíveis e facilmente configuráveis. Os arquivos de configuração também são lidos pelo interpretador do Python, facilitando a leitura e atualização das configurações. Por fim, são identificadas como limitações do protótipo o modo como as credenciais são definidas (baseadas na identificação do usuário) e a dependência de outras tecnologias, principalmente ao implementar o canal seguro de comunicação. 


\section{AMBIENTE DE EXPERIMENTAÇÃO}

Este capítulo apresenta o ambiente de experimentação utilizado para avaliar a solução proposta com base nos requisitos definidos e nos objetivos da pesquisa. O capítulo está organizado da seguinte forma:

\subsection{Configuração do ambiente de teste}

Para a realização dos testes foram utilizadas apenas duas máquinas físicas: uma contendo as aplicações cliente e outra com os serviços e o SGC servidor. A Figura 28 resume as características das máquinas, a rede do ambiente de teste, e os principais elementos da solução, incluindo o SGC e os elementos originais do OpenStack. Em ambas as máquinas foi instalado o sistema operacional Ubuntu 12.04 (codinome

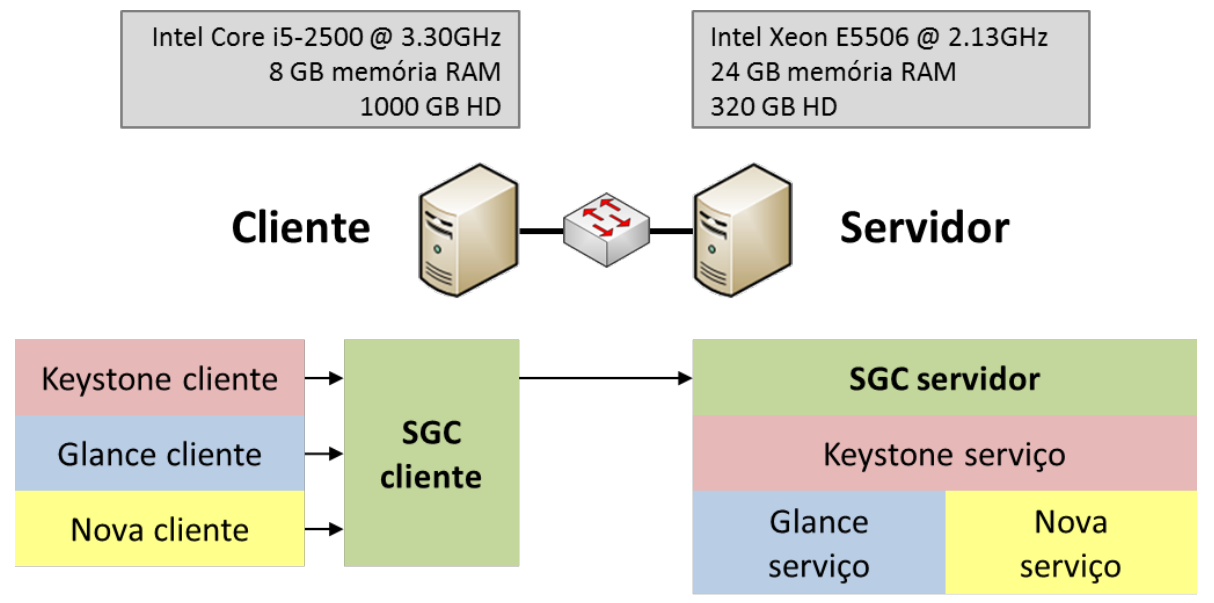

Figura 28: Especificações das máquinas, rede, e topologia

Precise Pangolin), utilizando kernel versão 3.2.0-51-generic na máquina cli- 
ente e 3.5.0-25-generic na máquina servidora. A solução de SSH instalada é a OpenSSH versão 5.9p1, código Debian-5ubuntul . 1 com OpenSSL 1 . 0 . 1.

\section{2 $\quad$ Testes}

Os seguintes testes foram realizados:

- Teste 1, com SGC, proteção parcial: Verifica o funcionamento da solução para o cenário em que as informações do requisitante devem ser protegidas, mas o conteúdo da operação em si deve ser mantido às claras.

- Teste 2, com SGC, proteção total: Verifica o funcionamento da solução para o cenário em que tanto as informações do requisitante quanto o conteúdo da operação devem ser protegidos.

- Teste 3, com SGC, não autorizado: Verifica o funcionamento da solução para o cenário em que o usuário não está autorizado a realizar a operação.

- Teste 4, sem SGC: Verifica o funcionamento da solução para o cenário em que o usuário tenta utilizar um serviço sem o intermédio do SGC, isto é, executando a aplicação cliente original.

- Teste 5, sem SGC, reusando token: Verifica o funcionamento da solução para o cenário em que um usuário tenta reutilizar um token gerado previamente.

Nos diagramas de sequência apresentados são utilizados os seguintes elementos. Note que os termos SGC (Sistema de Gerenciamento de Credenciais) e CMS (Credential Management System) são utilizados de maneira intercambiada.

- Keystone cliente (dummy): Link simbólico que redireciona o tráfego do Keystone cliente para o SGC cliente. 
- CMS cliente: SGC cliente, responsável pela interceptação da requisição no lado cliente e também pela execução da etapa inicial de autorização.

- políticas cliente: Arquivo contendo políticas que definem se as operações devem ser parcialmente ou integralmente protegidas.

- Keystone cliente (escondido): Executável cliente original, utilizado para enviar as requisições de serviço.

- CMS servidor (middle): SGC middleware, captura requisições assim que chegam nos serviços.

- CMS servidor (Keystone): Integração entre SGC e OpenStack Keystone.

- CMS servidor (engine): Módulos principais do SGC servidor.

- usuários: Lista de usuários cadastrados no SGC, com base nas informações obtidas do Keystone.

- políticas servidor: Arquivo de políticas de autorização (emissão de credenciais) com base nas identidades dos usuários.

- log: Arquivo que mantém a lista das credenciais emitidas, bem como os status das mesmas.

- Keystone cliente (cópia): Cópia da aplicação cliente, utilizada quando a operação é delegada para a máquina de serviço através do canal seguro.

- Keystone servidor: O serviço da nuvem em si.

\subsubsection{Teste 1: Com SGC, proteção parcial}

Neste cenário a operação desejada é tal que as informações sobre o usuário que está realizando a requisição devem ser protegidas (nome de usuário, senhas, tokens), mas a operação em si (uma nova imagem, uma nova máquina virtual) deve ser realizada às 
claras. Este cenário aplica-se nos casos em que proteger o conteúdo da operação não é necessário ou até mesmo inconveniente, caso por exemplo de uma imagem de disco que pode ocupar vários gigabytes de espaço em disco - encriptar este disco pode ser desnecessário e é em todo caso extremamente custoso.

\subsubsection{Sequência}

O comportamento do sistema neste cenário é ilustrado pelo diagrama de sequência apresentado nas Figuras 29 e 30.

O primeiro passo é a verificação da política no lado cliente, determinando se a operação deve ser totalmente protegida ou apenas parcialmente protegida. Neste caso a política encontrada determina que a operação deve ser parcialmente protegida, portanto os dados do usuário serão protegidos enquanto o conteúdo da operação será enviado às claras.

Após a verificação da política a solução inicia a etapa de autorização da operação, enviando as informações sobre o usuário (identificação, serviço, e operação). A requisição de autorização é recebida pelo SGC servidor que autoriza a operação com base nas informações do arquivo de políticas do SGC servidor. Note que a etapa de autorização é feita no canal convencional, visto que nenhum dado confidencial (senhas, tokens) é trafegado por meio da rede.

Com a operação autorizada o SGC cliente gera o token manualmente, enviando uma requisição de criação de token para o servidor por meio do canal seguro (visto que é necessário enviar a senha do usuário para obter o token). A requisição é enviada através do canal seguro para a cópia Keystone cliente presente no lado servidor, de modo que a criação deste token seja feita localmente na máquina do serviço. No entanto, requisições para o Keystone serviço são interceptadas pelo SGC middleware, que realiza a autorização da operação. O pacote de rede contendo a requisição é analisado em 


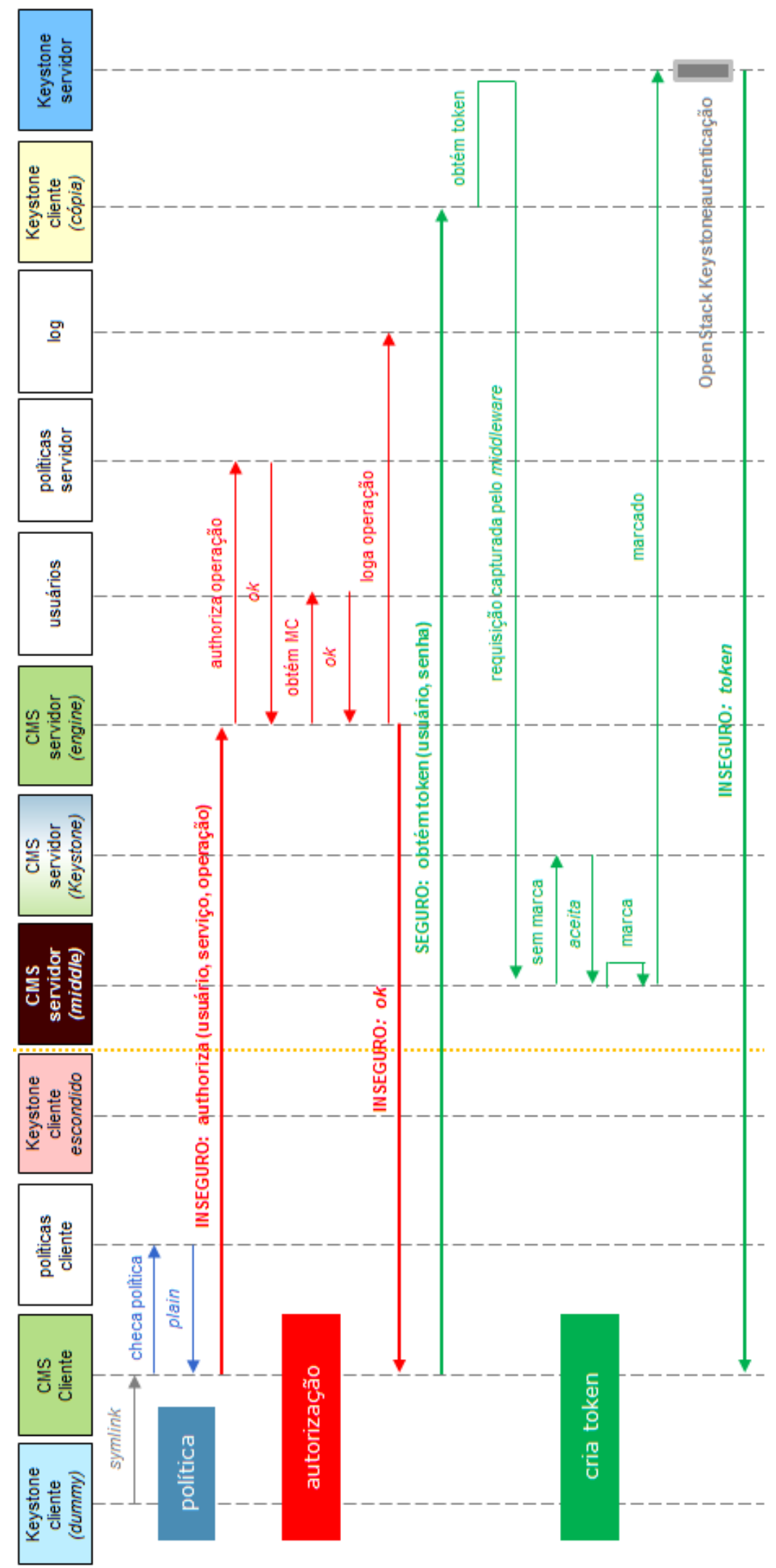

Figura 29: Diagrama de sequência para Teste 1 (a) 


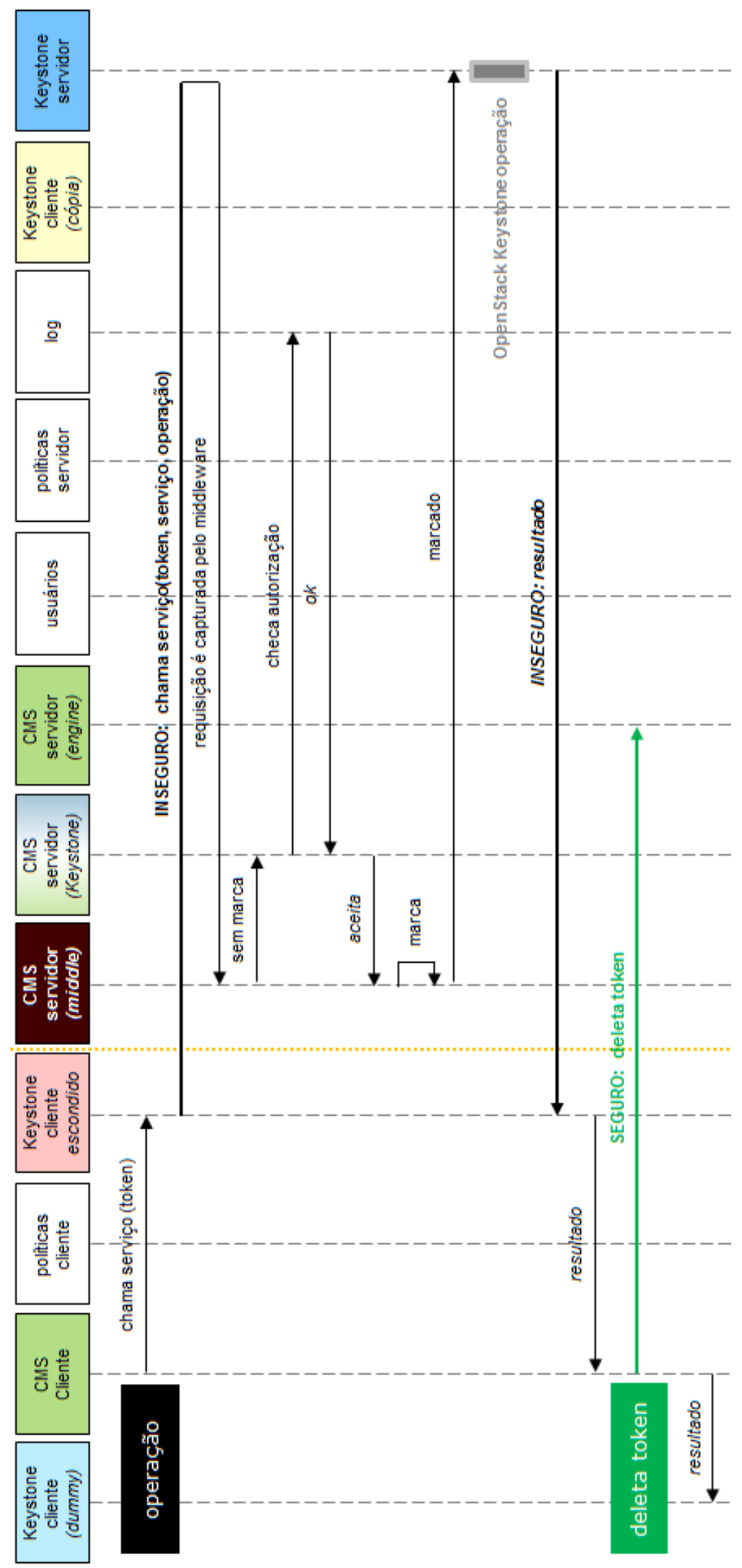

Figura 30: Diagrama de sequência para Teste 1 (b) (continuação) 
busca de uma marcação (implementada por meio de comandos do tipo iptables ${ }^{1}$ ). O pacote acabou de chegar no servidor, portanto ainda está sem marcação. Pacotes sem marcação são redirecionados para o SGC servidor, que verifica a validade da operação. Com a operação validada o pacote é marcado e retorna à interface de rede, e desta vez é aceito pelo SGC middleware. Pacotes marcados são enviados para o Keystone serviço, que dará prosseguimento à operação de autenticação e geração de token. Por fim o token é retornado para o SGC cliente por meio do canal seguro.

Continuando a operação, com posse do token é possível enviar a requisição de operação para o serviço adequado. O serviço é chamado e o token previamente gerado é enviado, porém desta vez às claras. Novamente é realizada a etapa de autorização da operação, iniciando no middleware, passando pelo SGC servidor, e voltando para o serviço original (que pode ser Glance, Nova, ou o próprio Keystone). Finalmente o resultado da operação é retornado para o SGC cliente e posteriormente para o usuário requisitante. Assim, o último passo da operação é remover o token que foi manualmente gerado, pois uma vez enviado por meio do canal convencional o token pode ser capturado e reutilizado. A remoção manual deste token impede que um atacante aproveite as credenciais do usuário legítimo para realizar outras operações dentro da nuvem.

\subsubsection{Teste}

A requisição realizada pelo cliente e a resposta recebida são observadas na Figura 31 No topo é destacada a linha de comando utilizada para executar a operação, que é a mesma linha de comando que seria utilizada caso o SGC não estivesse presente. Isto é essencial para maximizar a transparência da solução, de modo que quaisquer scripts desenvolvidos pelo usuário (ou outros programas que utilizem estes comandos) não precisam ser alterados. Logo após a linha de comando são destacadas as saí-

\footnotetext{
${ }^{1}$ http://linux.die.net/man/8/iptables
} 


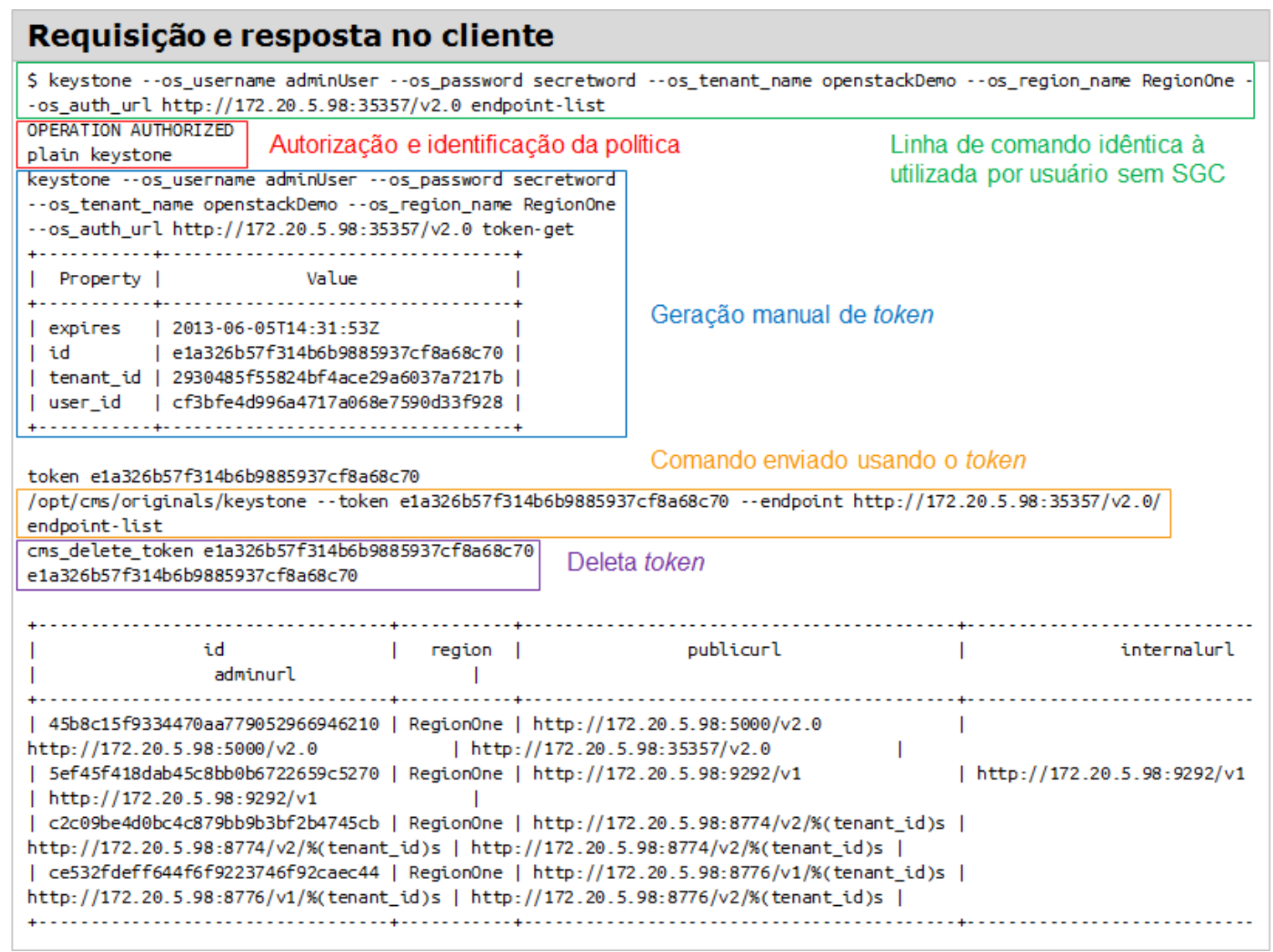

Figura 31: Requisição e resposta no cliente - Teste 1

das relativas ao resultado da operação de autorização (OPERATION AUTHORIZED) e identificação de política (plain keystone), indicando que o serviço desejado é o Keystone e o modo de operação é plain, isto é, proteção parcial com envio de dados às claras. Depois a saída mostra a geração do token (via token-get), o envio do comando desejado utilizando este token, a remoção manual do token (por meio do comando auxiliar cms_delete_token), e por fim o resultado da operação - a lista de pontos de acesso de serviço da nuvem.

A Figura 32 apresenta detalhes sobre as requisições recebidas no SGC servidor. A primeira requisição é a requisição de autorização proveniente do SGC cliente, e contém dados sobre o usuário, serviço, e operação desejados. Com estas informações o SGC servidor procura no arquivo de políticas pela regra adequada, primeiro no nível mais específico (regras de operação), e depois nos outros níveis (regras de serviço, regra 


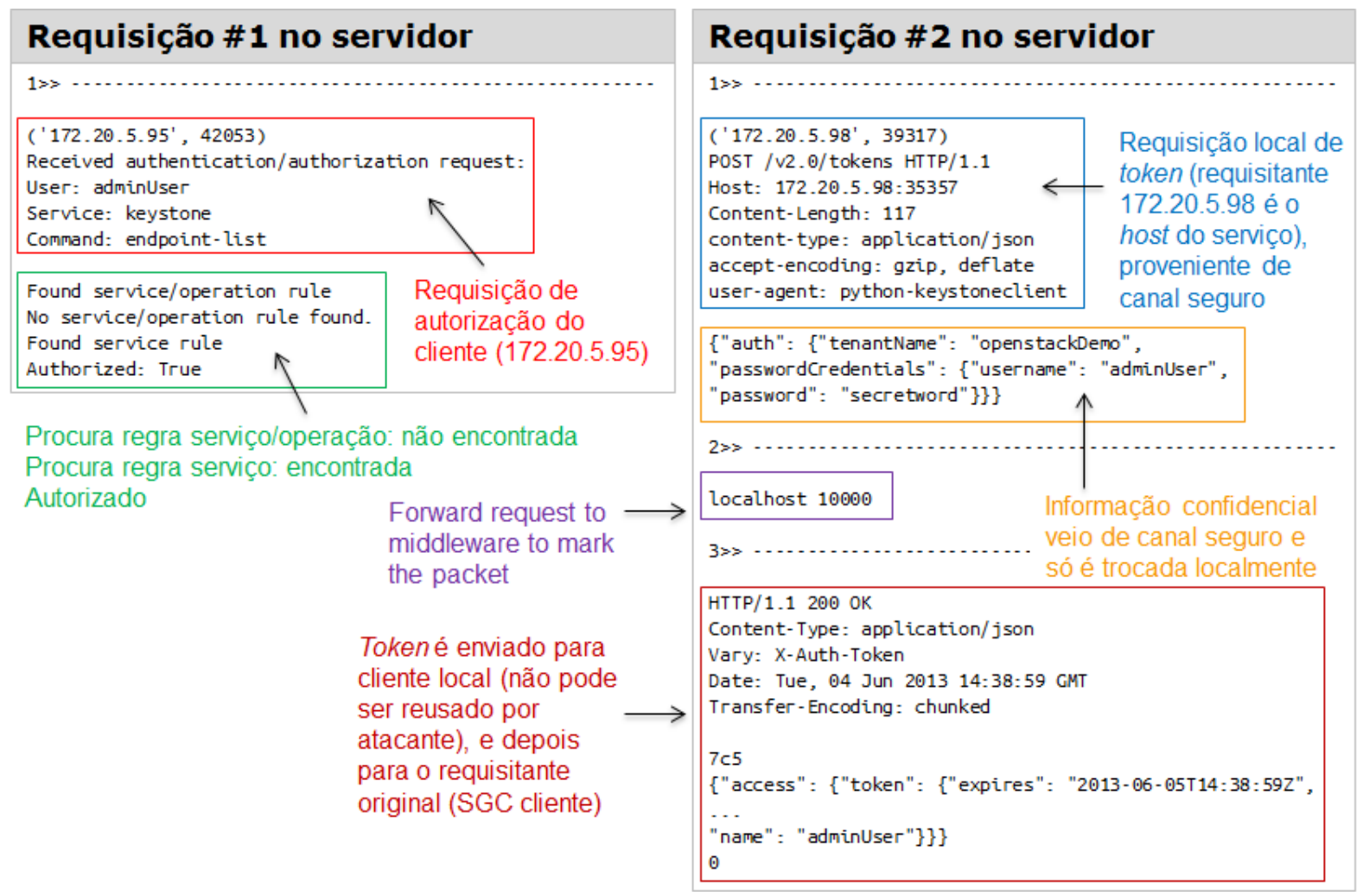

Figura 32: Requisições 1 e 2 recebidas no servidor - Teste 1

padrão). Neste caso é encontrada uma regra de serviço, e a operação é autorizada.

Posteriormente, a segunda requisição é relativa à criação manual do token. A requisição vem da aplicação Keystone cliente presente na máquina servidora, portanto a requisição é local (as informações confidenciais estão protegidas). O sistema de marcação de pacotes funciona com duas portas: porta 9999, onde o SGC servidor é executado; e porta 10000, para onde pacotes são enviados para serem marcados. Por fim o token é gerado e retornado para o SGC cliente por meio do canal seguro.

A Figura 33 apresenta detalhes sobre a última requisição recebida pelo SGC servidor, neste caso já relativa à operação desejada pelo usuário. A primeira parte da requisição contém informações sobre a operação a ser realizada (método GET visando listar os pontos de acesso da nuvem) e contém o token que foi gerado manualmente. Note que esta requisição foi enviada por meios convencionais, sem utilização do canal seguro, logo o token pode ser lido e reusado por um atacante. Em todo caso, o SGC 


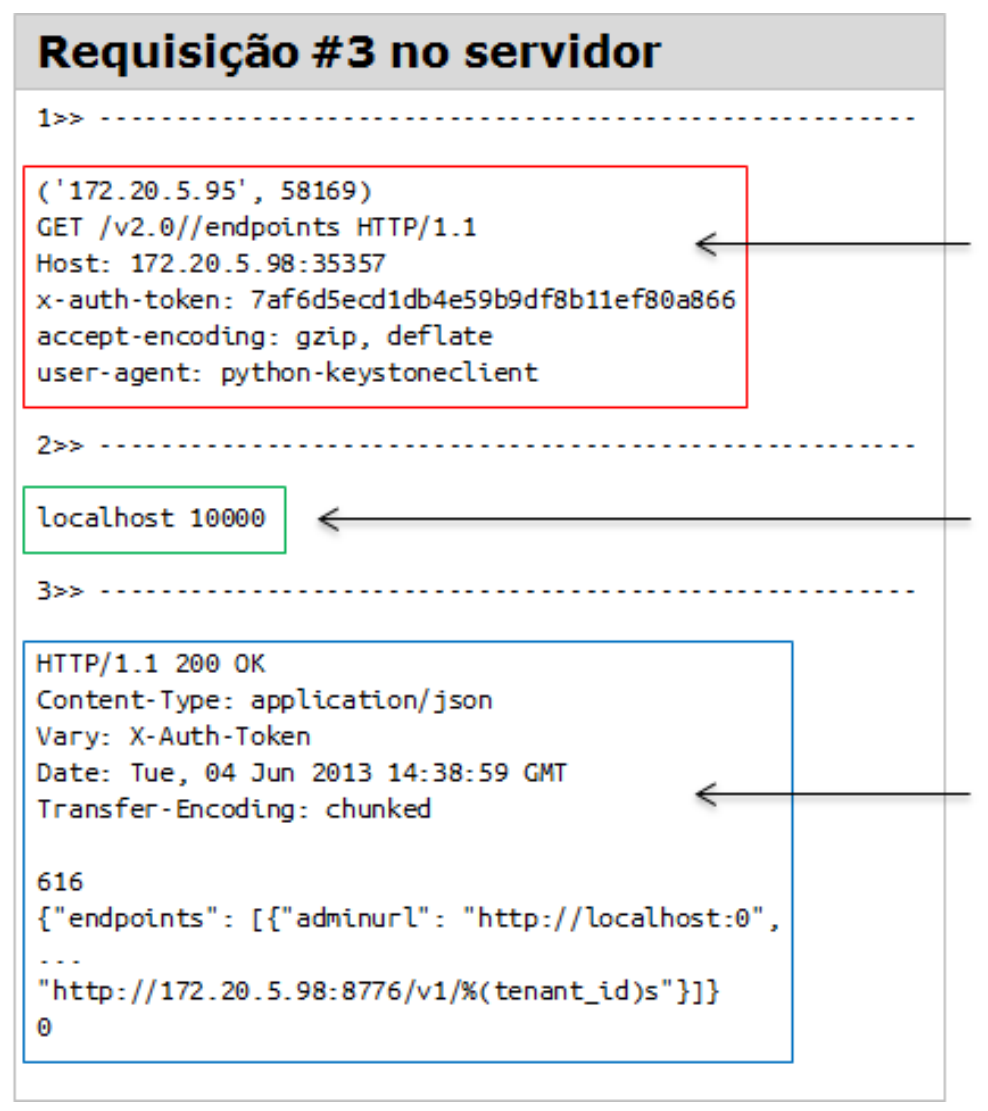

Operação original (listar endpoints) usando token gerado manualmente

Operação autorizada, envie para o middleware para marcar o pacote

Resultado da operação, que é enviado para requisitante original

Figura 33: Requisição 3 recebida no servidor - Teste 1

servidor prossegue com as etapas de autorização, marcação, e execução da operação. O resultado é retornado para o SGC cliente, e a remoção do token é feita pela ferramenta auxiliarcms_delete_token.

A Figura 34 mostra o tráfego legível enviado e recebido pelo cliente relativo à etapa de autorização. O tráfego foi capturado utilizando Wireshark, mas também poderia ser capturado por outros sniffers, como o tcpdump. A partir destas informações só é possível saber se o usuário executou ou não alguma operação, e se esse operação foi autorizada ou não. Não é possível capturar dados do usuário, senhas, tokens, ou credenciais.

Finalmente, a Figura 35 mostra o tráfego legível enviado e recebido pelo cliente relativo à execução da operação. Com estes dados só é possível obter informações sobre a operação realizada (o que não é problema, visto que a operação foi configurada para ser executada no modo de proteção parcial). 


\section{Tráfego enviado pelo cliente (capturado via Wireshark, legível)}

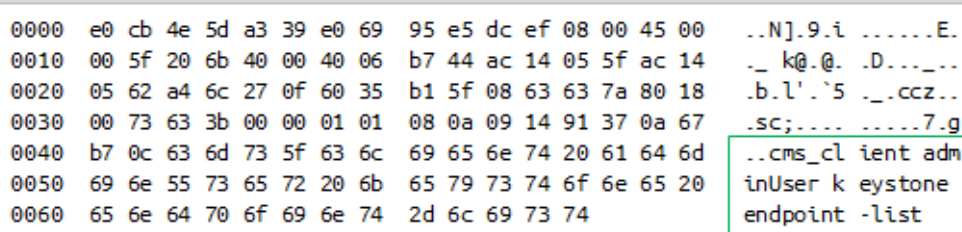

\section{Tráfego recebido pelo cliente (capturado via Wireshark, legível)}

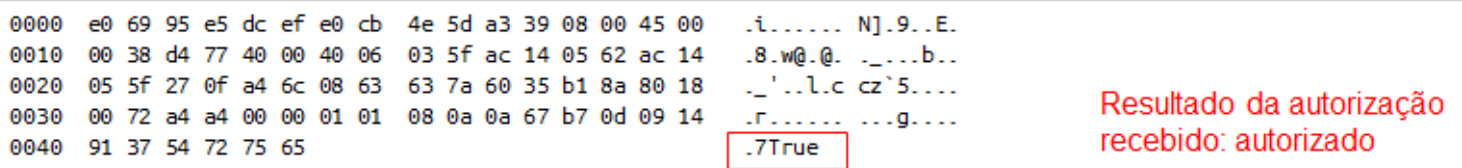

Figura 34: Tráfego enviado e recebido pelo cliente relativo à etapa da autorização -

Teste 1

\section{Tráfego enviado pelo cliente (capturado via Wireshark, legível)}

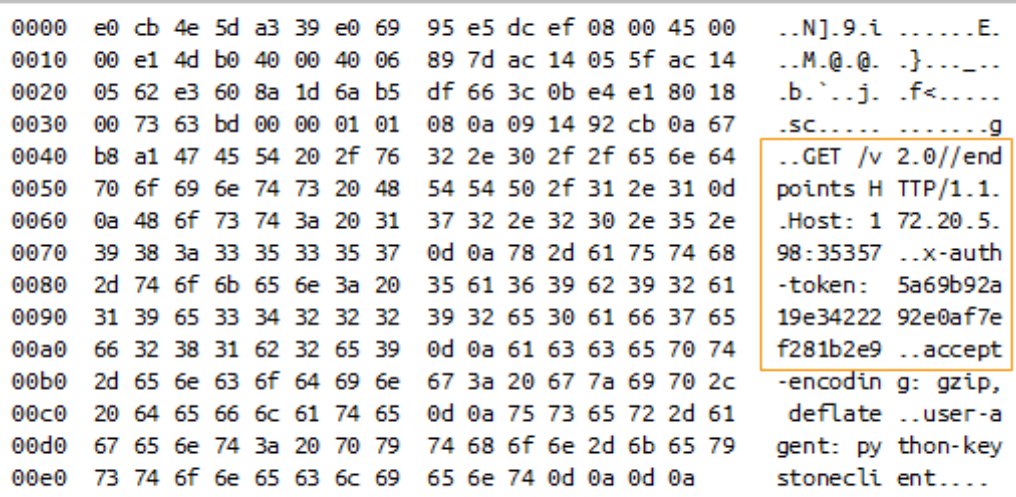

Operation itself, containing the token previously generated.

Notice that the token generation is performed through the secure channel

\section{Tráfego recebido pelo cliente (capturado via Wireshark, legível)}

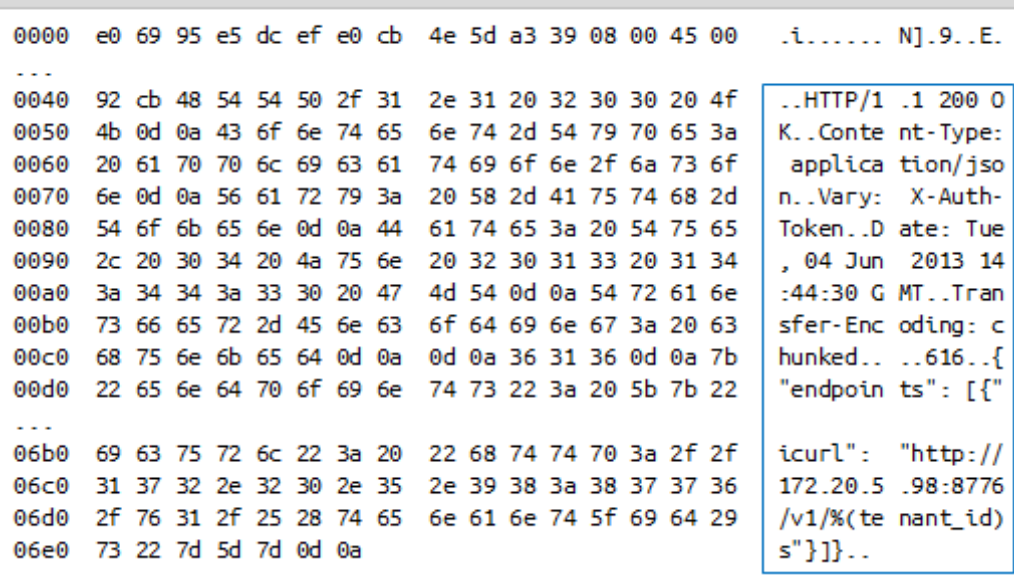

Figura 35: Requisição e resposta no cliente - Teste 1 


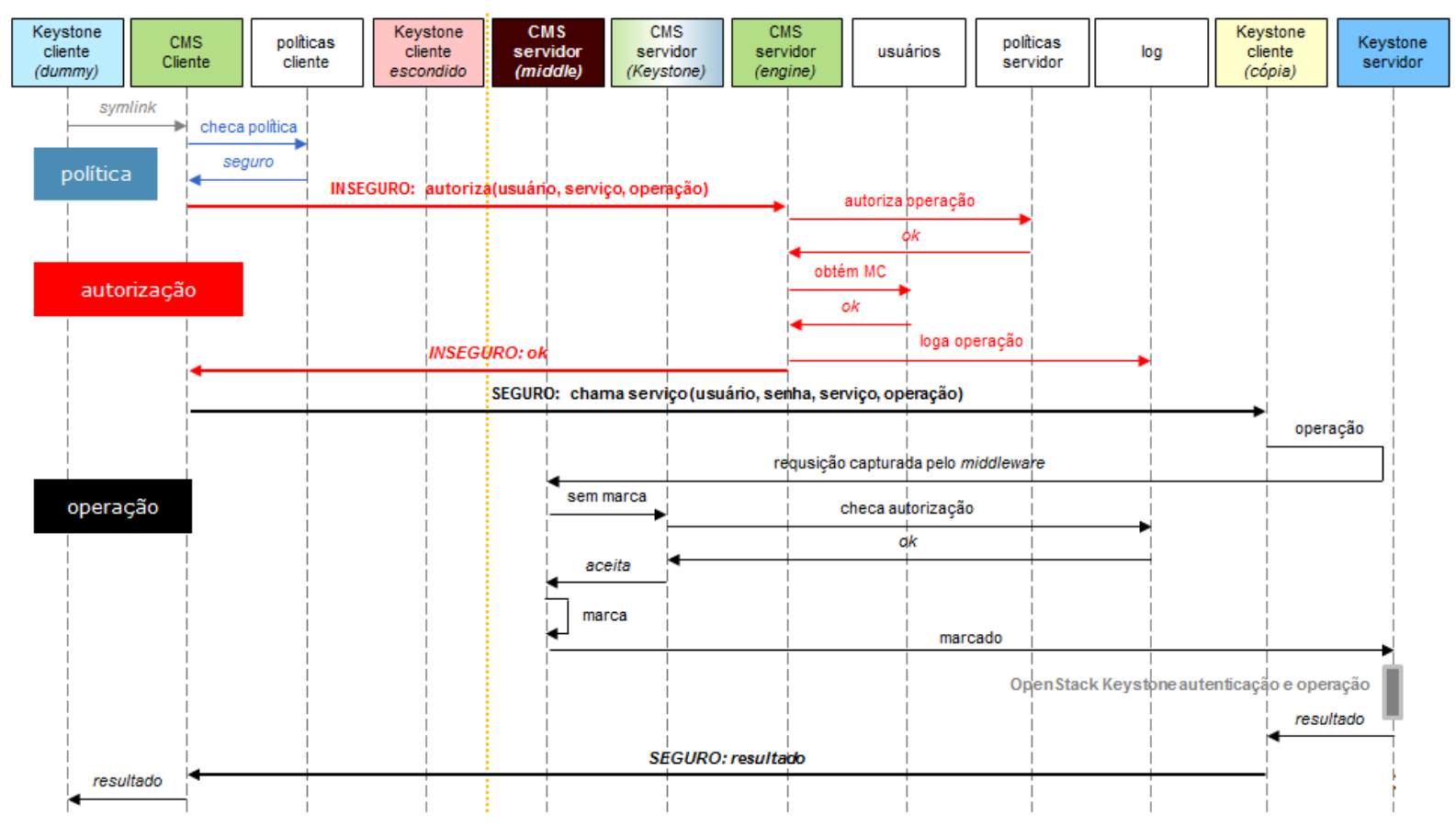

Figura 36: Diagrama de sequência para Teste 2

\subsubsection{Teste 2: Com SGC, proteção total}

Neste cenário a operação deve ser totalmente protegida, isto é, não só as informações sobre o usuário requisitante devem ser protegidas, mas também o conteúdo da operação em si. Este cenário aplica-se, por exemplo, quando um administrador deseja criar um novo usuário. Para criar o usuário o administrador deve utilizar sua senha, que deve ser protegida. No entanto, o novo usuário também precisa de uma senha que é definida por meio dos argumentos passados para a operação. A senha do novo usuário também deve ser protegida, portanto tanto os dados do administrador como os do novo usuário devem ser enviados por meio do canal seguro de comunicação.

\subsubsection{Sequência}

O comportamento do sistema neste cenário é ilustrado pelo diagrama de sequência apresentado nas Figura 36. A sequência de operações no modo totalmente seguro é mais simples pois não é necessário gerar manualmente o token do Keystone, visto que a operação inteira é enviada por meio do túnel e executada localmente na máquina do 
serviço. A etapa de verificação de política cliente revela que o modo de operação é de proteção completa, portanto o SGC cliente envia a requisição integral para o SGC servidor. A autorização é feita de maneira similar ao modo de operação com proteção parcial. O SGC servidor, por sua vez, executa a fase de autorização, marcação, execução, e devolução (retorno) do resultado da operação.

\subsubsection{Teste}

A Figura 37 mostra a requisição executada no cliente e a resposta recebida. São

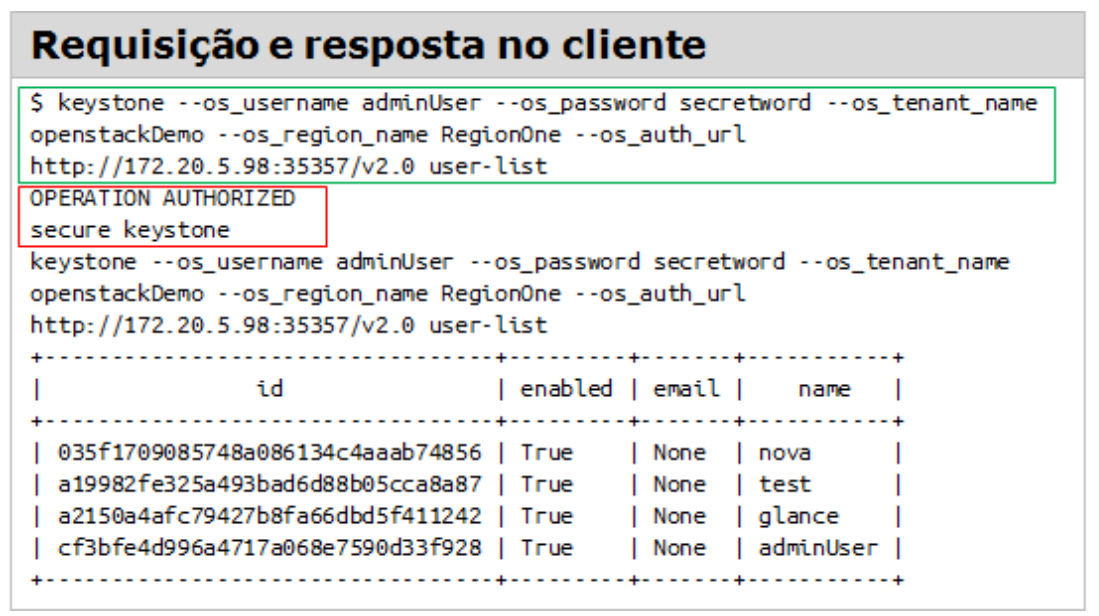

Linha de comando idêntica à utilizada por usuário sem SGC

Resultado da autorização (sucesso) e identificação da politica (SEGURO)

Figura 37: Requisição e resposta no cliente - Teste 2

destacadas a requisição inicial, idêntica a que seria realizada caso o SGC não estivesse presente (novamente para ressaltar a transparência da solução), e o resultado da verificação da política cliente (neste caso de proteção total).

Figura 38 mostra as requisições recebidas pelo servidor. A primeira é a de autorização de operação, contendo o nome do usuário, serviço, e operação desejada. Já a segunda requisição é de geração de token, desta vez proveniente da própria máquina de serviço.

Figura 39 mostra a terceira requisição recebida pelo servidor. Ela contém a requisição (no caso, obter a lista de usuários da nuvem) que é proveniente do Keystone cliente localizado na própria máquina de serviço, lembrando que a requisição completa 


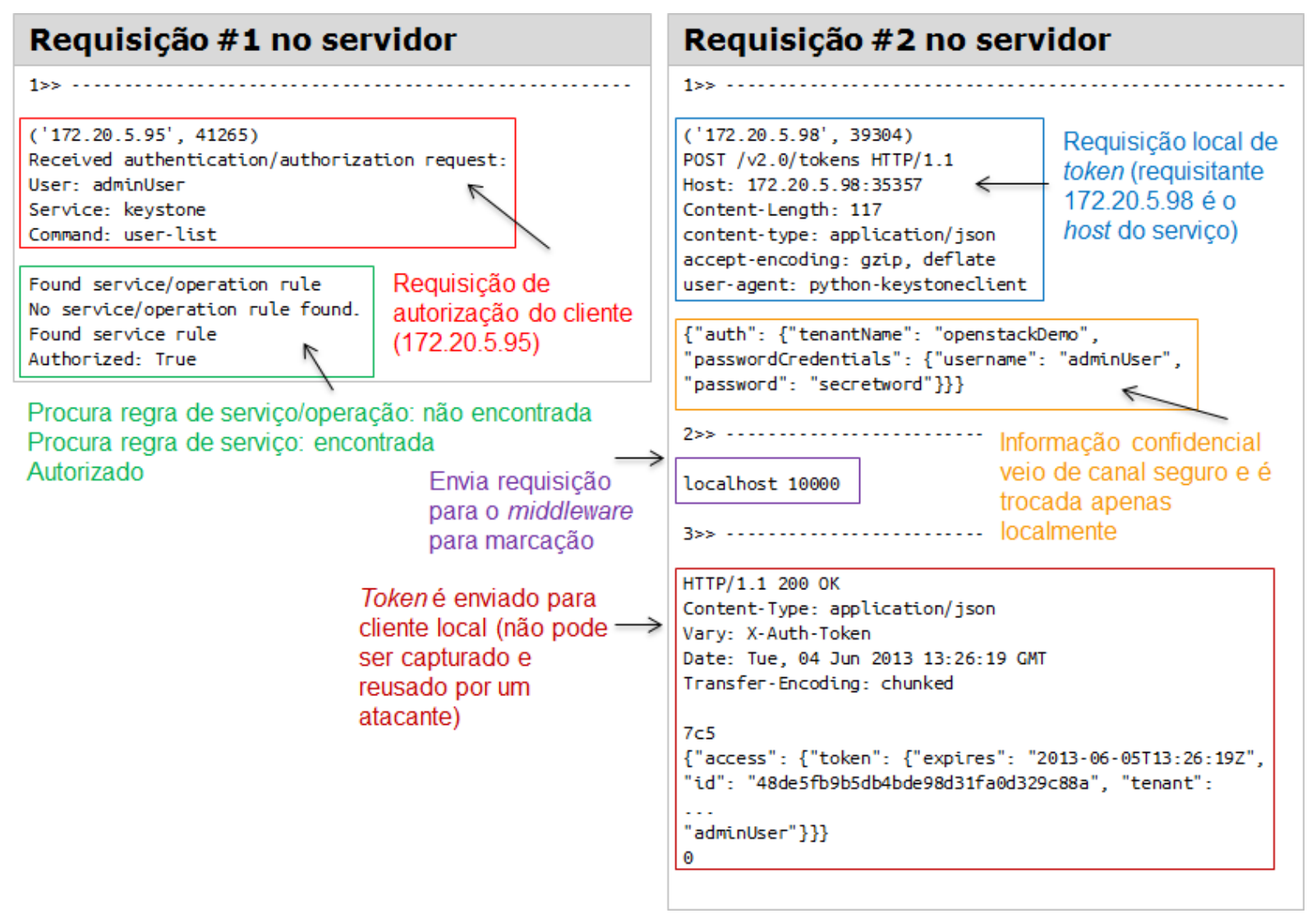

Figura 38: Requisições 1 e 2 recebidas pelo servidor - Teste 2

foi enviada por meio de um túnel seguro a partir do SGC cliente. Nesta fase é feita a checagem de autorização, a credencial de uso único (UC) é consumida, a operação é executada, e o resultado é retornado para o usuário.

Por fim, a Figura 40 mostra o tráfego legível capturado no cliente ao longo da operação. A única informação que pode ser lida é o nome do usuário, a operação realizada, e o resultado da autorização. Todas as informações confidenciais permanecem protegidas pelo canal seguro.

\subsubsection{Teste 3: Com SGC, não autorizado}

Neste cenário a requisição não deve ser autorizada pelo SGC. 


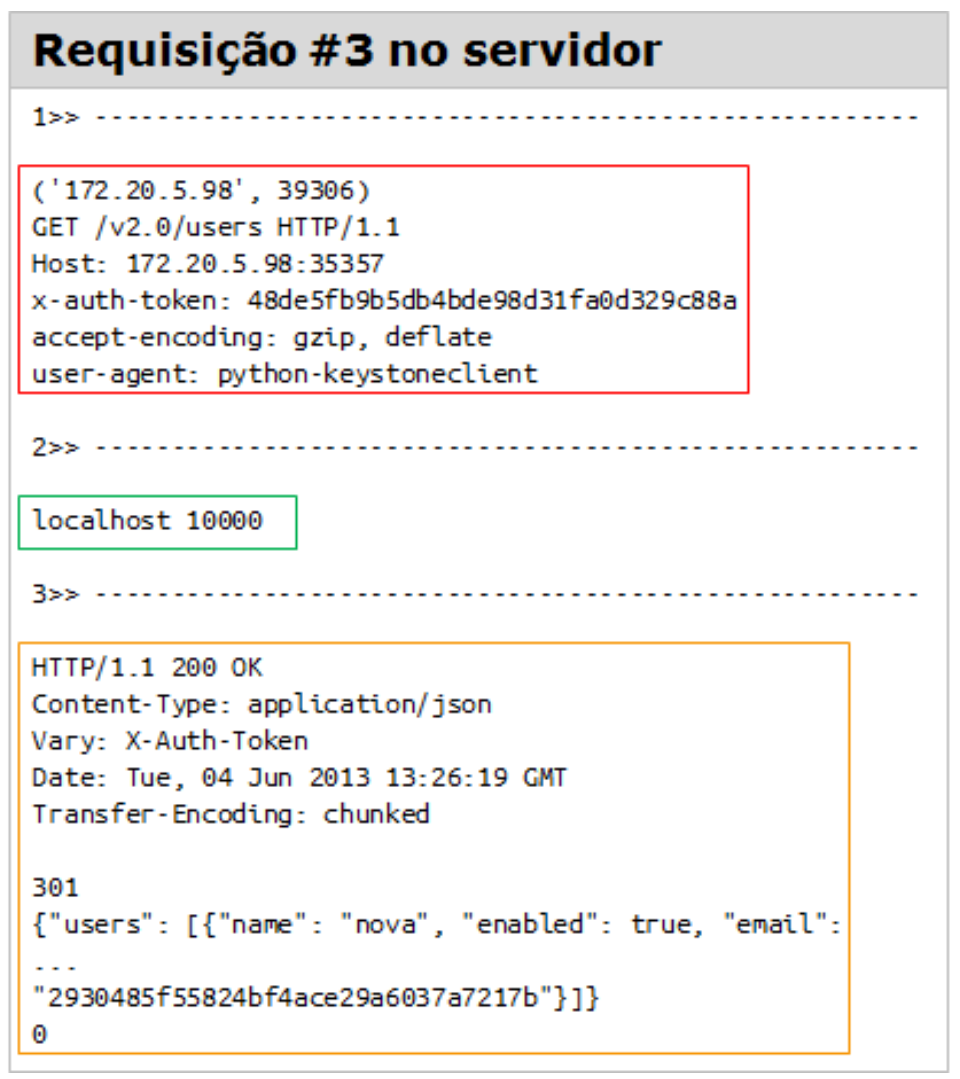

Operação (obter lista de usuários) também é realizada localmente resultado é retornado ao cliente local

Forward request to middleware to mark the packet

Operation result (list of users was shortened), which is first returned to the local client, then sent back to the original requester using the secure channel

Figura 39: Requisição e resposta no cliente - Teste 2

\section{Tráfego enviado pelo cliente (capturado via Wireshark, legível)}

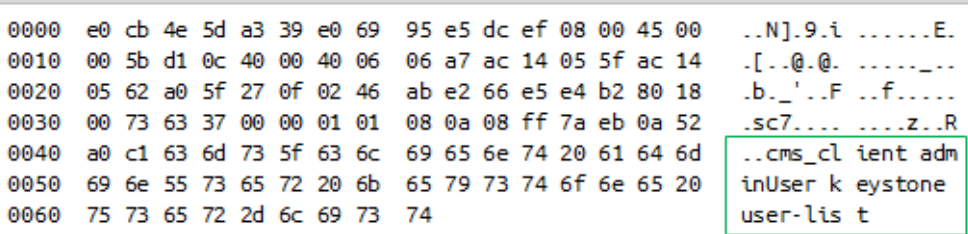

Operation authorization request

containing user name, service

and command

\section{Tráfego recebido pelo cliente (capturado via Wireshark, legível)}

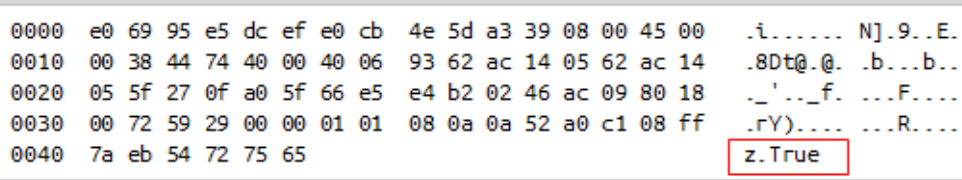

Authorization succeded

Figura 40: Requisição e resposta no cliente - Teste 2

\subsubsection{Sequência}

O comportamento do sistema neste cenário é ilustrado pelo diagrama de sequência apresentado nas Figura 41. Após a verificação da política (proteção integral ou parcial) 


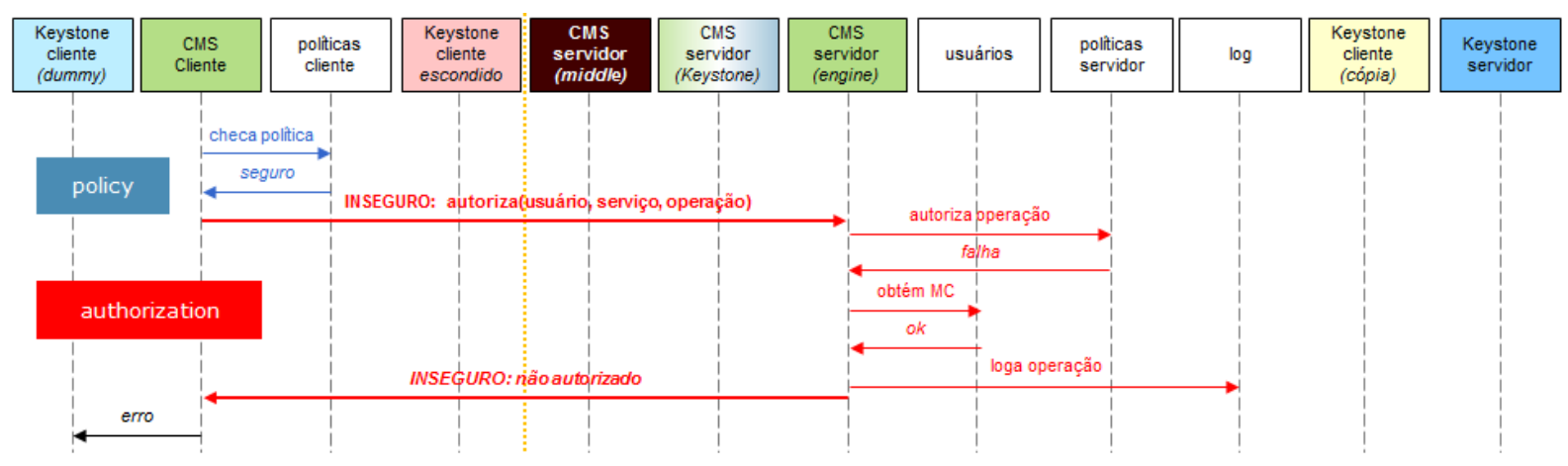

Figura 41: Diagrama de sequência para Teste 3

o SGC cliente envia a requisição de autorização. O SGC servidor analisa a identidade do usuário, serviço desejado, e operação desejada. Com base no arquivo de políticas é encontrada uma regra que não autoriza o usuário, e este resultado é retornado ao SGC cliente. A operação é finalizada.

\subsubsection{Teste}

A Figura 42 mostra a interação observada pelo cliente e a única requisição recebida pelo servidor. A linha de comando permanece idêntica à observada no uso convencio-

\section{Requisição e resposta no cliente}

\begin{tabular}{|c|}
\hline $\begin{array}{l}\text { \$ keystone - -os_username } \\
\text { openstackDemo - -os_regior } \\
\text { http: //172.20.5.98:35357 }\end{array}$ \\
\hline $\begin{array}{l}\text { OPERATION NOT AUTHORIZED } \\
\text { User: adminUser } \\
\text { Service: keystone } \\
\text { Command: tenant-list }\end{array}$ \\
\hline
\end{tabular}

Linha de comando idêntica à utilizada por usuário sem SGC

Resultado da autorização (não autorizado)

\section{Requisição \# 1 no servidor}

('172.20.5.95', 41938)

Received authentication/authorization request:

User: adminUser

Service: keystone

Command: tenant-list

Found service/operation rule

Authorized: False

Requisição de autorização do cliente (172.20.5.95)

Regra serviço/operação encontrada: não autorizado

Figura 42: Requisição e resposta no cliente, e requisição recebida pelo servidor - Teste 3 
nal do serviço, e o resultado da autorização é retornado ao cliente. Já no lado servidor é mostrada a evolução da etapa de autorização, com a identificação dos parâmetros de autorização (nome de usuário, serviço, operação) e o resultado (não autorizado).

Figura 43 mostra o tráfego observado no cliente via Wireshark. A única diferença

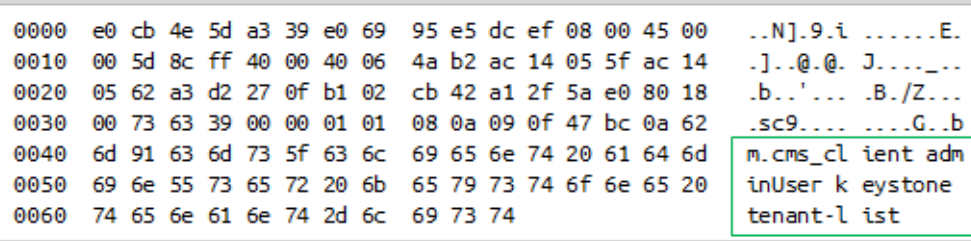

Operation authorization request containing user name, service and command

\section{Tráfego recebido pelo cliente (capturado via Wireshark, legível)}

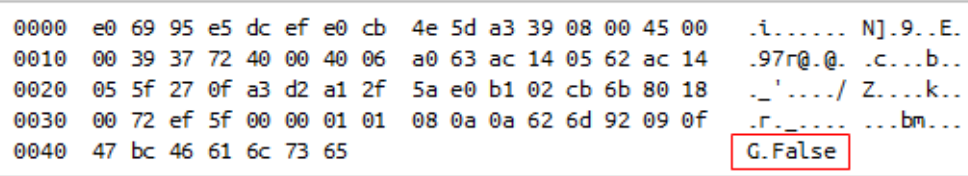

Response from CMS: not authorized

Figura 43: Tráfego enviado e recebido - Teste 3

é o resultado da autorização (False), nenhuma informação confidencial é enviada.

\subsubsection{Teste 4: Sem SGC}

Neste cenário o usuário tenta utilizar um serviço do OpenStack sem o intermédio do SGC cliente. Note que o SGC servidor está em execução - caso não estivesse o comportamento seria o de uma instalação OpenStack convencional.

\subsubsection{Sequência}

O comportamento do sistema neste cenário é ilustrado pelo diagrama de sequência apresentado nas Figura 44. Neste diagrama no lado cliente só é representado o cliente Keystone original, visto que os elementos do SGC cliente não são utilizados. A requisição é enviada em texto às claras (modo padrão de operação do Keystone e dos outros 


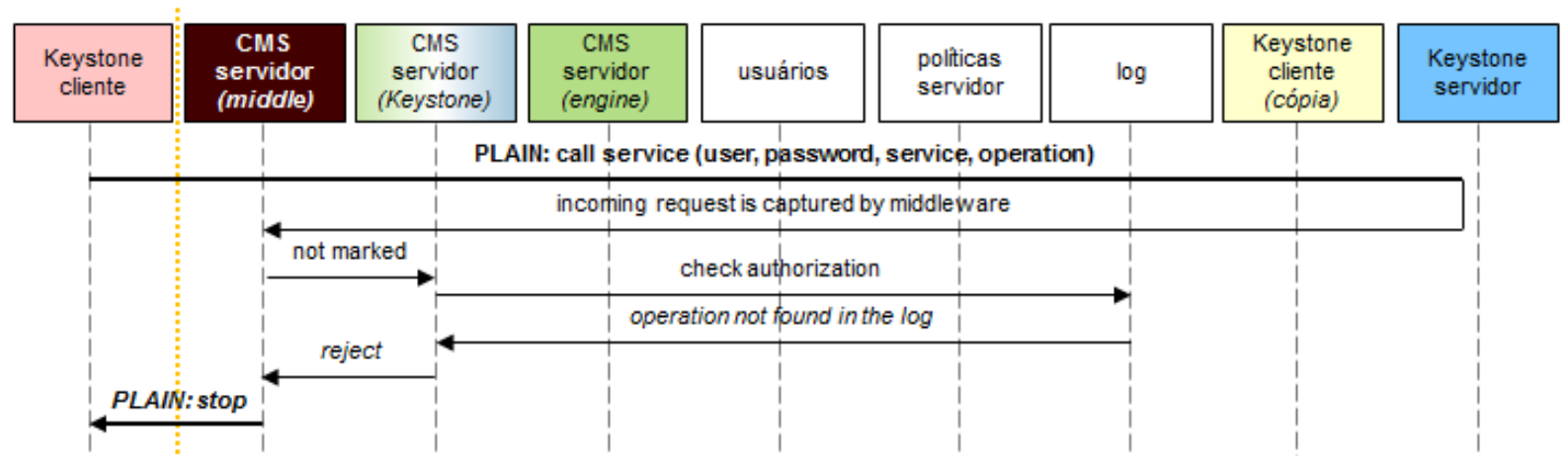

Figura 44: Diagrama de sequência para Teste 4

serviços do OpenStack), e esta requisição é capturada pelo SGC middleware (que está em execução no lado servidor). O middleware verifica que o pacote não está marcado, portanto ele é enviado para o SGC servidor. O SGC servidor verifica se a operação está autorizada, e ela não é encontrada na lista de UCs. A operação é rejeitada e um erro é retornado para a aplicação cliente.

\subsubsection{Teste}

A Figura 45 mostra a requisição e resposta no cliente, bem como as requisições recebidas pelo servidor. A requisição contém a linha de comando utilizada para chamada do serviço, e o resultado recebido é um erro genérico de autenticação do Keystone. Já no servidor a primeira requisição recebida é de obtenção de token. Note que esta requisição veio pelo canal convencional (texto às claras), contendo dados do usuário, senha, grupo de trabalho, etc. A operação de geração de token é validada pelo SGC servidor, mas a segunda requisição de execução da operação é rejeitada. O erro UC not found! é emitido, indicando que a credencial de autorização não pode ser encontrada.

A Figura 46 mostra o tráfego legível capturado relativo às comunicações realizadas pelo cliente. O tráfego enviado corresponde ao pedido de token, e novamente é possível observar a passagem de dados confidenciais às claras. A resposta contém o token gerado, que pode ser reusado por um atacante para realizar operações dentro da nuvem. 


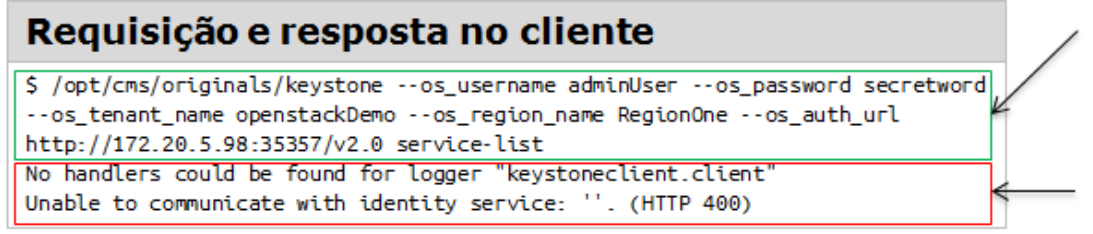

Linha de comando usando aplicação original

Mensagem de erro padrão (devido à problema de conexão com o serviço)

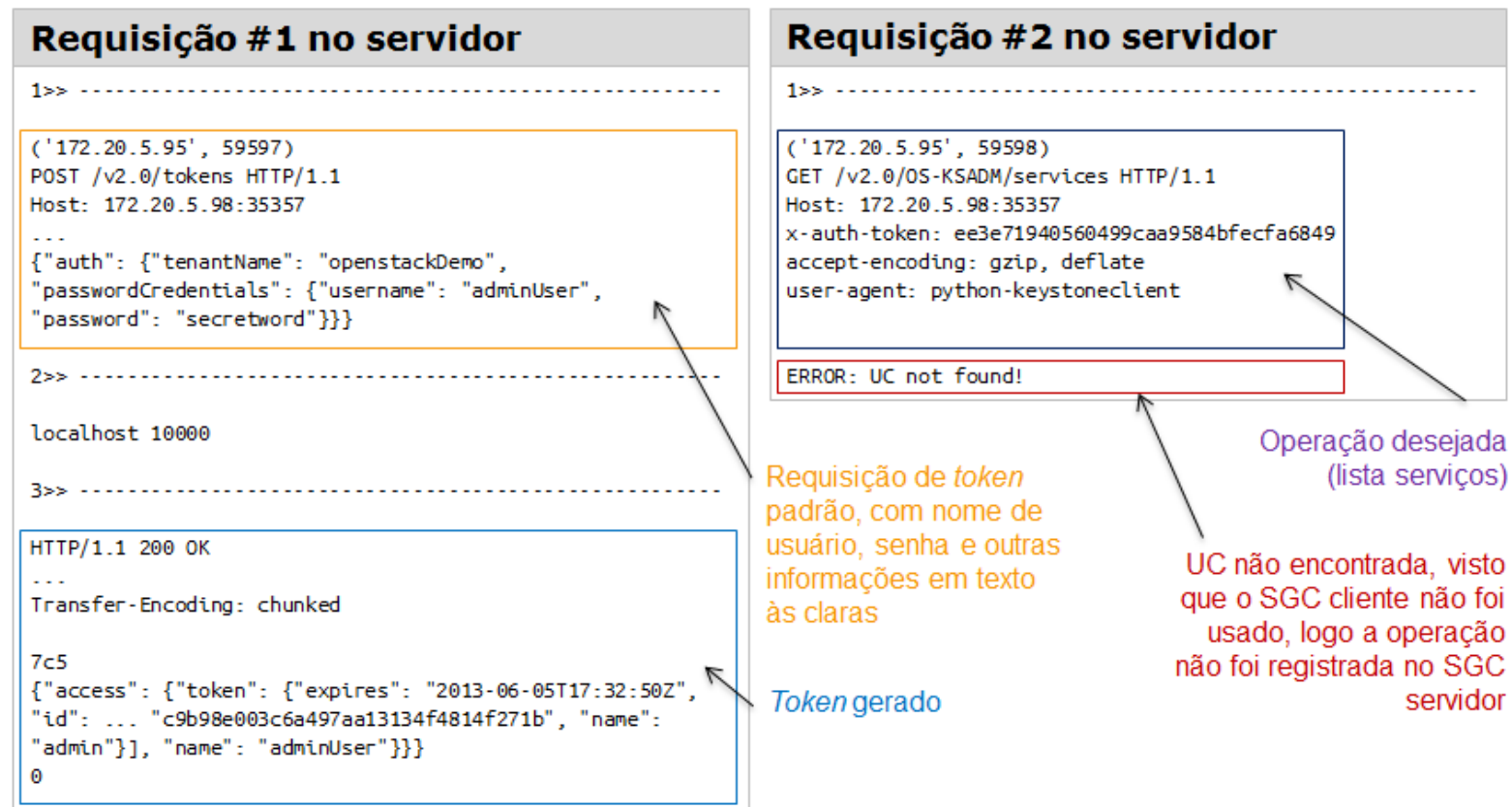

Figura 45: Requisição e resposta no cliente, e requisições recebidas pelo servidor Teste 4

A Figura 47 mostra o tráfego legível capturado no cliente quando a requisição de execução de operação é enviada. Observa-se novamente o token da operação, que pode ser reutilizado.

\subsubsection{Teste 5: Sem SGC, reusando token}

Neste cenário o usuário não possui ou utiliza o SGC cliente, e tenta reutilizar um token gerado anteriormente.

\subsubsection{Sequência}

O comportamento do sistema neste cenário é ilustrado pelo diagrama de sequência apresentado nas Figura 48. A requisição é enviada da aplicação cliente original para o serviço OpenStack correspondente, porém é capturada pelo middleware do SGC. O 


\section{Tráfego enviado pelo cliente (capturado via Wireshark, legível)}

\begin{tabular}{|c|c|c|c|c|c|c|c|c|c|}
\hline 000 & 0 & $4 e$ & ta & $a^{3}$ & 39 & e० & 69 & ef 08004500 & $9 . i$ \\
\hline 4 & $f$ e2 & 50 & $4 f$ & 53 & 54 & 20 & $2 f$ & $6322 \mathrm{e} 302 \mathrm{f} 746 \mathrm{f} 6 \mathrm{~b}$ & POST / V2.0/tok \\
\hline 956 & $656 \mathrm{e}$ & 73 & 20 & 48 & 54 & 54 & 50 & 31 od $0 \mathrm{a} 486$ & ns HTTP / 1 \\
\hline & & & & & & & & & \\
\hline eo & 6579 & 73 & 74 & $6 f$ & $6 e$ & 65 & 63 & c 6965 6e 74 od $0 \mathrm{a} 0$ & eystonec \\
\hline$f$ & $0 \mathrm{a} 7 \mathrm{~b}$ & 22 & 61 & 75 & 74 & 68 & 22 & 3a 207 b $2274 \quad 65$ 6e 61 & . \{"auth" : \{"tena \\
\hline 100 & 6e 74 & $4 e$ & 61 & $6 \mathrm{~d}$ & 65 & 22 & $3 a$ & 2022 6f 7065 6e 737 & ntName": \\
\hline 110 & 6163 & $6 b$ & 44 & 65 & $6 \mathrm{~d}$ & $6 f$ & 22 & 2c $20 \quad 2270 \quad 61 \quad 73 \quad 737$ & ackDemo", "passw \\
\hline 20 & $6 f 72$ & 64 & 43 & 72 & 65 & 64 & 65 & $6 e 7469616 c 73223$ & ordCrede ntials": \\
\hline 130 & 20 & 22 & 75 & 73 & 65 & 72 & $6 e$ & 61 6d $65 \quad 22$ 3a $2022 \quad 61$ & \{"usern ame": "a \\
\hline 140 & $646 \mathrm{~d}$ & 69 & $6 e$ & 55 & 73 & 65 & 72 & $\begin{array}{llllllll}22 & 2 c & 20 & 22 & 70 & 61 & 73 & 7\end{array}$ & dminUser ", "pass \\
\hline 150 & $776 f$ & 72 & 64 & 22 & 3a & 20 & 22 & $736563726574776 f$ & word": " secretwo \\
\hline 160 & 7264 & 22 & $7 d$ & 70 & . & & & & rd" \}\}\} \\
\hline
\end{tabular}

Informações do usuário (nome, senha) capturados na máquina cliente

\section{Tráfego recebido pelo cliente (capturado via Wireshark, legível)}

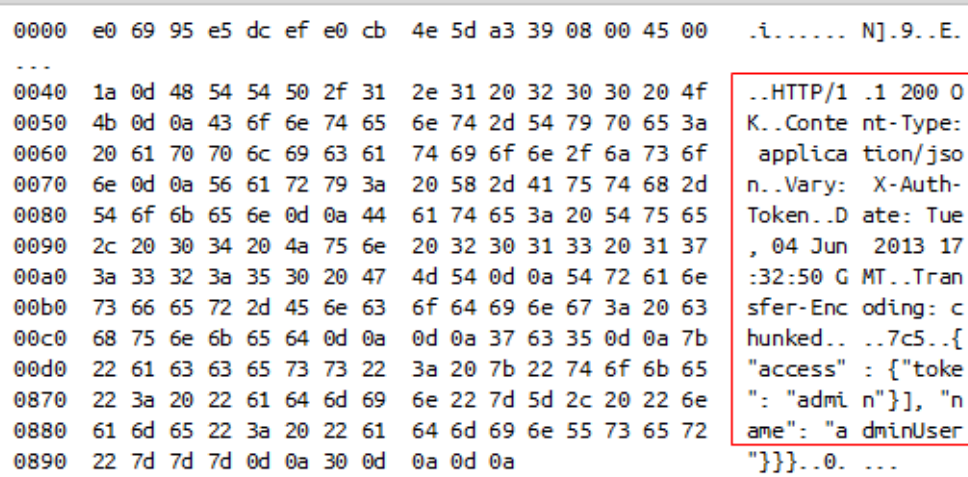

Figura 46: Tráfego capturado enviado e recebido pelo cliente - Teste 4

\section{Tráfego enviado pelo cliente (capturado via Wireshark, legível)}

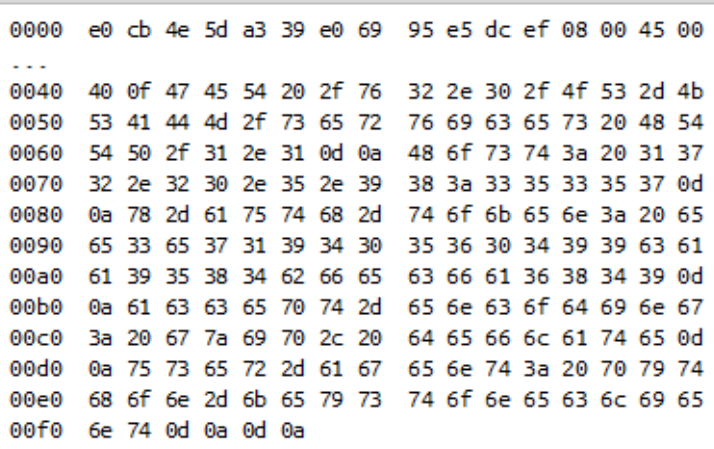

.N].9.i ......E.

@. GET /v 2.0/OS-K
SADM/ser vices HT
TP/1.1.. Host: 17
$2.20 .5 .98: 35357$.
.$x$-auth- token: e
e3e71940 560499ca
a9584bfe cfa6849.
.accept- encoding
: gzip, deflate.
.user-ag ent: pyt
hon-keys toneclie
nt....

Token gerado (pode ser reusado para outras operações com poder de administrador)

Figura 47: Tráfego enviado pelo cliente para execução da operação - Teste 4

pacote é verificado com relação à marcação, e como ela não é encontrada este pacote é enviado para o SGC servidor. Lá a operação é verificada juntamente com o token, e o SGC servidor verifica que a UC já foi consumida (as UCs consumidas são guardadas em uma base de dados separada). Um erro informando que a credencial já foi consumida é retornado à aplicação cliente. 


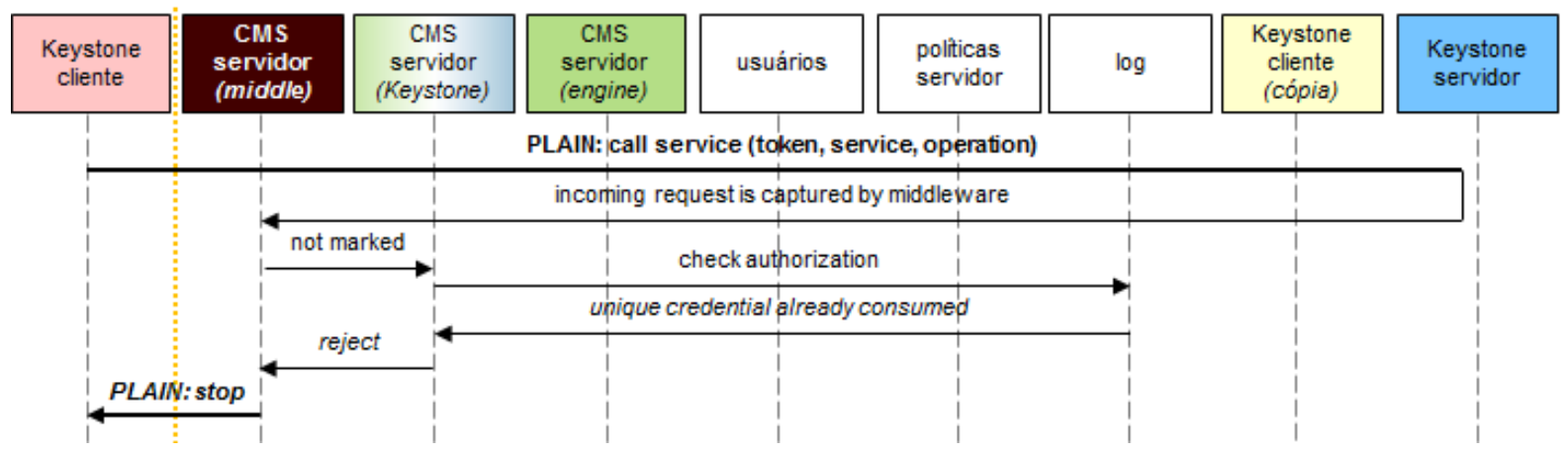

Figura 48: Diagrama de sequência para Teste 5

\subsubsection{Teste}

A Figura 49 mostra a requisição feita pelo cliente, a resposta recebida, e a requisição recebida no servidor. No cliente pode-se observar a especificação manual de um

\section{Client request and response \\ \$ /opt/cms/originals/keystone --token 4c39cfa8ee65418f905e9baee8e41ab2 -- endpoint http://172.20.5.98:35357/v2.0 user-list \\ No handlers could be found for logger "keystoneclient.client \\ Unable to communicate with identity service: [Errno 111] Connection refused. \\ (HTTP 400)}

\section{Server incoming request \# 1}

('172.20.5.95', 59457)

GET / v2.0/users HTTP/1.1

Host: $172.20 .5 \cdot 98: 35357$

x-auth-token: 4c39cfa8ee65418f905e9baee8e41ab2

accept-encoding: gzip, deflate

user-agent: python-keystoneclient

ERROR: UC already consumed:

34ece $96 f a 040 a 2233 d 4 c 5 b 33$ e64 $7 f 61 a 5 f d 4 c 1128060 b 7 a 020737597$ e0 380325
Atacante lê token de uma transação do cliente e tenta reusá-la

Erro genérico proveniente do cliente Keystone

Figura 49: Requisição e resposta no cliente, e requisição no servidor - Teste 5

token porventura capturado por um atacante. A resposta recebida é um erro genérico do Keystone. No servidor observa-se o recebimento da requisição com token definido, e a operação é verificada na tabela de operações autorizadas. A operação é encontrada porém encontra-se em status done, isto é, já foi executada. O SGC servidor retorna um erro UC already consumed. 


\subsection{Análise dos resultados}

Os dois primeiros testes demonstram o funcionamento dos principais casos de uso da solução quando o usuário está autorizado:

- Teste 1: Modo parcial (apenas os dados do requisitante são protegidos).

- Teste 2: Modo total (tanto os dados do requisitante quanto os parâmetros da operação são protegidos).

A principal diferença nas sequências de operações destes modos de operação é necessidade de geração e destruição manual do token no modo parcial. No modo total a operação é enviada para a máquina de serviço via túnel seguro, e posteriormente é executada localmente, portanto a geração do token ocorre por meio da interface de loopback, impedindo que um atacante consiga ler estes dados (a não ser que ele já tenha comprometido a infraestrutura da nuvem). Já no modo parcial a operação é enviada por meios convencionais, e como a geração do token requer a identificação e senha do usuário, é importante que estes dados sejam protegidos por meio do canal seguro estabelecido entre SGC cliente e SGC servidor. Posteriormente o token é enviado às claras juntamente com a operação, portanto é vital que este token seja manualmente destruído para evitar seu reuso por outro usuário. Tokens estão associados a um usuário e seus papéis dentro de um grupo de trabalho, portanto a posse de um token permite executar quaisquer operações que este usuário tenha permissão, não só a operação para a qual o token foi gerado. Isto requer cuidado especial principalmente com relação à tokens pertencentes a administradores, que podem liberar acesso total aos recursos e entidades da nuvem.

Outro ponto relacionado aos requisitos da solução é a utilização do SGC cliente, que não altera o modo como a aplicação original é utilizada. As chamadas de serviço e função são as mesmas, mantendo inalterado o modo como o usuário interage com os 
serviços e permitindo que scripts e dependências sejam mantidas sem esforço.

Os outros três testes mostram como o SGC se comporta em situações de erro. No Teste 3 o usuário não está autorizado a realizar a operação, decisão tomada com base no arquivo de políticas do SGC servidor. No Teste 4 o usuário tenta acessar a nuvem a partir de um cliente original, sem o SGC cliente. No entanto, é o SGC cliente que estabelece o canal seguro e realiza a requisição de autorização, portanto ao utilizar o cliente original a operação não é adequadamente autorizada. Por fim, no Teste 5 o usuário tenta reutilizar uma credencial, porém o SGC guarda tanto os tokens quanto às credenciais consumidas, impedindo que um atacante possa executar operações na nuvem utilizando as credenciais de um usuário legítimo.

A Tabela 9 resume os requisitos funcionais $(\mathbf{R F})$ e requisitos não funcionais (RNF) da solução e como estes foram atendidos.

\subsection{Considerações do capítulo}

Este capítulo apresentou os testes realizados para validar o protótipo e a proposta desta pesquisa. Os requisitos essenciais relacionados à autorização de operações e de transparência foram atendidos adequadamente, permitindo a integração entre a solução SGC e o serviço de nuvem (no caso, OpenStack). No lado cliente, o desvio de fluxo de execução realizado pelo SGC cliente intercepta requisições assim que elas são executadas pelo usuário, permitindo executar as etapas de autorização da operação. No lado servidor, o SGC middleware intercepta as requisições e busca pelas informações de autenticação e autorização, impedindo a execução de operações não autorizadas e evitando que credenciais possam ser reusadas. 
Tabela 9: Requisitos funcionais e não funcionais da solução e como eles foram atendidos

\begin{tabular}{|c|c|c|}
\hline$\#$ & Requisito & Como foi atendido \\
\hline RF 1 & $\begin{array}{l}\text { Proibir por padrão tráfego } \\
\text { de dados às claras, ou } \\
\text { permitir que este parâmetro } \\
\text { seja configurável. }\end{array}$ & $\begin{array}{l}\text { O arquivo de políticas no SGC cliente permite definir } \\
\text { quais serviços e operações devem ser protegidas } \\
\text { (parcialmente ou integralmente). }\end{array}$ \\
\hline RF 2 & $\begin{array}{l}\text { Permitir envio de dados às } \\
\text { claras desde que o SGC seja } \\
\text { configurado para fazê-lo. }\end{array}$ & $\begin{array}{l}\text { As operaçães fora do arquivo de políticas do SGC } \\
\text { cliente são executadas no modo de proteção parcial, } \\
\text { onde os dados do requisitante são protegidos mas o } \\
\text { conteúdo da operação não. }\end{array}$ \\
\hline RF 3 & $\begin{array}{l}\text { Evitar necessidade de } \\
\text { modificação das aplicações } \\
\text { originais controladas pelo } \\
\text { SGC. }\end{array}$ & $\begin{array}{l}\text { O SGC cliente implementa um mecanismo de desvio de } \\
\text { fluxo de execução que permite executar as etapas de } \\
\text { autorização sem qualquer modificação na aplicação } \\
\text { cliente ou servidora do serviço original. }\end{array}$ \\
\hline RF 4 & $\begin{array}{l}\text { Evitar duplicação de } \\
\text { informações sobre entidades } \\
\text { da nuvem. }\end{array}$ & $\begin{array}{l}\text { O SGC servidor implementa módulos de integração com } \\
\text { outros serviços para obter informações sobre as } \\
\text { entidades da nuvem. No protótipo a integração foi feita } \\
\text { com o Keystone, permitindo ao SGC obter informações } \\
\text { sobre os usuários da nuvem. }\end{array}$ \\
\hline RF 5 & $\begin{array}{l}\text { Toda entidade da nuvem } \\
\text { deve ser autenticada pelo } \\
\text { SGC. }\end{array}$ & $\begin{array}{l}\text { O SGC servidor possui um registro próprio dos usuários } \\
\text { da nuvem. As informações sobre os usuários são obtidas } \\
\text { por meio da integração com o Keystone, e todas as } \\
\text { credenciais são atreladas a um usuário autenticado. A } \\
\text { etapa de autenticação é delegada ao Keystone por meio } \\
\text { do módulo de integração. }\end{array}$ \\
\hline RF 6 & $\begin{array}{l}\text { Toda operação deve ser } \\
\text { autorizada pelo SGC. }\end{array}$ & $\begin{array}{l}\text { O arquivo de políticas no SGC servidor define as regras } \\
\text { para autorizar operações dentro da nuvem. Após a } \\
\text { instalação do SGC servidor na nuvem não é possível } \\
\text { utilizá-la sem um SGC cliente. Em outras palavras, não } \\
\text { é possível burlar os controles de acesso e caso um } \\
\text { usuário tente utilizar os serviços originais (neste caso do } \\
\text { OpenStack) a partir das aplicações cliente originais a } \\
\text { operação não será autorizada. }\end{array}$ \\
\hline RF 7 & $\begin{array}{l}\text { O SGC deve oferecer } \\
\text { interfaces para delegar } \\
\text { operações de autenticação e } \\
\text { autorização para outros } \\
\text { sistemas ou soluções. }\end{array}$ & $\begin{array}{l}\text { O SGC servidor foi implementado de modo a permitir a } \\
\text { integração com outros serviços para delegar estas } \\
\text { operações. No protótipo há uma integração com o } \\
\text { serviço Keystone, permitindo que a operação de } \\
\text { autenticação seja delegada para o mesmo (visto que este } \\
\text { serviço já possui as informações sobre os usuários e já } \\
\text { realiza a autenticação dos mesmos). }\end{array}$ \\
\hline RF 8 & $\begin{array}{l}\text { SGCs de diferentes } \\
\text { aplicações ou nuvens devem } \\
\text { estabelecer uma relação de } \\
\text { confiança. }\end{array}$ & $\begin{array}{l}\text { A integração entre SGCs é feita por meio dos SGCs } \\
\text { clientes. Caso um usuário deseje mover um recurso de } \\
\text { uma nuvem A para uma nuvem B a operação poderá ser } \\
\text { realizada desde que o usuário tenha uma conta válida em } \\
\text { ambas as nuvens. O restante do procedimento é } \\
\text { realizado pelos SGCs de cada nuvem, portanto desde } \\
\text { que o usuário esteja autenticado em ambos os SGCs a } \\
\text { integração é feita de maneira transparente. }\end{array}$ \\
\hline RF 9 & $\begin{array}{l}\text { O SGC deve implementar } \\
\text { mecanismos de single } \\
\text { sing-on. }\end{array}$ & $\begin{array}{l}\text { No protótipo o processo de autenticação do Keystone foi } \\
\text { mantido, porém a geração de credenciais é feita de } \\
\text { maneira transparente, com base nos arquivos de políticas } \\
\text { do SGC cliente e do SGC servidor. O usuário não } \\
\text { precisa realizar múltiplas autenticações e autorizações } \\
\text { para executar uma mesma operação. }\end{array}$ \\
\hline
\end{tabular}


Tabela 10: Requisitos funcionais e não funcionais da solução e como eles foram atendidos (continuação)

\begin{tabular}{|c|c|c|}
\hline \# & Requisito & Como foi atendido \\
\hline RF 10 & $\begin{array}{l}\text { O SGC deve implementar } \\
\text { mecanismos para controle } \\
\text { de expiração de credenciais. }\end{array}$ & $\begin{array}{l}\text { O protótipo implementa credenciais de uso único e } \\
\text { também inclui um mecanismo que transforma os tokens } \\
\text { do Keystone em tokens de uso único. Isto impede o } \\
\text { reuso destas credenciais para execução de novas } \\
\text { operações, exigindo que cada operação da nuvem seja } \\
\text { adequadamente autorizada. }\end{array}$ \\
\hline RF 11 & $\begin{array}{l}\text { Impedir o reuso de } \\
\text { credenciais expiradas. }\end{array}$ & $\begin{array}{l}\text { A base de dados do protótipo inclui uma lista das } \\
\text { credenciais consumidas, de modo que se um atacante ou } \\
\text { o próprio dono da credencial tente reusá-la a operação } \\
\text { será interrompida. }\end{array}$ \\
\hline RF 12 & $\begin{array}{l}\text { Regras de autorização } \\
\text { devem ser baseadas na } \\
\text { identidade ou nos papéis da } \\
\text { entidade. }\end{array}$ & $\begin{array}{l}\text { O protótipo implementa as regras de controle de acesso } \\
\text { com base nas informações das identidades dos usuários. } \\
\text { As permissões são organizadas em uma hierarquia de } \\
\text { operações, serviços, e a regra padrão. }\end{array}$ \\
\hline RF 13 & $\begin{array}{l}\text { O SGC deve se integrar com } \\
\text { outros serviços da nuvem } \\
\text { para obter informações } \\
\text { sobre os pontos de acesso } \\
\text { da nuvem. }\end{array}$ & $\begin{array}{l}\text { No lado cliente, o desvio de fluxo de execução permite } \\
\text { integrar o SGC aos serviços da nuvem de maneira } \\
\text { transparente. No lado servidor, o SGC middleware } \\
\text { captura as requisições feitas para os serviços da nuvem e } \\
\text { permite verificar as informações de autenticação e } \\
\text { autorização da operação. Os dados sobre os pontos de } \\
\text { acesso são obtidos a partir da integração com o } \\
\text { Keystone. }\end{array}$ \\
\hline RNF 1 & $\begin{array}{l}\text { Permitir que um número } \\
\text { mínimo desejável de } \\
\text { usuários possa utilizar o } \\
\text { SGC. }\end{array}$ & $\begin{array}{l}\text { A utilização do SGC é limitada apenas pela capacidade } \\
\text { de receber e tratar requisições provenientes dos clientes, } \\
\text { da mesma forma que os serviços originais seriam } \\
\text { limitados. Entretanto, o protótipo do SGC servidor foi } \\
\text { implementado para execução em thread única, portanto } \\
\text { em caso de requisições simultâneas existe a formação de } \\
\text { uma fila de espera. }\end{array}$ \\
\hline RNF 2 & $\begin{array}{l}\text { Minimizar o overhead do } \\
\text { SGC. }\end{array}$ & $\begin{array}{l}\text { A principal característica de minimização de overhead } \\
\text { do SGC é o modo de proteção parcial, permitindo que } \\
\text { operações custosas (envio de imagem de disco, criação e } \\
\text { migração de máquina virtual) possam ser } \\
\text { adequadamente protegidas sem comprometer o } \\
\text { desempenho da nuvem. }\end{array}$ \\
\hline RNF 3 & $\begin{array}{l}\text { Evitar que o modo de } \\
\text { funcionamento da aplicação } \\
\text { original seja modificado. }\end{array}$ & $\begin{array}{l}\text { Nenhuma linha de código ou arquivo de configuração } \\
\text { das aplicações originais foi alterada. }\end{array}$ \\
\hline
\end{tabular}




\section{CONSIDERAÇÕES FINAIS}

A solução proposta de gerenciamento de credenciais apresentada nesta dissertação atingiu os objetivos com relação ao oferecimento de mecanismos de autenticação e autorização baseados em credenciais para computação em nuvem. A validação foi obtida por meio do levantamento dos requisitos da solução e posterior desenvolvimento do protótipo que atendeu a estes requisitos de maneira satisfatória. O protótipo permitiu verificar que o sistema de credenciais não afeta o funcionamento das aplicações originais da nuvem, oferecendo meios transparentes para proteger os serviços e as informações dos usuários.

Dois mecanismos principais podem ser identificados no que tange a proteção dos dados e reforço das políticas de controle de acesso: o desvio de fluxo presente no cliente, e o middleware no lado servidor. O desvio de fluxo implementado por meio de links simbólicos que apontam para o SGC cliente faz com que todas as requisições para serviços da nuvem passem pelo SGC, realizando as etapas iniciais de identificação do usuário e autorização da operação. Posteriormente a requisição é capturada pelo middleware, que verifica estas informações e bloqueia tentativas de utilizar uma credencial consumida previamente.

\subsection{Contribuições e inovações}

A principal contribuição da pesquisa é a descrição conceitual da solução de gerenciamento de credenciais, que foi validada por meio da implementação do protótipo. A 
solução proposta adiciona uma camada transparente de autenticação e autorização sem modificar a aplicação original. As políticas que definem se a operação deve ser parcialmente ou totalmente protegida são definidas pelo usuário, pois é o usuário que conhece suas necessidades em termos de proteção dos seus dados confidenciais. Já as políticas de autorização de operações são definidas na nuvem, pois é o provedor da nuvem que conhece o perfil dos usuários e define quais são os direitos e deveres destes usuários dentro da nuvem. As políticas de autorização são definidas por meio de credenciais de uso único, impedindo o reuso destas credenciais para execução de novas operações no intuito de burlar o sistema de autorização proposto.

O mecanismo de inserção do SGC dentro do contexto da nuvem e, principalmente, entre as aplicações cliente e servidor da aplicação original, é a principal inovação da solução proposta. Esta inserção ocorre de maneira transparente, sem necessidade de modificação na aplicação original.

\subsection{Publicações}

As seguintes publicações foram produzidas durante a pesquisa:

- Regular paper: GONZALEZ, N. M.; MIERS, C. C.; REDÍGOLO, F. F.; CARVALHO, T. C. M. B.; SIMPLÍCIO, M.; NASLUND, M.; POURZANDI, M. A taxonomy model for cloud computing services. International Conference on Cloud Computing and Services Science (CLOSER 2011), pags. 56-65. Noordwijkerhout, Holanda. 7 à 9 de maio de 2011.

Esta foi a primeira publicação sobre computação em nuvem, dando início à pesquisa e também encaminhando os estudos posteriormente para o campo de segurança em computação em nuvem. A publicação propõe um modelo hierárquico de classificação de serviços de computação em nuvem, baseado no modelo proposto pelo NIST. 
- Regular paper: GONZALEZ, N. M.; MIERS, C. C.; REDÍGOLO, F. F.; CARVALHO, T. C. M. B.; SIMPLÍCIO, M.; NASLUND, M.; POURZANDI, M. A quantitative analysis of current security concerns and solutions for cloud computing. 2011 IEEE Third International Conference on Cloud Computing Technology and Science (CloudCom 2011), pags. 231-238. Atenas, Grécia. 29 de novembro à 1 de dezembro de 2011.

Primeira publicação sobre segurança em computação em nuvem, contendo a classificação de segurança utilizada na pesquisa apresentada nesta dissertação, bem como os resultados obtidos do estudo de referências e trabalhos relacionados.

- Periódico internacional: GONZALEZ, N. M.; MIERS, C. C.; REDÍGOLO, F. F.; CARVALHO, T. C. M. B.; SIMPLÍCIO, M.; NASLUND, M.; POURZANDI, M. A quantitative analysis of current security concerns and solutions for cloud computing. Journal of Cloud Computing - Advances, Systems and Applications (JoCCASA 2012).

Extensão da publicação anterior publicada em um periódico internacional.

- Periódico nacional: GOnZALEZ, N. M.; Carvalho, T. C. M. B. Segurança das Nuvens Computacionais - uma visão dos principais problemas e soluções. Revista USP, ed. 97. Dossiê Computação em Nuvem, n. 97, pp. 27-42, Março, 2013.

Publicação ainda relacionada à classificação de segurança e análise quantitativa.

- Regular paper: GONZALEZ, N. M.; ROJAS, M. A. T.; DA SILVA, M. V. M.; REDÍGOLO, F. F.; CARVALHO, T. C. M. B.; MIERS, C. C.; NASLUND, M.; AHMED, A. S. A framework for authentication and authorization credentials in cloud computing. The 12th IEEE International Conference on Trust, Security and Privacy in Computing and Communications (IEEE TrustCom-13). Mel- 
bourne, Australia, 16-18 July, 2013

Publicação relacionada à segurança em computação em nuvem, contendo o arcabouço de autenticação e autorização que formou a base da proposta de solução de gerenciamento de credenciais para computação em nuvem.

Outras publicações não relacionadas ao tópico de segurança em computação em nuvem, mas ainda assim relacionadas à computação em nuvem:

- Regular paper: MIERS, C.; BARROS, M.; SIMPLÍCIO M.; GONZALEZ, N.; EVANGELISTA, P.; GOYA, W.; CARVALHO, T.; HELLVIST, S.; HALÉN, J.; MÅNGS, J.; MELANDER, B.; SOUZA, V. Using Trade Wind to Sail in the Clouds. Parallel and Distributed Computing and Systems (PDCS 2011). Dallas, EUA. 14 à 16 de dezembro de 2011.

Uma proposta de solução para desenvolvimento de aplicações para nuvem utilizando interfaces de programação pré-definidas (API). A API desenvolvida foi utilizada em uma aplicação de streaming de vídeo.

- Short paper: GONZALEZ, N. M.; GOYA, W. A.; LANGONA, K.; PEREIRA, R. F.; ANDRADE, M. R.; ZUCCHI, A. C.; CARVALHO, T. C. M. B.; MÅNGS, J.; SEFIDCON, A. Cloud distributed processing using Trade Wind. IEEE 2nd International Congress on Big Data. Santa Clara Marriott, CA, USA. 27 de junho à 2 de julho, 2013.

Esta publicação resume uma proposta de solução de processamento distribuído utilizando a infraestrutura de uma nuvem computacional. A nuvem foi utilizada para calcular operações matemáticas sobre dados climáticos coletados a partir de fontes públicas da Internet.

- Short paper: PEREIRA, R. F.; ANDRADE, M. R.; ZUCCHI, A. C.; LANGONA, K.; GOYA, W. A.; GONZALEZ, N. M.; CARVALHO, T. C. M. B.; 
MÅNGS, J; SEFIDCON, A. Distributed processing from large scale sensor network using Hadoop. IEEE 2nd International Congress on Big Data. Santa Clara Marriott, CA, USA. 27 de junho à 2 de julho, 2013.

Outra publicação dentro do contexto de processamento na nuvem, esta utilizando o Hadoop, uma solução para processamento distribuído na nuvem baseada no algoritmo MapReduce.

\subsection{Trabalhos futuros}

Em termos de publicações planeja-se escrever um artigo final para periódico com os resultados da pesquisa e detalhes sobre o modelo teórico, sobre o protótipo, e sobre as especificidades da solução. Outro ponto importante é a continuação do desenvolvimento do modelo e do protótipo para adequar a solução a cenários mais complexos, como nuvens híbridas, federações e nuvens com serviços integrados.

Com relação ao funcionamento da solução é importante realizar um levantamento sobre aspectos funcionais, tais como desempenho, tempo de execução, overhead, dentre outras métricas adequadas. Algumas propostas já foram sugeridas ao longo do texto, como utilização de threading para permitir o tratamento de múltiplas requisições sem a criação de filas Estas propostas podem ser implementadas e agregadas à solução final do SGC. 


\section{REFERÊNCIAS}

ABELSON, H. Architects of the information society - Thirty-five years of the laboratory for computer science at MIT. : MIT Press, 1999.

ADAMS, C.; LLOYD, S. Understanding PKI: Concepts, Standards, and Deployment Considerations. 2nd ed.. ed. : Addison-Wesley, 2002. ISBN 0-672-32391-5.

AGARWAL, A. The Legal Issues Around Cloud Computing. Julho 2010. Disponível em: <http://www.labnol.org/internet/cloud-computing-legal-issues/14120/>.

ALHAMAD, M.; DILLON, T.; CHANG, E. Conceptual sla framework for cloud computing. In: Digital Ecosystems and Technologies (DEST), 2010 4th IEEE International Conference on. 2010. p. 606-610. ISSN 2150-4938.

ALVA, A. et al. The Notorious Nine - Cloud Computing Top Threats in 2013. Fevereiro 2013.

ANDRZEJAK, A.; KONDO, D.; YI, S. Decision model for cloud computing under sla constraints. In: Modeling, Analysis Simulation of Computer and Telecommunication Systems (MASCOTS), 2010 IEEE International Symposium on. 2010. p. 257-266. ISSN 1526-7539.

ARCHER, J. et al. Top Threats to Cloud Computing V1.0. Março 2010.

ARMBRUST, M. et al. Above the Clouds - A View of Cloud Computing. 2010.

ARRINGTON, M. Google defends against large scale Chinese cyber attack: may cease Chinese operations. 2010. Disponível em: <http://techcrunch.com/2010/01/12/google-china-attacks/>.

BADGER, L. et al. US Government Cloud Computing Technology Roadmap Volume II Release 1.0 (Draft). NIST Special Publication 500-293, p. 85, Novembro 2011.

BAKSHI, A.; YOGESH, B. Securing cloud from ddos attacks using intrusion detection system in virtual machine. In: Communication Software and Networks, 2010. ICCSN '10. Second International Conference on. Feb. p. 260-264.

BALKAN, A. Why Google App Engine is broken and what Google must do to fix it. 2008. Disponível em: <http://aralbalkan.com/1504/>.

BENANTAR, M. Access control systems - security, identity management and trust models. : Springer, 2005. 
BENTLEY, L. E-Discovery in the Cloud Presents Promise and Problems. Abril 2009. Disponível em: <http://www.itbusinessedge.com/cm/community/features/interviews/blog/e-discovery-in-the-cloud-presents-promise-and-problems/?cs=31698 > .

BERTINO, E.; TAKAHASHI, K. Identity Management - Concepts, Technologies, and Systems. : Artech House Publishers, 2010.

BISHOP, M. Introduction to computer security. : Addison-Wesley Professional, 2004.

BOSCH, J. Google Accounts Attacked by Phishing Scam. 2009.

BRANDIC, I. et al. Compliant cloud computing (c3): Architecture and language support for user-driven compliance management in clouds. In: Cloud Computing (CLOUD), 2010 IEEE 3rd International Conference on. 2010. p. 244-251.

BREZAK, J. E. et al. Credential management. : Google Patents, Abril 2007. US Patent 7,210,167.

BRISCOE, G.; MARINOS, A. Digital ecosystems in the clouds: Towards community cloud computing. In: Digital Ecosystems and Technologies, 2009. DEST '09. 3rd IEEE International Conference on. 2009. p. 103-108.

CAMENISCH, J. et al. Privacy and identity management for everyone. In: ACM. Proceedings of the 2005 workshop on Digital identity management. 2005. p. 20-27.

CATTEDDU, D.; HOGBEN, G. Benefits, risks and recommendations for information security. Novembro 2009.

CELESTI, A. et al. How to enhance cloud architectures to enable cross-federation. In: IEEE. Cloud Computing (CLOUD), 2010 IEEE 3rd International Conference on. 2010. p. 337-345.

. Security and cloud computing: Intercloud identity management infrastructure. In: Enabling Technologies: Infrastructures for Collaborative Enterprises (WETICE), 2010 19th IEEE International Workshop on. 2010. p. 263-265. ISSN 1524-4547.

CHELLAPPA, R. Intermediaries in cloud-computing - a new computing paradigm. Proc. INFORMS Intermediaries in Electronic Markets, 1997.

CHOW, R. et al. Controlling data in the cloud: outsourcing computation without outsourcing control. In: Proceedings of the 2009 ACM workshop on Cloud computing security. New York, NY, USA: ACM, 2009. (CCSW '09), p. 85-90. ISBN 978-1-60558-784-4. Disponível em: <http://doi.acm.org/10.1145/1655008.1655020>.

CLARKE, G. Microsoft BPOS cloud outage burns Exchange converts. Maio 2011. Disponível em: <http://www.theregister.co.uk/2011/05/13/microsoft_bpos_apology/>.

CPNI. Information Security Briefing 2010. Março 2010.

DAVESLAB. Does using non-SQL databases obviate the need for guarding against "SQL injection"? 2009. Disponível em: < http://stackoverflow.com/questions/1823536/does-using-non-sql-databases-obviate-the-need-for-guarding-against-sqlinjectio>. 
DAVIS, K. Payment Application Data Security Standard. Payment Card Industry (PCI), p. 55, Outubro 2010.

DINOOR, S. Got Privilege? Ten Steps to Securing a Cloud-Based Enterprise. Outubro 2010. Disponível em: <http://shlomidinoor.sys-con.com/node/1571649>.

DORION, P. Data destruction services: When data deletion is not enough. 2010. Disponível em: <http://searchdatabackup.techtarget.com/tip/Data-destructionservices-When-data-deletion-is-not-enough $>$.

ESPINER, T. Salesforce tight-lipped after phishing attack. 2007. Disponível em: $<$ http://www.zdnet.com/salesforce-tight-lipped-after-phishing-attack-3039290616/>.

FITO, J.; GOIRI, I.; GUITART, J. Sla-driven elastic cloud hosting provider. In: Parallel, Distributed and Network-Based Processing (PDP), 2010 18th Euromicro International Conference on. 2010. p. 111-118. ISSN 1066-6192.

GADIA, S. Cloud Computing: An Auditor's Perspective. 2009. Disponível em: $<$ http://www.isaca.org/Journal/Past-Issues/2009/Volume-6/Pages/Cloud-ComputingAn-Auditor-s-Perspective1.aspx $>$.

GENOVESE, S. Akamai introduces cloud-based firewall. 2009. Disponível em: <cloudcomputing.sys-con.com/node/1219023>.

GIORDANELLI, R.; MASTROIANNI, C. The cloud computing paradigm Characteristics, opportunities and research issues. 2010.

GONG, C. et al. The characteristics of cloud computing. In: Parallel Processing Workshops (ICPPW), 2010 39th International Conference on. Sept. p. 275-279. ISSN 1530-2016.

GONZALEZ, N. M. et al. A quantitative analysis of current security concerns and solutions for cloud computing. In: IEEE. Cloud Computing Technology and Science (CloudCom), 2011 IEEE Third International Conference on. 2011. p. 231-238.

. A quantitative analysis of current security concerns and solutions for cloud computing. Journal of Cloud Computing - Advances, Systems and Applications, v. 1, 2012. $\overline{56-65 .}$

. A Taxonomy Model for Cloud Computing Services. In: CLOSER. 2011. p.

A framework for authentication and authorization credentials in cloud computing. In: The 12th IEEE International Conference on Trust, Security and Privacy in Computing and Communications (IEEE TrustCom-13). 2013.

GRAY, P. Legal issues to consider with cloud computing. 2013. Disponível em: $<$ http://www.techrepublic.com/blog/tech-manager/legal-issues-to-consider-withcloud-computing/8161>.

HULME, G. V. CloudPassage aims to ease cloud server security management. 2011. 
HUNTER, S. E-discovery: Ascending to the cloud creates negligible e-discovery risk. Julho 2011. Disponível em: <http://www.insidecounsel.com/2011/07/06\% -/e-discovery-ascending-to-the-cloud-creates-negligi $>$.

ITU-T. Recommendation ITU-T Y.2720 - NGN identity management framework. Janeiro 2009.

JAEGER, T.; SAILER, R.; SREENIVASAN, Y. Managing the risk of covert information flows in virtual machine systems. In: Proceedings of the 12th ACM symposium on Access control models and technologies. New York, NY, USA: ACM, 2007. (SACMAT '07), p. 81-90. ISBN 978-1-59593-745-2. Disponível em: $<$ http://doi.acm.org/10.1145/1266840.1266853>.

JANSEN, W.; GRANCE, T. Guidelines on Security and Privacy in Public Cloud Computing. NIST Special Publication 800-144, p. 80, Dezembro 2011.

JANSEN, W. A. Cloud hooks - security and privacy issues in cloud computing. In: IEEE. System Sciences (HICSS), 2011 44th Hawaii International Conference on. 2011. p. 1-10.

JENSEN, M. et al. On technical security issues in cloud computing. In: IEEE. Cloud Computing, 2009. CLOUD'09. IEEE International Conference on. 2009. p. 109-116.

JIN, S.; HUH, J. Secure mmu: Architectural support for memory isolation among virtual machines. In: Dependable Systems and Networks Workshops (DSN-W), 2011 IEEE/IFIP 41st International Conference on. 2011. p. 217-222.

KAUFMAN, C.; VENKATAPATHY, R. Windows Azure Security Overview. 2010. Disponível em: <http://download.microsoft.com/download/6/0/2/6028B1AE-4AEE46CE-9187-641DA97FC1EE/Windows\%20Azure\%20Security\%20Overview\%20v1.01.pdf $>$.

KRAUTHEIM, F. J. Private virtual infrastructure for cloud computing. In: USENIX ASSOCIATION. Proceedings of the 2009 conference on Hot topics in cloud computing. 2009. p. 5-5.

KUMAR, B.; CHENG, J. C.; MCGIBBNEY, L. Cloud computing and its implications for construction it. In: Int. Computing Conf. on Civil and Building Engineering. 2010.

LI, H. et al. Identity-based authentication for cloud computing. Cloud Computing, Springer, p. 157-166, 2009.

LICKLIDER, J. C. Memorandum for members and affiliates of the intergalactic computer network. Apr, v. 23, p. 350-1, 1963.

LICKLIDER, J. C. R. Man-computer symbiosis. Human Factors in Electronics, IRE Transactions on, IEEE, n. 1, p. 4-11, 1960.

LINTHICUM, D. Defining the Cloud Computing Framework. Janeiro 2009. Online. Disponível em: <cloudcomputing.sys-con.com/node/811519>. 
LYLE, M. Redundancy in Data Storage. 2011. Disponível em: <http://www.definethecloud.net/redundancy-2-geographical-replication>.

MACGREGOR, W.; DUTCHER, W.; KHAN, J. An Ontology of Identity Credentials - Part 1 - Background and Formulation. NIST Special Publication 800-103, p. 70, Outubro 2006.

MAGOULES, F. Fundamentals of grid computing - theory, algorithms and technologies. : Chapman \& Hall/CRC, 2009.

MARKIEWICZ, D. HIPAA Security Rule Policy Map. Fevereiro 2008.

MARSTON, S. et al. Cloud computing - the business perspective. Decision Support Systems, v. 51, n. 1, p. 176 - 189, 2011. ISSN 0167-9236. Disponível em: <http://www.sciencedirect.com/science/article/pii/S0167923610002393>.

MCMILLAN, R. Google attack part of widespread spying effort. 2010.

Disponível em: <http://www.computerworld.com/s/article/9144221-

/Google_attack_part_of_widespread_spying_effort $>$.

MEADE, P. T.; RABELO, L. The technology adoption life cycle attractor understanding the dynamics of high-tech markets. Technological Forecasting and Social Change, Elsevier, v. 71, n. 7, p. 667-684, 2004.

MELL, P.; GRANCE, T. The NIST Definition of Cloud Computing. NIST Special Publication 800-145, p. 7, Setembro 2011.

MILLS, E. Behind the China attacks on Google (FAQ). 2010. Disponível em: <http://news.cnet.com/8301-27080_3-10434721-245.html>.

MOGULL, R. Cloud Data Security: Archive and Delete (Rough Cut). 2009.

Disponível em: <https://securosis.com/blog/cloud-data-security-archive-and-deleterough-cut/>.

MUSTHALER, L. Cost-effective data encryption in the cloud. 2009. Disponível em: $<$ http://www.networkworld.com/newsletters/2009/121409bestpractices.html>.

NELSON, S. D.; SIMEK, J. W. Virtualization and Cloud Computing: Benefits and E-Discovery Implications. Julho 2011. Disponível em: <http://www.slaw.ca/2011/07/19/virtualization-and-cloud-computing-benefits-and-e-discovery-implications/> .

O'NEILL, J. E. The role of arpa in the development of the arpanet, 1961-1972. Annals of the History of Computing, IEEE, IEEE, v. 17, n. 4, p. 76-81, 1995.

PAVOLOTSKY, J. Top Five Legal Issues For The Cloud. 2010. Disponível em: $<$ http://www.forbes.com/2010/04/12/cloud-computing-enterprise-technology-cionetwork-legal.html $>$.

PEARSON, S. Taking account of privacy when designing cloud computing services. In: Software Engineering Challenges of Cloud Computing, 2009. CLOUD '09. ICSE Workshop on. 2009. p. 44-52. 
PFITZMANN, A.; HANSEN, M. A terminology for talking about privacy by data minimization - anonymity, unlinkability, undetectability, unobservability, pseudonymity, and identity management. dud.inf.tu-dresden.de/literatur/Anon_Terminology_v0, v. 34, 2010.

PROTIVITI. Internal Audit's Role in Cloud Computing. 2012. Disponível em: $<$ http://www.protiviti.com/en-US/Documents/White-Papers/Risk-Solutions/IA-RoleCloud-Computing-Protiviti.pdf $>$.

RAJ, H. et al. Resource management for isolation enhanced cloud services. In: Proceedings of the 2009 ACM workshop on Cloud computing security. New York, NY, USA: ACM, 2009. (CCSW '09), p. 77-84. ISBN 978-1-60558-784-4. Disponível em: <http://doi.acm.org/10.1145/1655008.1655019>.

REID, J. et al. Privacy and trusted computing. In: IEEE. Database and Expert Systems Applications, 2003. Proceedings. 14th International Workshop on. 2003. p. 383-388.

RISTENPART, T. et al. Hey, you, get off of my cloud: exploring information leakage in third-party compute clouds. In: ACM. Proceedings of the 16th ACM conference on Computer and communications security. 2009. p. 199-212.

ROBERTS, L. The arpanet and computer networks. In: ACM. Proceedings of the ACM Conference on The history of personal workstations. 1986. p. 51-58.

ROSE, J. Cloudy with a chance of 0-day. 2009. Disponível em: <https://www.owasp.org/images/1/12/Cloudy $\backslash \%$ underline with $\lfloor$ a $\lfloor$ chance $\lfloor$ of $\lfloor 0 \backslash$ day $\backslash-\lfloor$ Jon $\lfloor$ RoseTom $\lfloor$ Leavey.pdf $>$.

ROSS, R. et al. Guide for Conducing Risk Assessments. NIST Special Publication 800-30 Revision 1, p. 95, Setembro 2012.

. Security and Privacy Controls for Federal Information Systems and Organizations. NIST Special Publication 800-53 Revision 4, p. 455, Fevereiro 2013.

. Recommended Security Controls for Federal Information Systems and Organizations. NIST Special Publication 800-53 Revision 3, p. 237, Agosto 2009.

. Guide for Assessing the Security Controls in Federal Information Systems and Organizations. NIST Special Publication 800-30 Revision 1, p. 399, Junho 2010.

SADEGHI, A.-R.; SCHNEIDER, T.; WINANDY, M. Token-based cloud computing. In: ACQUISTI, A.; SMITH, S.; SADEGHI, A.-R. (Ed.). Trust and Trustworthy Computing. Springer Berlin Heidelberg, 2010, (Lecture Notes in Computer Science, v. 6101). p. 417-429. ISBN 978-3-642-13868-3. Disponível em: <http://dx.doi.org/10.1007/978-3-642-13869-0_30>.

SALESFORCE. Salesforce Security Statement. 2011. Disponível em: <salesforce.com/company/privacy/security.jsp $>$.

. Security Implementation Guide. 2013. Disponível em: <http://login.salesforce.com/help/doc/en\% -/salesforce_security_impl_guide.pdf $>$. 
SHANKLAND, S. Amazon cloud outage derails Reddit, Quora. Abril 2011. Disponível em: <http://news.cnet.com/8301-30685_3-20056029-264.html>.

SIMMONDS, P.; REZEK, C.; REED, A. Security Guidance for Critical Areas of Focus in Cloud Computing V3.0. p. 177, Dezembro 2011.

TECH, C. Examining Redundancy in the Data Center Powered by the Cloud and Disaster Recovery. 2010. Disponível em: <http://consonustech.hubpages.com/hub/Examining-Redundancy-in-the-Data-Center>.

TOMPKINS, D. Security for Cloud-based Enterprise Applications. Fevereiro 2009. Disponível em: <dt.org/index.php/2009/02/security-for-cloud-based-enterpriseapplications/>.

TRENDMICRO. Making Virtual Machines Cloud-Ready. Maio 2010.

VAN, H. N.; TRAN, F.; MENAUD, J.-M. Sla-aware virtual resource management for cloud infrastructures. In: Computer and Information Technology, 2009. CIT '09. Ninth IEEE International Conference on. 2009. v. 1, p. 357-362.

VAQUERO, L. M. et al. A break in the clouds - towards a cloud definition. ACM SIGCOMM Computer Communication Review, ACM, v. 39, n. 1, p. 50-55, 2008.

WANG, L. et al. Cloud computing - a perspective study. New Generation Computing, Springer, v. 28, n. 2, p. 137-146, 2010.

Scientific cloud computing - early definition and experience. In: IEEE.

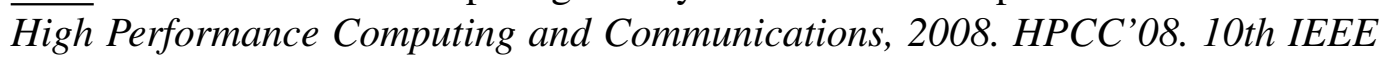
International Conference on. 2008. p. 825-830.

WESTERVELT, R. Phishing attacks target users of Facebook, other social networks. 2010. Disponível em: <http://searchsecurity.techtarget.com/news/1519804/Phishingattacks-target-users-of-Facebook-other-social-networks $>$.

WINTERFORD, B. Amazon EC2 suffers huge outage. Abril 2011. Disponível em: $<$ http://www.crn.com.au/News/255586,amazon-ec2-suffers-huge-outage.aspx>.

YAN, L.; RONG, C.; ZHAO, G. Strengthen cloud computing security with federal identity management using hierarchical identity-based cryptography. Cloud Computing, Springer, p. 167-177, 2009.

YEE, A. Implications of Salesforce Phishing Incident. 2007. Disponível em: $<$ http://www.ebizq.net/blogs/security insider/2007/11/implications of salesforce phi.php>.

YOUSEFF, L.; BUTRICO, M.; SILVA, D. D. Toward a unified ontology of cloud computing. In: IEEE. Grid Computing Environments Workshop, 2008. GCE'08. 2008. p. $1-10$.

ZIERICK, J. The Special Case of Privileged Users in the Cloud. Junho 2011.

Disponível em: < beyondtrust.com/the-special-case-of-privileged-users-in-the-cloud>. 